Portland State University

PDXScholar

$3-11-2021$

\title{
The Soniferous Experience of Public Space: A Soundscape Approach
}

Kenya DuBois Williams

Portland State University

Follow this and additional works at: https://pdxscholar.library.pdx.edu/open_access_etds

Part of the Urban Studies and Planning Commons

Let us know how access to this document benefits you.

\section{Recommended Citation}

Williams, Kenya DuBois, "The Soniferous Experience of Public Space: A Soundscape Approach" (2021). Dissertations and Theses. Paper 5650.

https://doi.org/10.15760/etd.7522

This Dissertation is brought to you for free and open access. It has been accepted for inclusion in Dissertations and Theses by an authorized administrator of PDXScholar. Please contact us if we can make this document more accessible: pdxscholar@pdx.edu. 
The Soniferous Experience of Public Space: A Soundscape Approach

by

Kenya DuBois Williams

A dissertation submitted in partial fulfillment of the requirements for the degree of

\author{
Doctor of Philosophy \\ in \\ Urban Studies
}

\author{
Dissertation Committee: \\ Ethan Seltzer, Chair \\ Sy Adler \\ Hunter Shobe \\ Geoffrey Duh
}

Portland State University

2021 
(C) 2021 Kenya DuBois Williams 


\begin{abstract}
This research explores the awareness and perceptions of practitioners regarding the role of the soundscape in understanding and managing public spaces. Without considering the role of the soundscape as part of public spaces, urban planners, designers, and policy officials cannot accurately engage in placemaking that provides a complete sensory experience. The antiquated practice of enforcing noise codes has been the traditional approach to mitigate noise (unwanted sounds). However, sound is an overlooked element in the sensory experience of cities and how individuals and communities construct a "sense of place." This study considers the implications of the soundscape approach and soundwalks in understanding the role of the soundscape in urban places as part of the management, planning, and urban design processes. This research will add to how awareness of the soundscape can help to create livable, meaningful cities.

For this qualitative study, the soundscape of Tom McCall Waterfront Park was explored by thirty-one practitioners who participated in soundwalks and responded to surveys. The thematic analysis showed five themes, which describe the practitioners' perceptions and how they increase their awareness about the role the soundscape plays in enhancing the soniferous experience of parks and urban spaces. Insights and theoretical and practical implications have been derived from the findings to diminishing the gap in knowledge about soundscapes for urban planning theory and practice.
\end{abstract}




\section{Acknowledgements}

I want to extend my sincere gratitude to my advisor, Dr. Ethan Seltzer, for the years of encouragement and guidance. I am very fortunate to have had the opportunity to work with him for many years.

I would also like to thank my committee members, Drs. Sy Adler, Hunter Shobe, and Geoffrey Duh for the support and advice that each of them provided me over the years. I also want to acknowledge Drs. Connie Ozawa, Charles Heying, Richard White, and Vivek Shandas for their positive impacts on my academic development during my years of study in the Toulan School of Urban Studies and Planning at Portland State University.

I want to express my gratitude to the research participants for their time and contribution to my research. I also cannot forget the countless friends and family around the world that kept me determined and inspired to succeed.

Ultimately, I would not be experiencing this dream realized without the unconditional love, support, and sacrifice of my wife and daughter. For their faith, patience, and perseverance, I will be forever beholden. In this new orbit, I promise to make the stars jealous. 


\section{Table of Contents}

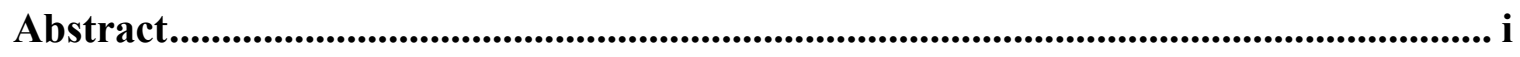

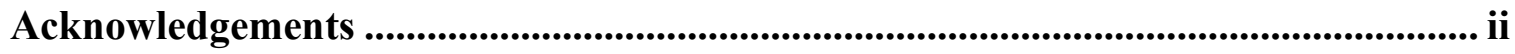

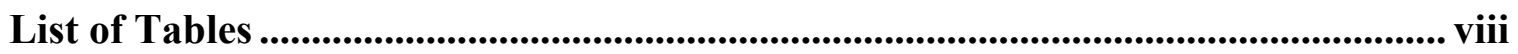

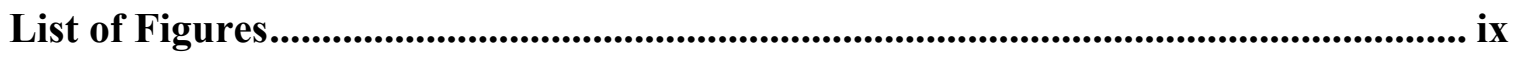

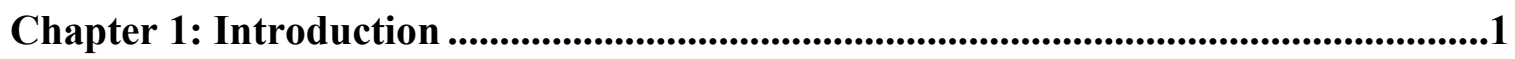

Statement of the Problem....................................................................................... 1

Research Questions ........................................................................................ 3

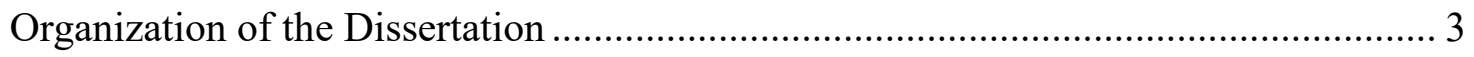

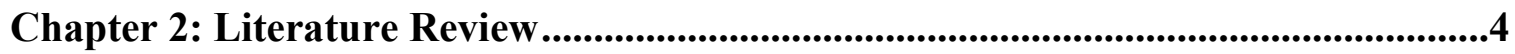

The Soundscape and Urban Spaces: Sound, Urban Planning, and Urban Spaces......... 4

Defining Soundscapes and Acoustic Ecology .................................................... 5

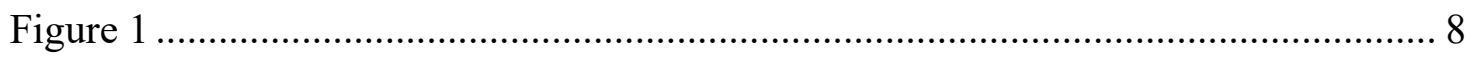

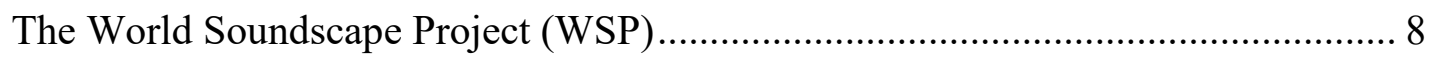

Soundscape and Human Perception ............................................................... 9

The Noise Mitigation vs. the Soundscape Approach:.......................................... 10

Two Lines in Planning Urban Spaces .................................................................. 10

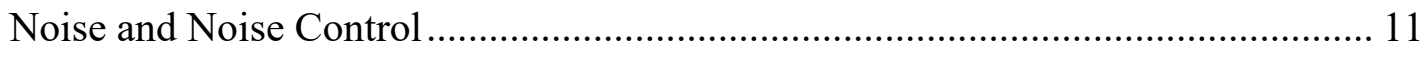

Difficulties with Noise Mitigation ................................................................. 13

An Alternative to the Noise Mitigation Approach:................................................ 14

Introduction to the Soundscape Approach .......................................................... 14

The Soundscape Approach: A New Perspective in Urban Design and Planning ..... 15 
The Shift in the Traditional Paradigm in Urban Planning................................. 16

Incorporating the Soundscape Approach into Urban Design and Planning........ 18

Research Outcomes about the Soundscape Approach .......................................... 27

Perceptions and Preferences Regarding Soundscapes in Urban Spaces ............. 29

The Soundscape in Urban Squares and Plazas .................................................. 31

Balancing Visual Aesthetics and Soundscapes ................................................... 33

Practitioner Perceptions about Urban Soundscapes........................................... 34

Studies on Soundscapes and Urban Planning in the United States...................... 36

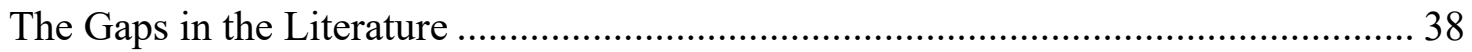

Closing the Gaps between Noise Management and Soundscape Approaches ......... 40

Lessons from the Literature Review ..................................................................... 42

Chapter 3: Methodology................................................................................................................44

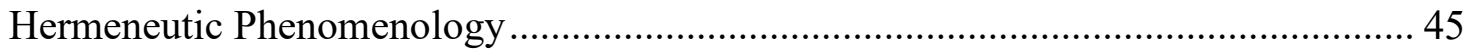

The Soundwalk as a Tool to Assess Soundscapes ........................................................... 47

A Brief History of the Soundwalk Method................................................................ 48

Soundwalks as a Method to Immerse Participants in a Given Soundscape.............. 49

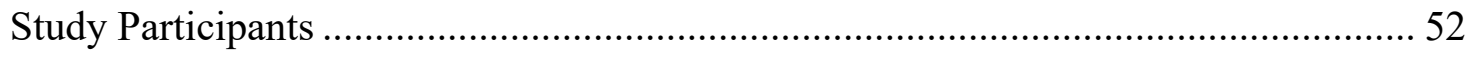

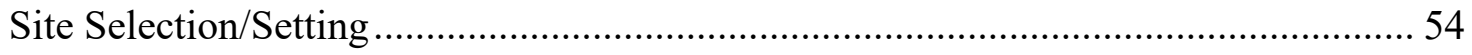

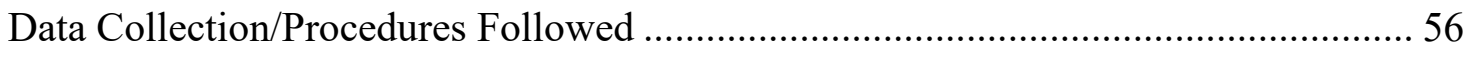

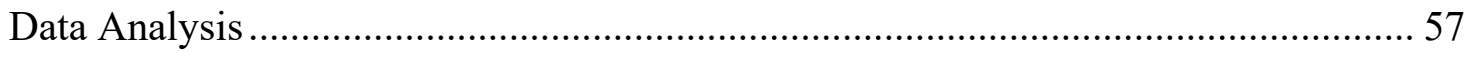

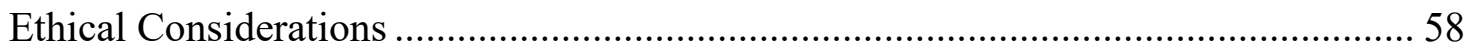

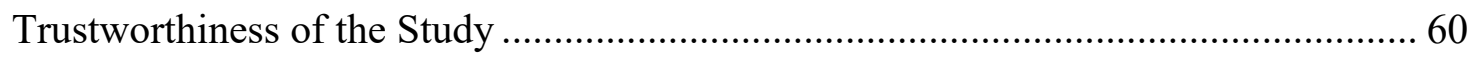

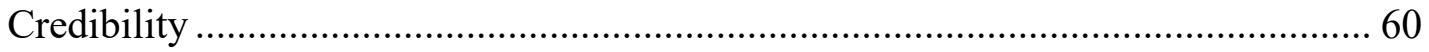


Transferability

Reliability 61

Confirmation 62

Limitations 62

Chapter 4: Findings ......................................................................................................................63

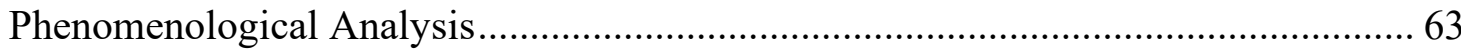

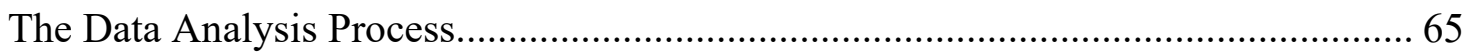

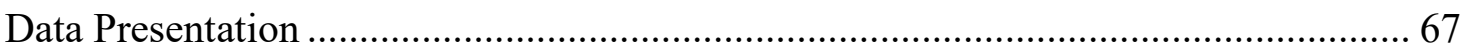

Theme 1: The Experience of the Soundscape of Tom McCall Waterfront Park ...... 67

Sub-Theme 1: Typical Mixture of Human, Nature, and Highway Sounds........... 69

Sub-Theme 2: Pleasant Areas in the Park ....................................................... 69

Sub-Theme 3: Pointing to Specific Noises ..................................................... 70

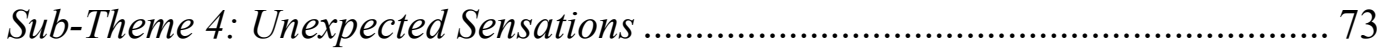

Answering the First Research Question............................................................ 74

Theme \#2: Evaluation of Tom McCall Waterfront Park's Soundscape .................. 75

Sub-Theme 1: Positive or Negative Assessments of the Park ............................. 76

Sub-Theme 2: Evaluation of Different Points of View...................................... 76

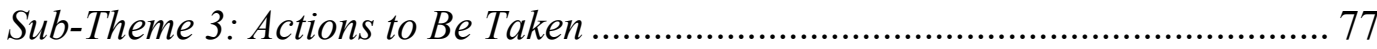

Theme 3: Daily Activities and Their Impact on Tom McCall Waterfront Park's

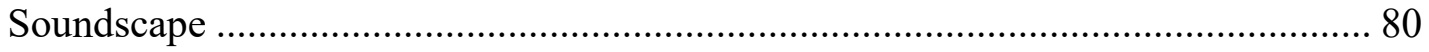

Sub-Theme 1: Usual Activities and Large Events in the Park........................... 81

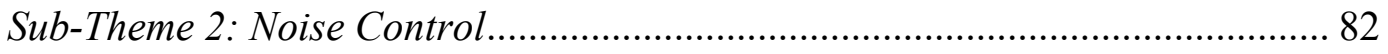

Sub-Theme 3: Projects Affecting the Soundscape of the Park............................ 82 
Sub-Theme 4: Code of Behavior

Theme \#4: Practitioners' Suggestions for Balancing the Soundscape of Tom McCall

Waterfront Park 84

Sub-Theme 1: Addition of Pleasant Sounds to Balance the Soundscape of the Park

Sub-Theme 2: Addition or Removal of Elements to Palliate/Eliminate Negative

Sounds 86

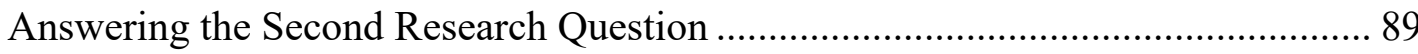

Theme 5: Foreseeing the Future at Tom McCall Waterfront Park ………................ 91

Sub-Theme 1: Isolating Unpleasant Noises ...................................................... 92

Sub-Theme 2: Redesigning the Park................................................................... 95

Answering the Third Research Question ................................................................. 97

Chapter 5: Discussion .................................................................................................................99

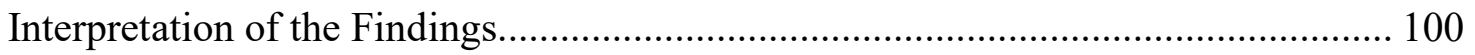

Theme 1: The Experience of the Soundscape of Tom McCall Waterfront Park .... 100

Theme 2: Evaluation of Tom McCall Waterfront Park's Soundscape ................... 102

Theme 3: Daily Activities and Their Impact on Tom McCall Waterfront Park's

Soundscape 110

Theme 4: Practitioners' Suggestions for Balancing the Soundscape of Tom McCall

Waterfront Park 111

Theme 5: Foreseeing the Future at Tom McCall Waterfront Park ......................... 116

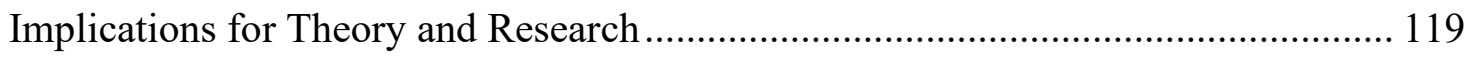

Soundwalks as a Tool for Assessing Soundscapes: Theoretical Implications........ 121 
Implications for Practice

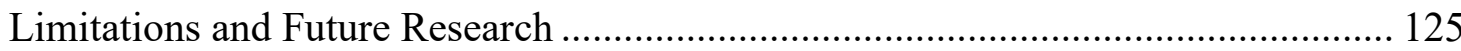

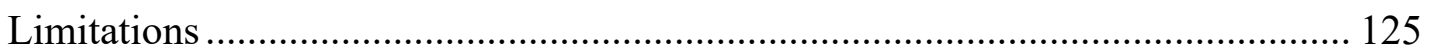

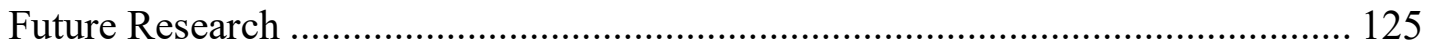

Chapter 6: Conclusions ...........................................................................................................128

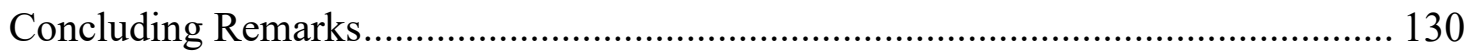

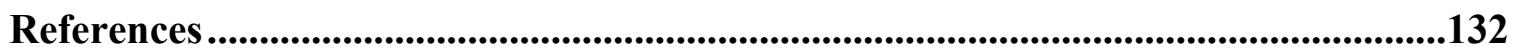

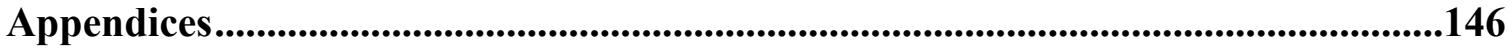

Appendix A: Pre-Sound Walk Survey ..........................................................................146

Appendix B: Post-Soundwalk Survey Questions ................................................................165

Appendix C: Participant Narrations....................................................................................169

Appendix D - Participant Demographics ...........................................................................174

Appendix E - Quadrant Soundscape Analysis...................................................................177

Appendix F: Invitation to Participate ..................................................................................194

Appendix G: Consent to Participate in Research ............................................................197

Appendix H: The Textural Description ...............................................................................201

Appendix I: The Final Phenomenological Nature of the Soundscape Experience of the Governor Tom McCall Waterfront Park .....................................................................202

Appendix J: Approved IRB Application ...........................................................................205 


\section{List of Tables}

Table 1. The Different Foci of Environmental Noise and Soundscape Approaches......41 


\section{List of Figures}

Figure 1. Relationships between Acoustic Ecology, Acoustic Environment, and

Soundscape............................................................. 8

Figure 2. Role of the Soundscape Expert during the Pre-Application Stage.............20

Figure 3. Role of the Soundscape Expert during the Application: First Phase..........22

Figure 4. Role of the Soundscape Expert during the Application: Second Phase........23

Figure 5. Role of the Soundscape Expert during the Final Application: Third Phase.....24

Figure 6. The Data Analysis' Process to Answer the Research Questions...............65

Figure 7. Theme 1: The Experience of the Soundscape of Tom McCall Waterfront

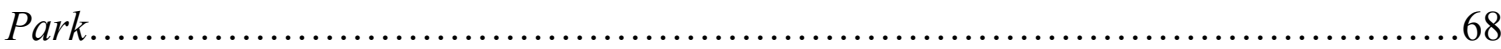

Figure 8. Theme 2: Evaluation of Tom McCall Waterfront Park's Soundscape........75

Figure 9. Theme 3: Practitioners' Daily Activities and Their Impact on Tom McCall

Waterfront Park's Soundscape................................................ 80

Figure 10. Theme 4: Practitioners' Suggestions for Balancing the Soundscape of the Tom

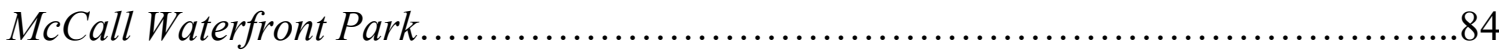

Figure 11. Theme 5: Foreseeing the Future at Tom McCall Waterfront Park............92

Figure 12. Primary Sounds and Characteristics from Each Quadrant..................104 


\section{Chapter 1: Introduction}

Urban planners and urban designers are often tasked with implementing or preserving the quality of life and sense of community through the plans they create and recommend. Although an urban area's acoustic properties affect its residents' quality of life (Aletta et al., 2018; Alves et al., 2014, 2015), current urban planning practices do not often include approaches that consider the soundscape in urban spaces. Rather than enhancing the soniferous experience of public spaces, current practices focus on adhering to noise codes and regulations that could potentially eliminate sounds from a place (Schafer, 1977). Noise code enforcement is a result of complaint-driven processes that uses measurements to determine what sounds should be regarded as a nuisance instead of as beneficial sensory resources. The soundscape is a powerful contributor to our wellbeing, sense of place, and overall experience. Thoughtful planning and management of the soundscape in urban spaces and parks are necessary because the soundscape can be harnessed to increase human enjoyment of public spaces (Brown, 2007).

\section{Statement of the Problem}

The soundscape of urban spaces and parks has been considered by acousticians, noise management practitioners, and engineers but typically not urban planners. When urban sound has the attention of urban planners and designers, the sound is often an afterthought or addressed as a nuisance, something to be eliminated to provide people with quiet spaces, which are considered synonymous with a good quality of life. Solutions are based on traditional quantitative noise control practices usually conducted by engineers, acousticians, and noise management practitioners. 
Soundscape and acoustic ecology approaches and awareness have yet to be incorporated into urban planning and design practice to enhance the soniferous experiences of public spaces and parks. Due to this void, urban planners and designers lack the awareness, pedagogy, theory, and methods (Steel et al., 2013) that could enable them to implement plans and designs that mitigate the degradation of the sonic environment and which value all sounds, rather than designating some sounds as unnecessary. Without considering the role of the soundscape as part of public spaces, urban planners, designers, and policy officials cannot accurately engage in placemaking that includes a complete sensory experience for residents of and visitors to cities.

\section{Purpose of the Study}

This qualitative research examines the soundscape of Governor Tom McCall Waterfront Park, its meaning to and influence on park and planning practitioners, and the role that the soniferous experience of a public space can play in utilizing and managing the soundscape on behalf of the public good. This study aims to increase the awareness of practitioners who have training and the agency to plan, design, maintain, and manage policies for urban spaces and parks. This research and data could be especially important for diminishing the knowledge gap for urban planning theory and practice regarding the beneficial aspects and effects of the soundscape. By doing so, this research will add to the ways that planning can contribute to creating livable, meaningful public spaces. 


\section{Research Questions}

The following questions will ground the research agenda and guide the study: RQ1: What are the soniferous experiences for practitioners who do a soundwalk of Tom McCall Waterfront Park?

RQ2: How do practitioners who do a soundwalk of the park understand the soniferous experience of Tom McCall Waterfront Park?

RQ3: How does the soniferous experience of practitioners who do a soundwalk of the park inform future planning and design considerations of Tom McCall Waterfront Park?

\section{Organization of the Dissertation}

This dissertation is organized and presented in six chapters. The first chapter introduces the problem statement, purpose and significance of the study, and the research questions. Chapter Two offers an overview of the existing literature and establishes the foundations that shape this dissertation. The third chapter presents the phenomenology research methodology employed to complete the research study. Chapter Four presents the research findings, the analysis of the themes that emerged, and how they answer the research questions. Chapter Five discusses the results and how the findings relate to the theoretical framework exposed in the literature review. The final chapter presents specific study conclusions. 


\section{Chapter 2: Literature Review}

\section{The Soundscape and Urban Spaces: Sound, Urban Planning, and Urban Spaces}

Urban planners are engaged in the social (re)production of space, and draw on the physical and social aspects of places to anticipate how changes may create changes in the experience of that place on the part of both residents and visitors. Scholars such as Karahan (2019) have recently highlighted the significant role of sounds in urban areas, stating: "It has been concluded that it is necessary to evaluate soundscape as a social sphere within the process of the social reproduction of space" (p. 1). Therefore, sound should be considered as part of this social construction of places.

However, despite the abundance of literature on the theory and practice of planning and designing public spaces (Bild et al., 2016; Brown \& Muhar, 2004; Friedmann, 2010; Knox, 2005; Madanipour, 1999; Palermo \& Ponzini, 2015; Southworth, 2003; Toolis, 2017; Vernon \& Tiwari, 2009), the focus on sound in this literature is about noise mitigation efforts. In essence, the consideration of sound and the soundscape has not been adequately explored, if it has been recognized at all. Its importance has simply not been part of the conversation by urban planners, designers, and policy officials.

Bild et al. (2016) pointed out that "in the planning of cities, the multisensory aspect of the lived urban experience has been largely considered as an afterthought" (p. 419). Similarly, Steele (2018) also specified the importance of sounds and the soundscape as part of human beings' senses. This author stated: "While urban interventions have mainly been focused on the visual modality... one aspect of urban environments capable 
of playing a role in our overall perception is the auditory modality" (p. 3). These studies' focus on multisensory experiences have led to a change in studies on this topic, creating an opening to address noise problems from another perspective. Practitioners of acoustic ecology, soundscape studies, and other disciplines are contributing to more awareness and approaches that help facilitate the shift from primarily quantitative methods of noise mitigation in cities (Brown, 2010; Brown \& Muhar 2004; Kurakula \& Kuffer, 2008; Kurakula et al., 2007) to more holistic methods that consider sound as a resource, integral to the human sensory experience, and not a nuisance or waste (Adams et al., 2006; Aravot, 2002; Luzzi, 2013; Raimbault \& Dubois, 2005). I argue in this study that incorporating the analysis of the sounds in urban spaces will provide significant insights into sound, a subjective element that impacts everyday users of urban spaces in different ways.

\section{Defining Soundscapes and Acoustic Ecology}

The term soundscape was introduced in the late 1960s by Canadian composer and educator R. Murray Schafer. Murray Schafer (1969) conceived of soundscapes as a complex recombination of natural, human, and technological sounds, which mixed to offer a pleasant/unpleasant soundscape. In his book The New Soundscape. A Handbook for the Modern Music Teacher, he stated:

Anything in our world that moves vibrates air... If it moves in such a way that it oscillates at more than about 16 times a second, this movement is heard as sound (...) The sounds heard could be divided into sounds made by nature, by humans, and by electric or mechanical gadgetry. (pp. 5-6) 
A concrete definition of "soundscape" was found in Schafer's 1977 publication, The Tuning of the World, where Schafer (1977a) wrote:

SOUNDSCAPE: The sonic environment. Technically, any portion of the sonic environment regarded as a field for study. The term may refer to actual environments or to abstract constructions such as musical compositions and tape montages, particularly when considered as an environment. (pp. 274-275).

Schafer defined the soundscape as a sound or combination of sounds that forms or arises from an immersive environment. Wrightson (2000) has declared: The philosophy underpinning Acoustic Ecology is simple yet profound: its author- $\mathrm{R}$. Murray Schafer, a musician, composer, and former Professor of Communication Studies at Simon Fraser University (SFU) in Burnaby, BC, Canada — suggests that we try to hear the acoustic environment as a musical composition. (p. 10) Vickers (2011) also recognized Schafer's significant insights and impact:

In Schafer's worldview, we are encouraged to treat the environments we find ourselves in as musical compositions. By this, we are transformed from being mere hearers of sound into active and analytic listeners - exactly the characteristic needed to benefit most from an auditory display. (p. 458) Since Schafer's original definition, the concept of the soundscape has evolved, and new terms have joined it, based on the writings on Schafer and others. In 1977, R. Murray Schafer published The Tuning of the World, the most recognized and encompassing primer on acoustic ecology as a nascent discipline, Schafer expressed his observations that society was dominated by 'eye culture' and that listening skills were deteriorating (Wrightson, 2000). In addition, the term "soundscape" was formalized as 
the audible equivalent of a landscape by Schafer. Schafer believed that it is possible to systematically study the sonic environment's characteristics, just as we are able to study landscapes. Thus, the concept of acoustic ecology was defined by Schafer (1977a) in the following way:

ACOUSTIC ECOLOGY: Ecology is the study of the relationship between living organisms and their environment. Acoustic ecology is thus the study of the effects of the acoustic environment or SOUNDSCAPE on the physical responses or behavioral characteristics of creatures living within it. Its particular aim is to draw attention to imbalances which may have unhealthy or inimical effects. (p. 271).

For Schafer, the terms soundscapes and acoustic environment are synonymous; he named the study of the impacts/effects of the acoustic environment on living organisms acoustic ecology. An analogous concept about soundscape was exposed by Truax (2007), who defined it as "the relationship of man and sonic environments of every kind" (p. 36). In the same fashion, other scholars, such as Westerkamp (2002), have also stated similar definitions concerning acoustic ecology:

Acoustic ecology or soundscape studies-the study of the inter-relationship between sound, nature, and society-is the arena from which this work and thus, the term soundscape composition emerged in the first place in the mid-seventies, and it is that arena that gave it its context, its voice and its strength. (p. 2)

Finally, for Wrightson (2000), acoustic ecology is the relationship — mediated through sound - between living beings and their environment. The figure below illustrates the relationships among these concepts. Schafer's definitions of soundscape and acoustic ecology will be used for this research. 


\section{Figure 1}

Relationships between Acoustic Ecology, Acoustic Environment, and Soundscape
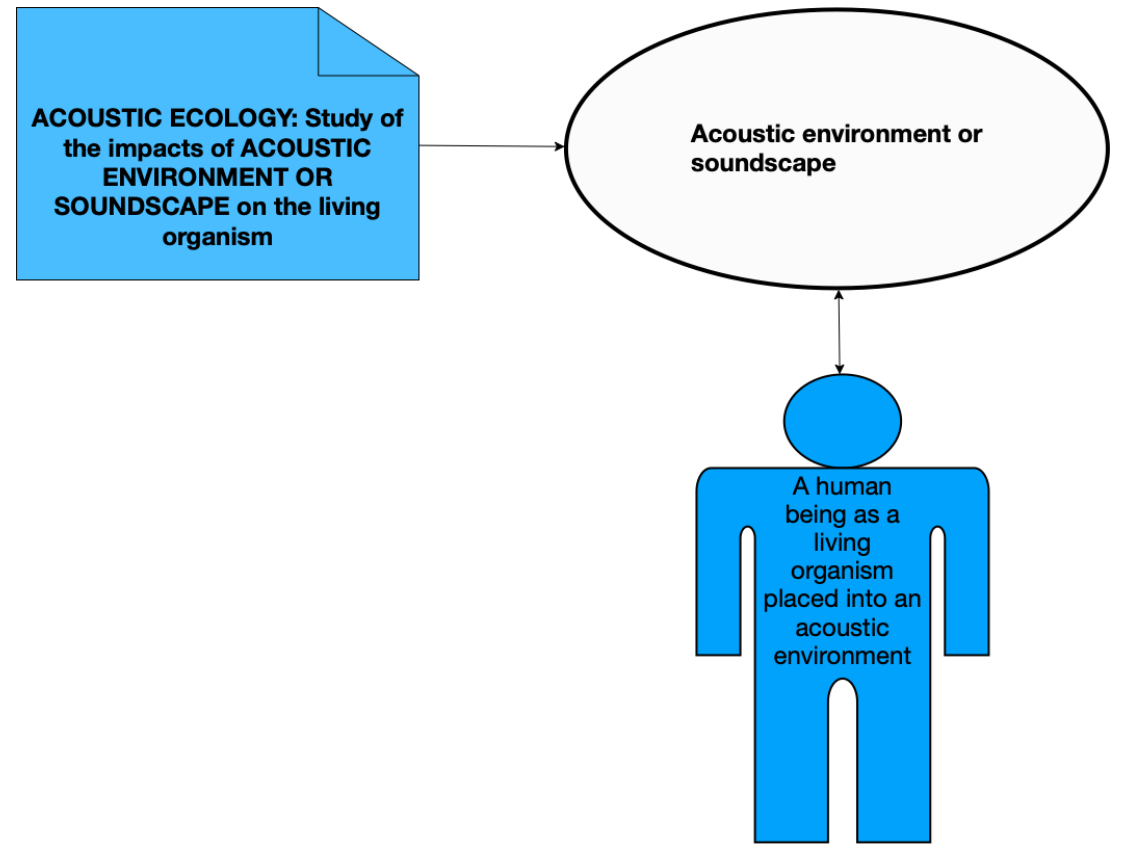

(Truax, 2007; Westerkamp, 2002; Wrightson, 2000)

\section{The World Soundscape Project (WSP)}

Before writing The Tuning of the World, Schafer recruited several of his

colleagues and students to form the World Soundscape Project (WSP). Truax (1996), one of the creators of the project, declared:

Schafer's call for establishing the WSP was answered by a group of highly motivated young composers and students supported by The Donner Canadian Foundation. The group embarked first on a detailed study of the immediate locale, published as The Vancouver Soundscape (WSP, 1978a). (p. 54)

Schafer and his team made audio field recordings, measured sound pressure levels, and produced Isobel maps in and around Vancouver, British Columbia. Specific products emerged as the result of the long-term development of the project, such as The 
Vancouver Soundscape. Also, in 1973, the group produced Soundscapes of Canada, a tour of sound recordings across Canada. In 1975, a similar production was made across five countries in Europe when the group and Schafer recorded more than 300 tapes in a soundscape analysis called Five Village Soundscapes.

Although Schafer's World Soundscape Project was monumental in investigating the sonic qualities of a wide variety of places, there is much that we still do not know about the soundscapes of the outdoor environment. Truax (2001) argued that there are several unknown aspects regarding the role of the soundscape as part of public spaces. Truax (2001) mentioned that there is an absence of knowledge about correctly measuring people's experiences of the soundscape in public spaces. Also, this experience tracked people's engagement levels with space/activity, visual/aural interactions, the potential restorative functions of soundscapes, and the role of listening states - analytical listening vs. distracted listening. In conclusion, the soundscape of cities has been previously studied by Schafer and his cohorts. However, a research gap exists concerning the interrelationships among the soundscape and people and its impact on living organisms.

\section{Soundscape and Human Perception}

Although we considered the concepts of soundscape and acoustic ecology above, other scholars such as Brown (2012) refer to the soundscape as a term involving both the sounds and the living organisms that perceive the sound. From a perceptual perspective, and looking at Brown's suggestions, this author moves forward and introduces the notion of perception into the inner sphere of the soundscape. Brown (2012) has signaled that the term soundscape is fundamental to how people and society perceive the sonic environment (Brown, 2012). According to Brown (2012), "central to the term soundscape 
is an individual's, or society's, perception and understanding of the acoustic environment. Thus, a soundscape exists through human perception—but always within the context of a particular time, place, and activity" (p. 73). Brown (2012) argued that a full understanding of the soundscape includes the novelty of considering the perception of others, i.e., the people's perception of the sounds surrounding them in space: "The acoustic environment as perceived and understood, by people, in context, is a definition of soundscape that may be adopted in a future acoustic standard" (p. 73).

Brown also argued that both places and physical environments are the spaces where we develop our everyday lives and activities. In this sense, the perceptual suggestion of Brown's soundscape involves the trio person-place-activity, which directly implies the personal relationships that an individual can establish with a particular space/area through the activity that they perform there. Brown (2012) concluded that our everyday lives, activities, and interactions are essential to the perception of the soundscape.

However, the debate about soundscapes, sounds in cities, or sound in general, is a discussion that rarely happens without addressing the aspects of unwanted sound, i.e., noise.

\section{The Noise Mitigation vs. the Soundscape Approach:}

\section{Two Lines in Planning Urban Spaces}

Traditionally, cities and urban spaces were perceived as environments where visual perception was privileged over a complete sensorial experience (Steele, 2018). Indeed, urban designers in the 1960s and 1970s gave prevalence to the visual experience 
over the sense of smell and sound, with smells and sounds considered awful sensorial experiences that must be controlled (Zardini, 2012). This restricted approach led to more control of unfavorable odors, i.e., pollution, and unwanted sounds, i.e., noise.

However, over time, the approach to urban planning and the perception of the city changed to conceive of the city as a complex environment when compared to the approaches of urban planning in previous decades. In this regard, the perception of cities and urban spaces focused more on the individual experience, and such practices were approached from a holistic perspective, where a complete sensorial experience is favored (Zardini, 2012).

\section{Noise and Noise Control}

Studies about noise and noise control were the first attempts to incorporate sounds into urban planning through noise mapping. Noise mapping studies have been conducted to regulate and control noise. According to Adams et al. (2009): "These noise maps have been used to create action plans to prevent and reduce environmental noise in identified areas" (p. 3). Equally, many research studies related to sound in cities or urban spaces (Aletta et al., 2018; Alves et al., 2014, 2015) have primarily detailed the adverse effects of noise on community health and presented recommendations that mainly address the negative aspects of sound. Similarly, Aletta et al. (2018) stated: "The adverse health effects of environmental noise on people and communities have been thoroughly investigated by world-wide research institutions and international health organizations over the past decades" (p. 1). Similar purposes have also been identified by Alves et al. (2014), who specifically indicated the impact of the incidence of noise in community health: 
The traditional approach of urban sound planning is based on the concept that an acoustic intervention is only necessary when someone complains about the noise. However, when that happens, it is because a real problem already exists and people's health is already being affected. (p. 1)

Wothge et al. (2017) supported such results:

The Noise Related Annoyance Cognition and Health (NORAH) research initiative is one of the most extensive studies on the physiological and psychological longterm effects of transportation noise in Europe. It includes research on the quality of life and annoyance and cardiovascular effects, sleep disturbance, breast cancer, blood pressure, depression, and the cognitive development of children. (p. 871) Sound abatement and noise coverage seem to be two strategies followed in European countries to deal with unfavorable soundscapes. Specifically, Adams et al. (2009) highlighted the positive effect of mutual collaboration between different disciplines around urban planning spaces. For example, urban planners are incorporated into the soundscape of cities in the United Kingdom:

Many disciplines outside of traditional acoustics have recently worked together to confront epistemological assumptions regarding the place of soundscapes in an urban planning context and to develop an interdisciplinary understanding of soundscapes in that realm. Through this interdisciplinary work, The Positive Soundscapes Project has identified a means whereby the concept of soundscapes might effectively be incorporated into planning. (p. 1) 


\section{Difficulties with Noise Mitigation}

The primary difficulty of traditional noise management is that it aims to eliminate unfavorable sounds. In their study, Riambault and Dubois (2005) indicated that "the only matter in engineering noise control remains currently the noise level. Planners, however, questioned the generic concept of the noise level, if not related to the identification and thus the qualification of a source" (p. 345). Also, Hedfors (2003) pointed out another limitation of the noise management approach when he stated: "Classical noise research considers the risks of damages and disturbances, but lacks developed terminology for the creation of desirable acoustic environments" (p.13).

Additionally, traditional noise management approaches are rooted in numbers and quantitative analyses that cannot convey what the soundscape means in terms of livability. These noises are determined through policy and political decision-making, often by individuals and processes with no attachment or vested interest in the sounds that are being regulated, eliminated, or considered unwanted. In this respect, Job and Hatfield (2001) stated: "Noise regulation is often based, to a significant extent, on predicting the reaction that particular noise exposure is likely to produce" (p. 120). It often remains theoretical.

This research argues that the study of sounds in urban areas cannot be reduced to simple measures of noise mitigation, codes, or policies of control; sound and noise in urban spaces must be approached from a different perspective, as indeed, it was suggested by Lewis Wirth (1938, cited in Atkinson, 2007): "Wirth himself called on urbanists to look beyond the physical, economic and cultural structure of the city to uncover the underlying elements of urbanism" (p. 1905). Wirth was an urban sociologist 
and scholar who defined living conditions in a city and the significant characteristics of urbanism. He asserted that noise and other nuisances decide the desirability of different parts of the city and determine where different population groups will live or not choose to live.

\section{An Alternative to the Noise Mitigation Approach: \\ Introduction to the Soundscape Approach}

In recent years, research and attention have shifted from traditional methods that mitigate community noise to an approach that considers the other (potentially positive) characteristics of sounds. For this purpose, Bohme (2000) argued that "city planning can no longer be content with noise control and abatement but must pay attention to the character of the acoustic atmosphere of squares, pedestrian zones, of whole cities" (p. 16). How people perceive of the sonic environment and sound in their communities has become an aspect of study, given sound's subjective nature, i.e., the same sound can be evaluated very differently from one person to the other.

In turn, Atkinson (2007) highlighted some of the most critical characteristics of sound, as it is transitory and intangible:

Sound... provides a means of exploring the more ephemeral and shifting elements of urbanism that often slip through our fingers when we try to give a concrete assessment of its character. This ambient envelope of urban life is challenging to reduce or to measure in meaningful ways. (p. 1905)

I highlight the last sentence, where Atkinson stressed the impossibility of mitigating or doing substantial assessments by measuring the different sounds found in urban spaces. The fleeting and temporary characteristics of sound imply that assessing sound in urban 
areas is difficult to execute: "The power of this intangible domain has generally been under-examined in urban studies" (Atkinson, 2007, p. 1905).

Furthermore, regarding the nature of sound, Dubois et al. (2006) have also argued that "the concept of soundscape explicitly includes a subjective component, namely how the environment is perceived and understood by an individual or by a community ( $\mathrm{p}$. 865). Thus, urban planners shifted their attention to the quality of sound, rather than the suggestion of reducing 'noise,' by incorporating a soundscape approach into urban planmaking and implementation to achieve a complete holistic sensory experience in cities and regions (Atkinson, 2007; Dubois et al., 2006). Through design and soundscape approaches that manage wanted and unwanted sounds, urban designers have the opportunity to create a stronger sense of place, increase the quality of life, improve overall community health, and protect the sonic environment by embracing the soundscape as a resource (Steele, 2018). The soundscape approach, which concentrates on the conscious perception and interaction between people and sounds, can provide opportunities to gain more insights about the difficulties of traditional noise management approaches (Brambilla \& Maffei, 2010). The next section will detail the characteristics of the soundscape approach and its advantages and disadvantages in scholarly literature.

\section{The Soundscape Approach: A New Perspective in Urban Design and Planning}

This section will present the principal outcomes from previous scholarly research where the soundscape has been studied using the soundscape approach. This section is divided into five parts: a) the shift in the traditional paradigm in urban planning, b) incorporating the soundscape approach into urban design and planning, c) research outcomes about the soundscape approach, d) people's perceptions and preferences about 
soundscapes, and e) the practitioners' (urban designers, urban planners, architects, and engineers) perceptions about the soundscape.

\section{The Shift in the Traditional Paradigm in Urban Planning}

When designing urban spaces, the traditional paradigm in urban planning has had, as its primary goal, the management and control of noise. Indeed, noise abatement or masking noise has been the immediate priority for many practitioners. Steele et al. (2019) indicated that "urban sound management often relies on a reduction in sound level to improve sound quality in urban spaces" (p. 1). In this regard, noise has been considered waste, or in other words, sounds have been considered unpleasant noise that annoy the people visiting in or inhabiting urban spaces.

However, in recent years, scholarly efforts (see De Coensel et al., 2010) have created a paradigm shift in urban noise and soundscape research. The traditional paradigm looked only to manage and mitigate noise without considering the overall soundscape in the area. Using this new perspective, noise is not viewed as waste that needs to be eliminated or mitigated, but instead, is considered as a resource, with less favorable sounds being balanced by an optimal arrangement of pleasant sounds in the same area (Adams et al., 2009; Hedfors, 2003). Essentially, the soundscape approach embraces both the unpleasant and pleasant sounds in an ensemble that looks to reach a balance through taking account of all sound sources to achieve sonic harmony in the area.

The soundscape approach has been manifested in several ways by individuals, primarily within acoustic ecology and soundscape studies. Schafer defined sounds as keynotes, signals, foreground sounds, and soundmarks (Yang \& Kang, 2005), regardless

of the variation of the soundscape approach. The paradigm shift considers the soundscape 
and the perception of environmental sound as two vital factors in the urban planning and design processes, as it was recently highlighted by Steele et al. (2019) concerning the outcomes of the research: "The results suggest implications for urban design and planning in that sound design can improve perceived sound character, but more importantly for traditional planning purposes, perceived sound level” (p. 1). As part of the soundscape approach, this shift in thinking contributes to the discourse in which not all sounds are noise, and some sounds do belong in and even improve some environments (Adams et al., 2009; Hedfors, 2003).

In turn, Adams et al. (2009) highlighted the features of the soundscape approach as a perspective integrating researchers from many different areas, such as acoustics, sociology, architecture, geography, urban planning, engineering, and anthropology, among other disciplines that currently are involved in the design of urban open spaces. Indeed, all these disciplines accept the importance of the soundscape in the global assessment of the human experience, especially when new areas will be designed. Also, these practitioners assume that the soundscape is an element that must be integrated at the beginning of planning open urban spaces (Adams et al., 2009). In this regard, Adams et al. (2009) declared the following concerning the already importance given by UK authorities to the soundscape as a crucial factor in planning urban areas:

Soundwalks and focus groups with urban design professionals, including planners, architects, developers, and consultants, have helped develop an understanding of how soundscapes might be incorporated. A lot of the work that planners do is reactive to developers. So there is much scope for changing things by working with the developer and architect directly before plans even get to the 
planning system... One way of doing this is to involve soundscape experts at the pre-application stage. However, there is only so much that can be done by 'encouragement,' and there may need to be a legislative (whether local or national) requirement to consider soundscape issues. (p. 6)

In short, incorporating a soundscape approach into urban planning, and implementation should be viewed as a tool for designing urban areas with soundscapes that are pleasant, rather than a substitute for noise control strategies that perceive of sound as waste (Brambilla \& Maffei, 2010).

\section{Incorporating the Soundscape Approach into Urban Design and Planning}

Acoustic ecologists have critiqued the social construction of "noise" implicit in the policy agendas of most locations, arguing for a more sophisticated understanding of, and policy responses to, how the senses are implicated in placemaking in urban environments (Truax, 2001). Maffei (2008) also explored the concept of expanding the understanding of the soundscape by examining the acoustician's perspective and how this profession is defining new approaches to include contextual and subjective variables to describe the sonic environment of urban areas.

Maffei (2008) suggested that new approaches can lead to sound becoming viewed as a community resource. This author also suggested that understanding a city's soundscape requires an interdisciplinary approach that draws from the social and natural sciences, among other disciplines. Additionally, Maffei (2008) argued that the soundscape of a place cannot be described by metrics alone. While useful for describing the sound signal, psychoacoustic metrics— such as loudness, roughness, articulation index, etc. - cannot describe the soundscape in full, and these metrics are not offered in 
a format that is useful for urban planners (Cain et al., 2008). In short, the soundscape approach can be utilized as a positive tool, and its incorporation in the early stages of planning may contribute to building more pleasant urban environments.

In this regard, Adams, Davies, and Bruce (2009) identified places in the urban planning process in the United Kingdom (UK) where soundscape considerations could be considered to guide planning decisions. Specifically, Adams et al. (2009) proposed "soundscape process map," which consists of providing "an overview of how the concept of soundscape fits into the planning process" (p. 2). Indeed, the authors proposed a scheme supported by empirical data, where they outline the places (or the moments) where the soundscape must be incorporated into a specific planning process. Notably, they stated:

Drawing on research carried out in the Positive Soundscape Project, including structured soundwalks in Manchester and London with urban design professionals, focus groups with urban design professionals and laypeople, listening tests to develop a soundscape simulator, and discussions with planners, we posit a Soundscape Process Map that focuses on taking a planning application through to obtaining consent, concentrating on the roles of the developer, architect, and Local Planning Authority. (pp. 2-3)

Incorporating the soundscape and soundscape experts before and during urban planning has been carried out with relative success in the United Kingdom. Scholars such as Adams et al. (2009) specifically proposed a Soundscape Process Map where the soundscape can be incorporated in the early planning of urban spaces. As well, the 
incorporation of the soundscape expert is showed. The model proposed by Adams et al. (2009) is represented below through the following figure (see Figure 2).

\section{Figure 2}

\section{Role of the Soundscape Expert during the Pre-Application Stage}

\begin{tabular}{|c|c|c|c|}
\hline Architect / Developer & $\begin{array}{l}\text { Planning / Local } \\
\text { Authority }\end{array}$ & Soundscape Expertise & Soundscape Tools \\
\hline \multicolumn{4}{|c|}{ PRE-APPLICATION STAGE } \\
\hline $\begin{array}{l}\text { Architect/designer } \\
\text { receives brief for } \\
\text { development }\end{array}$ & & & \\
\hline $\begin{array}{l}\text { Preliminary } \\
\text { design concepts } \\
\text { and layouts }\end{array}$ & & $\begin{array}{l}\text { The need for the } \\
\text { architect/developer to } \\
\text { contact a Soundscapes } \\
\text { Expert is identified at this } \\
\text { stage and Soundscapes } \\
\text { information is provided }\end{array}$ & $\begin{array}{c}\text { A Soundwalk with all } \\
\text { parties }\end{array}$ \\
\hline $\begin{array}{c}\text { DECISION TO } \\
\text { PROCEED OR NOT }\end{array}$ & $\begin{array}{l}\text { Local Authority } \\
\text { Planners (and other } \\
\text { relevant bodies) }\end{array}$ & & \\
\hline
\end{tabular}

Note. Soundscape process map (adapted from Adams et al., 2009)

As shown in the figure above, the soundscape expert's role in planning is crucial to obtaining a well-informed design/plan. The soundscape expert is the ideal person to inform the other disciplines in how to balance the soundscape with the other features of built urban spaces. Noteworthy in the work of Adams et al. (2009) is the principle that soundscape intervention in planning and design begins with the initial idea about constructing urban spaces and thus, the soundscape expert should be part of the initial team. The soundscape should be taken into account from the beginning because of the benefits of the mutual exchange between city officials and soundscape experts early in the process: 
This soundscape process map shows the relationships between the architect, developer, and planner throughout the planning application, from the preapplication stage to a planning committee decision. Within these relationships, we have identified the locations at which soundscape expertise would effectively be incorporated. Referring to tools and methods developed through the Positive Soundscape Project, we have highlighted the role of the soundscape expert. (Adams et al., 2009, p. 8)

The soundwalk is an important tool in the planning process that represents the ideal opportunity to raise awareness among all team members concerning the importance of the soundscape before constructing urban spaces. As mentioned by Adams et al. (2009), soundwalks are an ideal opportunity to raise awareness and exchange opinions between the city officials:

Soundwalks... with urban design professionals, including planners, architects, developers, and consultants, have helped develop an understanding of how soundscapes might be incorporated. A lot of the work that planners do is reactive to developers, and so there is much scope for changing things by working with the developer and architect directly before plans even get to the planning system. (p. 6)

Once the concerned authorities have approved the pre-application, we pass to the plan's development, as illustrated below. 


\section{Figure 3}

Role of the Soundscape Expert during the Application: First Phase

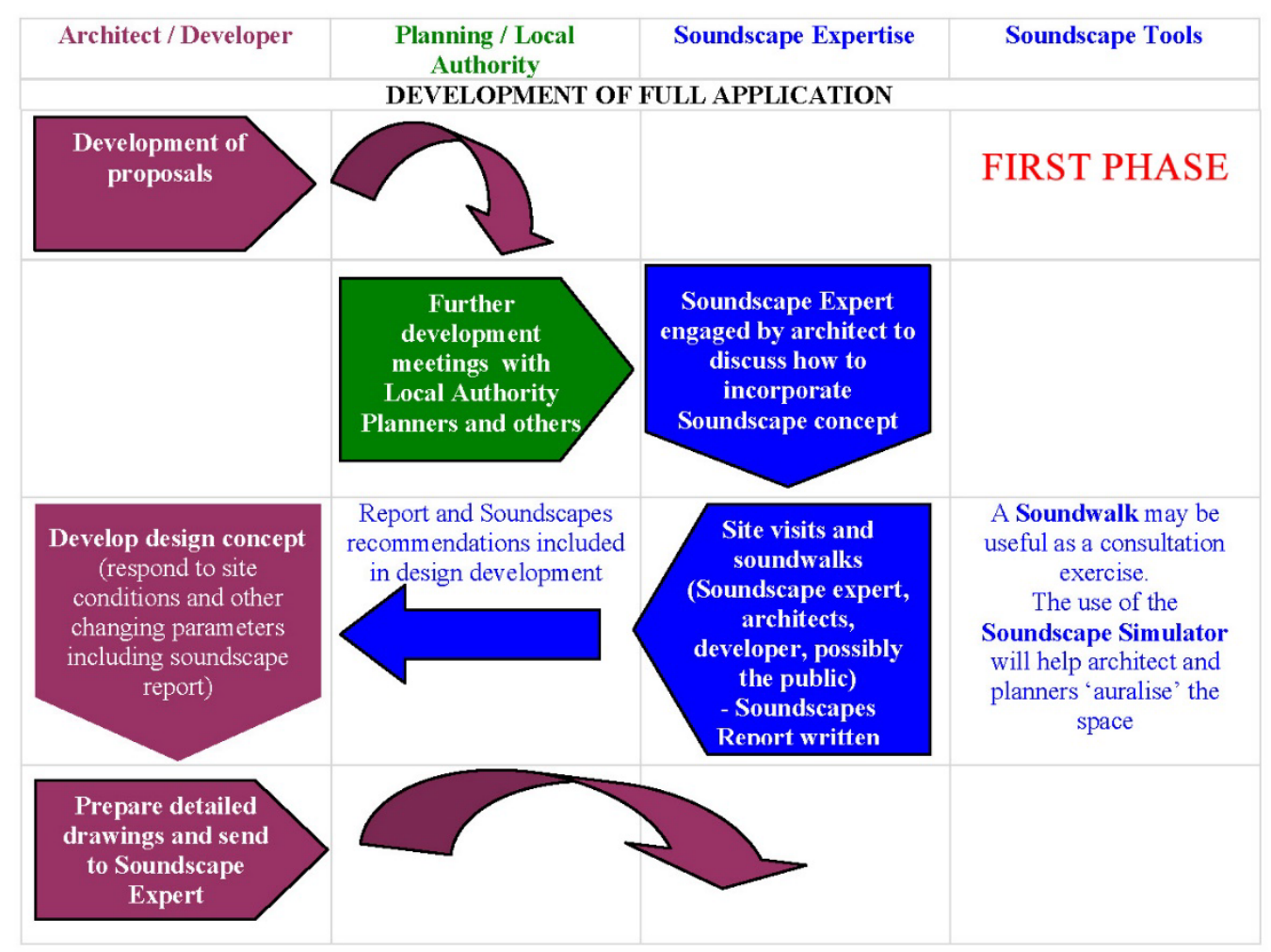

Note. Soundscape process map (adapted from Adams et al., 2009)

The figure above shows the first stage of development, which requires the soundscape expert's in-depth participation in doing two tasks: a) presenting the soundscape as a concept and b) demonstrating the place of the soundscape in the entire design. Again, soundwalks will confirm/infirm the team's discussion about the soundscape. Notice that a report is elaborated in this process, including the recommendation of the soundscape expert. 


\section{Figure 4}

\section{Role of the Soundscape Expert during the Application: Second Phase}

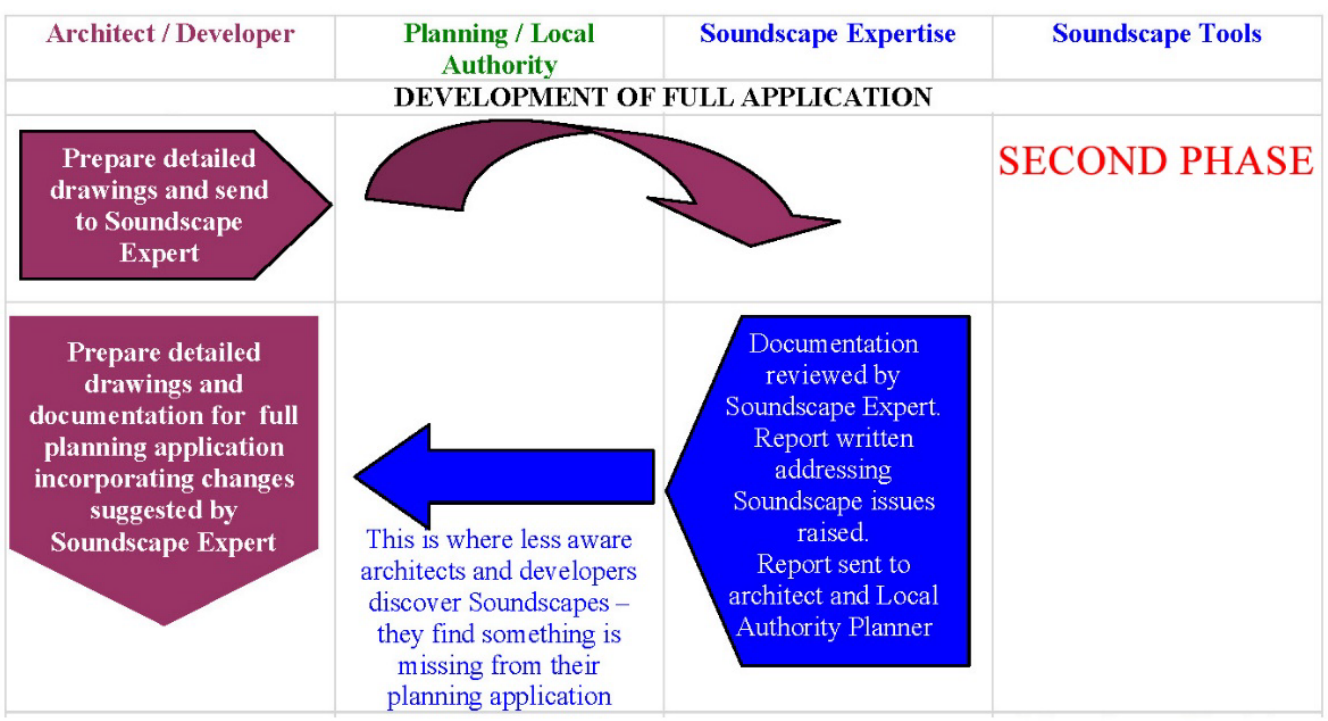

Note. Soundscape process map (adapted from Adams et al., 2009)

A second intervention of the soundscape expert implies the thorough revision of the drawing and documentation concerning the plan. This revision allows the expert to assess any soundscape element to evaluate its place in the entire project. For example, have urban designers and planners considered the recommendation of the soundscape expert? How and to what extent have they taken these recommendations into account? These are key questions that the expert must suggest during the evaluation of the plan. 


\section{Figure 5}

\section{Role of the Soundscape Expert during the Final Application: Third Phase}

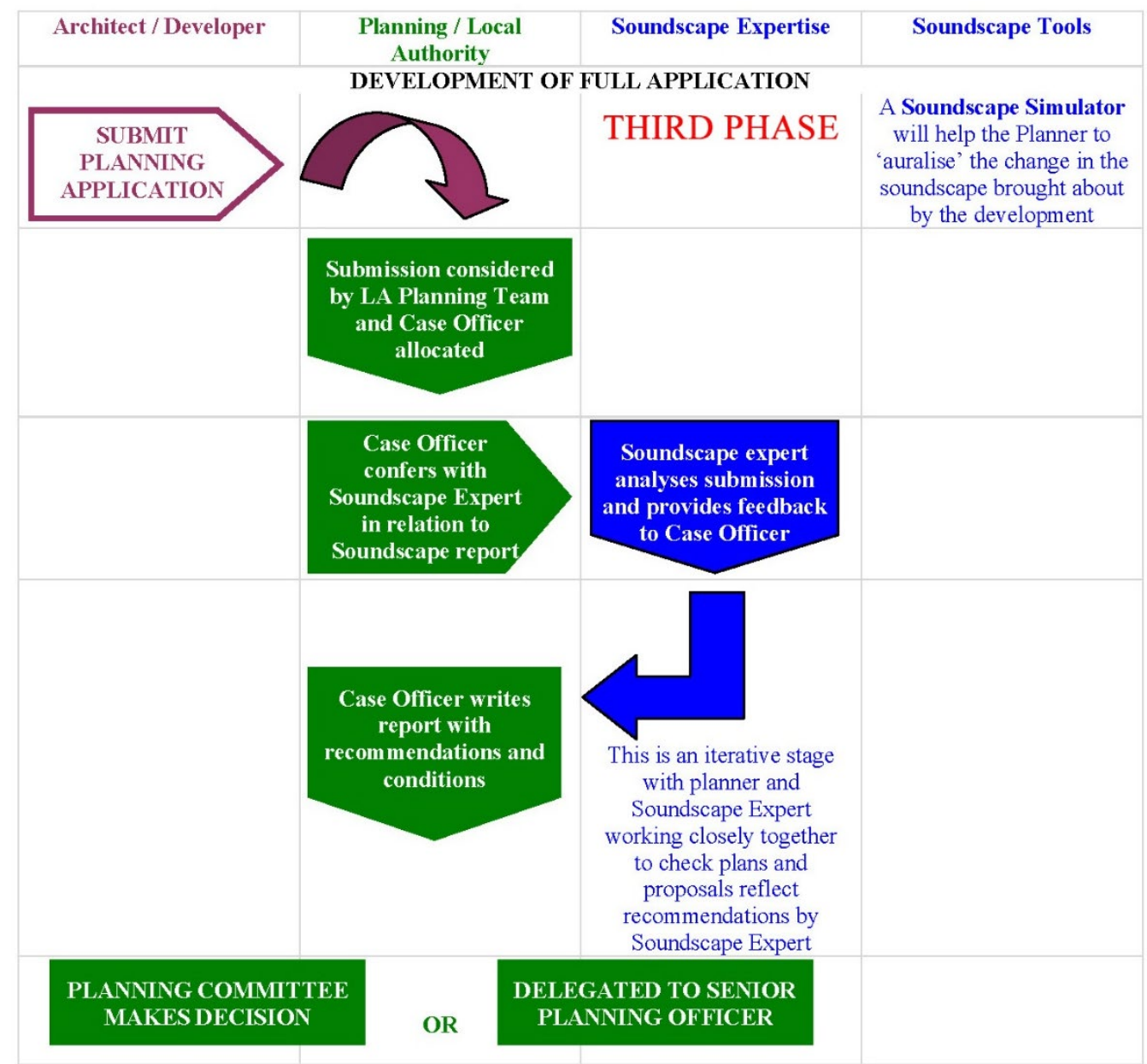

Note. Soundscape process map (adapted from Adams et al., 2009)

The third phase suggests that the soundscape expert must exchange their feedback with the Case Officer to clarify or explain why they support their recommendations and suggestions for using the soundscape approach in the urban space. Finally, once the officer is informed, they proceed to write an informed report concerning the project. As shown in the figure above, the soundscape expert works closely with professionals from 
other disciplines, revising them and assuring that all the expert's recommendations and suggestions have been considered and discussed.

When considering urban spaces, many researchers have suggested that urban parks and spaces are essential in supporting the health of residents who are impacted by the stress of their everyday routines; these spaces can provide a venue for activities such as recreation and relaxation. Some urban parks and spaces offer access to natural features such as waterways and green spaces, which are also vital for human well-being (Brambilla, Gallo, \& Zambon, 2013). The integration of the soundscape approach in urban spaces and parks benefits from the public's input about how the space is perceived to ensure that acoustic and sensory aspects are included as part of the planning and design guidelines (Aspuru, Fernandez, García, \& Herranz-Pascual, 2013).

A positive example of how the soundscape has been incorporated into the design and planning of open green spaces in a major urban area was a policy adopted by the City of Bilbao in Spain, where a policy ensures that public spaces are acoustically comfortable through the implementation of Sound Islands, i.e., areas in public urban spaces in which the soundscape encourages relaxation: "Bilbao City Council has committed to improving the comfort of the spaces so that citizens [use] those areas as an extension of their residence, contributing to their sense of identity and belonging to the city" (Aspuru et al., 2013, p.1). This example demonstrates how a proactive city government implemented a soundscape approach that benefited its citizens by offering them a non-visual amenity that contributed to improving the quality of select public spaces in Bilbao City.

The examples provided in this section concerning incorporating the soundscape approach in urban planning come from the European experience. However, what has 
been done in the United States about the same approach? There are not enough studies demonstrating the incorporation of the soundscape approach into urban planning in the United States (US). Kang et al. (2018) reported that the National Park Service in the United States had developed a comprehensive policy focused on rural spaces to conserve the sound environment experience for visitors and local fauna. Similarly, Miller (2008) reported his participation in the US National Park Service as an acoustician to provide informed advice concerning the management of the natural soundscape in National Parks. In this article, the author pointed out

fundamental questions that need to be answered for management of natural soundscapes, the types of noise issues that arise in parks, the need for quantitative data, approaches to identifying, measuring, and collecting those data, and a suggested approach for developing criteria designed to effectively manage sounds in natural areas. (p. 77)

Despite the importance of Miller's study, it focused on natural and rural areas, representing a different context from what we are proposing in the present research, which is focused on urban spaces.

In a different context, Lillis et al. (2018) have studied the soundscape of marine ecosystems; for these authors, the ambient acoustic environment, or soundscape, is of a broad interest in the study of marine ecosystems as both a source of rich sensory information to marine organisms and, more broadly, as a driver of the structure and function of marine communities. (p. 1) 
This study was conducted to explore marine populations and how they could be impacted by their acoustic environment. However, the study does not address the soundscape problem in open urban zones but maritime areas.

In conclusion, although the United States participates in the European COST Network on Soundscape of European Cities and Landscapes (Brown, 2011), studies reporting on a full consideration of the soundscape as an approach, instead of traditional noise management, have not been developed yet. Equally, studies about the soundscape in urban spaces have not been established either. Until now, we have found few studies that involved studying the soundscape, and all of them refer to environments very different from the urban environment we want to study. Therefore, it can be said that only a limited amount of research has studied the soundscape approach, including the "natural quiet" concept developed for National Parks in the United States, which represents the significant effort made in this regard (Brown, 2011).

\section{Research Outcomes about the Soundscape Approach}

By utilizing a soundscape approach, urban planners can add value to the existing soundscape and understand what the existing soundscape of a site means to current and future inhabitants. De Coensel et al. (2010) conducted a case study that examined how to incorporate a soundscape approach during the initial stages of the planning process of an urban site that was being redeveloped in Antwerp, Belgium in industrial and residential areas. The plan for the new development was comprised of residential areas, a school, an urban park, and roads closed to traffic. The authors completed the case study in two stages that focused on acoustic objects and planning methodology. During the first stage, advice was given about the locations of buildings and green spaces in relation to the 
acoustic conditions. The second stage of this study proposed an acoustic design that complemented the uses of the redeveloped public spaces. The existing soundscape was analyzed for 14 days through stationary measurements and other measurements, including temperature and weather. In addition, 15 selected people were interviewed by a questionnaire survey that contained questions about livability, noise, odor, and quality of life. The study found $75 \%$ of participants to be satisfied to very satisfied with their quality of life. Based on advice given by soundscape experts and survey results, architects and city planners were better informed as to where the building and the park should be located in relation to the roads and freeway. Noise maps and emissions modeling were also utilized to provide scenarios that simulated different planning decisions. All information mentioned above was compiled into an acoustic focused strengths, weaknesses, opportunities, and threats (SWOT) analysis.

Although stage two of the study had not started at the time of writing, this stage provided an overview of future details to serve as recommendations based on the completion of the second stage. They concluded that soundscape concerns should be included during the early stages of the planning process. Community members should also be involved in the plan-making process from inception.

Finally, it should be said that from the methodological point of view, the soundscape approach embraces more progressive methods compared to traditional noise control. However, it does not disregard the importance of working in tandem with conventional noise control methods that utilize regulatory actions when noise levels threaten livability and community health. 


\section{Perceptions and Preferences Regarding Soundscapes in Urban Spaces}

Over the last 80 years, most studies related to sound were focused on what sounds annoyed people in contrast to the research that examined what sounds are enjoyed or preferred (Brown, 2012). Questionnaires and surveys have been essential components to gaining a more meaningful understanding of how people perceive the soundscapes in their communities, with surveys being the most common method to evaluate soundscapes (Jeon et al., 2013).

Michael Southworth, an urban planner who researched how the visually impaired used sound to identify sonic areas, was also an early adopter of the term soundscape. Southworth conducted one of the earliest studies of soundscape perception in a city to evaluate the identity of sounds and the delightfulness of sounds based on the qualities which caused them to be liked or disliked. Three questions were explored for this study: What can one tell about the city by listening to it? What types of sonic settings do people like and dislike? How well do the sonic and visual environments correlate? (Southworth, 1969). The use of questionnaires and surveys are necessary in a practical sense to conduct opinion and preference-based studies. In this regard, Irvine et al. (2009) affirmed that "empirical research on soundscapes has used both objective (e.g., sound level measurements) and subjective (e.g., questionnaires) methods to study urban open spaces such as squares and streets" (p. 156).

In turn, researchers studying how sounds are perceived in urban squares found that attitudes towards natural sounds were very high. Sounds such as water and birdsongs were favored and contributed to a positive perception of the soundscape (Yang \& Kang, 2005). Like most soundscape studies and other research in acoustic ecology, these studies 
aim to encompass how sound is perceived and what sounds are preferred. Through questionnaires and surveys, urban planners and urban designers have the opportunity to capture data that could be utilized to create a new pattern language or terminology specific to urban planning that is soundscape-specific, which would be equivalent to a visual preference survey or a pattern language based on how the urban soundscape is described.

However, there are potential weaknesses to using questionnaires and surveys as data collection tools for understanding soundscapes. Guastavino and Dubois (2006) argued that the evaluation of soundscapes varies based on several factors, including location and time. Other weaknesses of quantitative data collection methods include how sounds are defined across cultures, and if sounds translate the same meanings from language to language, or in the context of different kinds of urban spaces such as markets, public squares, and parks. How people process and categorize urban soundscapes has become a popular research area but still needs to be developed to account for the diversity in soundscapes around the world, since people from different demographic and cultural backgrounds may have different sound preferences (Zhang \& Kang, 2004).

Steele et al. (2012) suggested that urban designers can express possible solutions through diagrams and drawings that have been compiled and applied to develop a pattern language. The authors see pattern language as a contemporary method based on the standardization of pre-existing soundscape methods and terminology. Brown, Kang, and Gjestland (2011) also suggested the need for a common language to standardize the soundscape assessment process, due to how the term "soundscape" is used to describe 
human perceptions of the sonic environment, in addition to the totality of sound. With regards to questionnaires, since there are no standard terms that reflect how the soundscape is perceived, the variety of language employed in the data collection process has the potential to skew the analysis of survey responses based on the subjectivity of the evaluator.

\section{The Soundscape in Urban Squares and Plazas}

An important component in most cities is the urban square or plaza. These public spaces are often in the hearts of cities and are surrounded by several contributors to the soundscape, such as buildings, transportation, and people. Some public spaces are more popular and, thus, more visited than others, especially when it comes to sites that attract visitors to the city from rural or suburban locales in the region. The popularity of such sites may fluctuate depending on the time of year, events in the area, and local traditions. It is essential to study what attracts people to entertainment, housing, and public spaces, while also considering the unique social and environmental conditions that exist in these spaces. In a case study conducted by Yang and Kang (2005), the general perceptions of urban soundscapes and sound preferences in urban squares were examined in order to determine the effects of demographic factors on sound preferences. Their findings suggested that soundscape preferences in urban squares vary between age and cultural backgrounds, with older people preferring natural and cultural sounds. Yang and Kang also conducted a soundscape study in 14 urban public spaces in Greece, the UK, Italy, Germany, and Switzerland. Even though this study was cross-cultural, the findings produced similar trends that people across cultural contexts preferred nature and cultural sounds rather than sounds produced by nearby traffic or construction. 
Most, if not all, parks in urban areas include the sounds of road traffic in the overall soundscape, which has contributed to the perception that urban parks and spaces are loud. This perception has also raised whether urban parks and spaces contain soundscapes that are considered pleasing or of higher quality than other urban spaces with noise, or unpleasant sounds. Lobo Soares and Bento Coelho (2011) conducted a study to examine which characteristics of the soundscape were most pleasing for users of four popular public parks in the City of Belem, Brazil. Additionally, the researchers focused on applying their findings to developing tools to improve the quality of the soundscape in other urban locations. The parks in their study were composed of diverse soundscapes, ranging from loud traffic sounds to natural sources of sounds. The researchers employed various methods in the field to capture and analyze the soundscapes from each of the four parks. These methods included sound maps, soundwalks, sound pressure readings, and field observations. The researchers found that sounds from road traffic dominated the measurements from all parks. They also found that the massive influx of weekend visitors contributed to a degraded soundscape quality; however, natural features in the parks such as vegetation and water features reduced the visitors' perceptions of urban sounds ascribed as noise.

Some researchers (Foale \& Davies, 2012; Raimbault \& Dubois, 2005) have argued that soundscape research should be more innovative by challenging the traditional perception questionnaire derived from the acoustics methodology of studying urban spaces. Instead, they suggest that people's lived experience should be more prominent in soundscape research to understand better why soundscapes matter. In this vein, Foale and Davies (2012) studied how people respond and interact with the soundscapes in urban 
spaces. Their objective was to prioritize listeners' perspectives to learn what was most important about their listening experiences. The researchers assigned each participant an audio recorder to create sound diaries that allowed each listener to engage their recorded sounds and critically contemplate the sounds they experienced, rather than employing a perception questionnaire. After two weeks, the participants were interviewed about their listening experiences. While the researchers intended participants to record their sound dairies in urban spaces, most participants recorded sounds of either work or home instead of public spaces.

\section{Balancing Visual Aesthetics and Soundscapes}

Although many researchers have argued that urban spaces and parks need to be planned with less focused on visual aesthetics, other researchers claim that the visual aspects of an urban space such as a park are significant contributors to how people identify a place in conjunction with the soundscape. Brambilla, Di Gabriele, Maffei, and Verardi (2008) examined 12 urban spaces to see if the soundscape of each urban space could be used for participants to recognize it. For this study, the researchers took binaural recordings and photos of each location. The recordings were played in a laboratory setting, and the photos were shown to two groups of participants. Afterward, participants were asked to rate and identify the sounds heard. The study found that participants had no difficulties identifying the sounds in the urban spaces and confirmed the importance of a site's sonic perception and visual information. Sounds and sights can complement each other in creating a complex soundscape. 


\section{Practitioner Perceptions about Urban Soundscapes}

What do urban planners, urban designers, architects, and engineers think about the effect of the soundscape on the global perception of urban spaces? How do they include such factors when planning urban spaces? Assem Al-Hajj (2014) highlighted the role played by balanced urban areas and the social commitment of urban planners to make people more comfortable in such spaces; as they stated, "both urban design and planning practice are playing a significant role in providing more livable public open spaces which entices and encourage the public to choose to spend more of their spare time in these spaces" (p. 81). Scholars outside the United States have inquired about the practitioners' knowledge concerning the soundscape and livability, and some research has demonstrated a growing interest in this area. However, following Eldien's (2014) statement: "Urban planners and designers need more information to improve the cities' environmental quality" (p. 342). There is a shift taking place among practitioners and researchers, away from interpreting sounds through noise management optics, with the objective of impeding noises that transform the urban environment into unlivable places. Recently, urban planning and design practitioners have become concerned with sound as an active and influential part of the built environment, key factors affecting the global perception of urban spaces in a holistic way. In this regard, it seems imperative to 'educate' urban planning and design practitioners on sounds and soundscapes as elements integral in the designs and installation of urban spaces. However, until now, there have not been many examples showing how to proceed with this pedagogical learning. Raimbault and Dubois (2005) insisted that there is an 'educational need' to provide knowledge and increase practitioners' awareness about the crucial role sound plays in 
urban areas. They stated: "Urban planning education and practice have traditionally been focused on noise mitigation, concentrating almost exclusively on reducing urban noise levels" (p. 1). Concerning the need to enhance urban planning and design practitioners' awareness through education, Steele et al. (2013) looked into

urban design and architectural resources on the pedagogy of both adopting scientific approaches in architecture, such as evidence-based design and soundscape design. They also performed a manual search by speaking to architecture and design colleagues, and the overwhelming result is that no such education exists. (pp. 7-8)

Recent approaches in soundscapes studies and urban design visualize sounds as positive resources and no longer as unwanted sounds (Aletta et al., 2018; Kang et al., 2016; Wothge et al., 2017). In this respect, Aletta et al. (2018) declared that: In policy-making and research alike, environmental sounds are often considered only as psychophysical stressors, leading to adverse health effects. The soundscape approach, on the other hand, aims to extend the scope of soundrelated research to consider sounds as resources, promoting healthy and supportive environments. (p. 1)

Herranz-Pascual et al. (2010) have proposed a theoretical model to study the impact of soundscapes in urban areas. Herranz-Pascual et al. (2010) pointed out the significance of the fact that soundscapes are finally an area of study:

the public spaces of our cities have become 'no places,' which people pass through without stopping and where there is no fostering of social relations of enjoyment of the place. Furthermore, soundscape studies can help urban planners 
to design public spaces for social cohesion and with restorative function (places where to relax, destress...) where persons and communities enjoy themselves and interact, which helps to improve the health and quality of life of the citizens. (p. 2) As seen through the studies of Herranz-Pascual et al. (2010), Aletta et al. (2018), and others, emerging studies and literature incorporate sound into the discussion in a positive and desired position (Adams et al., 2009). In short, sounds and soundscapes are currently being recognized as positive resources that contribute to the well-being of humans and animals. Nonetheless, these studies have been conducted mainly in European Union (EU) and the United Kingdom, which led me to examine research conducted in the United States.

\section{Studies on Soundscapes and Urban Planning in the United States}

Studies within the EU and Asia conclude that noise has primarily been considered a significant problem for cities and urban spaces (Raimbault \& Dubois, 2005). Such a situation has demanded the insertion of sound and the soundscape into the planning of urban spaces, which requires the presence and participation of specialists, such as acoustic ecologists, soundscape planners, and designers. In keeping with studies from the United Kingdom and Belgium, which highlighted the need for assistance when designing urban spaces and the requirement for urban planners and other stakeholders to participate in the soundscape planning of urban areas, Kang and Aletta (2018) stated the following:

There is a need for practical guidance in soundscape design, based on research and successful practical examples. It is also of significance to provide guidelines for preserving architectural heritage sites for soundscape perspectives [21, 22] 
(...). It is important to create awareness and promote communication concerning urban soundscapes and quiet areas among policymakers and stakeholders (p. 3). A similar statement was pronounced by Cerwen (2017):

Landscape planning and design involve decisions that have far-reaching effects, positive and negative, on the soundscape. However, landscape architecture and related disciplines have not fully recognized the possibilities of considering sound issues in design projects. This is problematic, considering that sound influences health and wellbeing and is an important factor in environmental experience. ( $\mathrm{p}$. 1)

The relevance of linking urban design and the soundscape became evident through the study conducted by Raimbault and Dubois (2005) in Nantes, France, where these scholars included architects, town planners, engineers, and landscape designers in assessing their soundscape awareness in urban projects:

After presenting city-users' experiences of soundscapes, our investigations were therefore concerned by decision-makers' and planners' awareness about the place and utility of the soundscape concept among urban projects. Interviews were carried out to investigate the attitudes and habits of a representative panel of urban planners and decision-makers. (p. 343)

Raimbault and Dubois' (2005) findings pointed out the many difficulties in assessing soundscapes and raising awareness among architects, urban designers, and urban planners:

All these results lead to the ambiguous position of urban politics and planners, expecting more noise policy and arguing the overstatement of noise as a 
community problem. These findings highlight the difficulty of dealing with the soundscape concern in the global question of urban management and also indicate the need to increase public awareness concerning urban soundscapes. (p. 346) Although "the concept of the soundscape as a resource has previously been recognized in national park management (e.g., US National Park Service)" (Brown, 2010, p. 494), in the United States, studies on soundscapes and urban planning are limited. A statement in this sense was affirmed by Kuehne et al. (2013) in their research in the state of Washington: "far few studies have described acoustic characteristics across a gradient of urbanization or as a function of land use" (p. e55661). Also, a study conducted by Joo et al. (2011) in Lansing, Michigan signaled the following: "Although many studies have addressed the effects of urban noise on acoustic communication of vocal organisms, little work has been done to understand the acoustic characteristics and the interaction between biological and anthropogenic sounds across urban-rural landscapes" (p. 1). Currently, in the United States, acoustic ecology and soundscape theories and methods that contribute to effective noise management are not included in design methodologies for urban designers or policies recommended by urban planners. What literature is available has not been contributed by urban planning, urban design, or urban studies scholars. With this idea in mind, in the next section, I address the gaps in the literature about the soundscape approach and noise management approach.

\section{The Gaps in the Literature}

Several scholars have pointed out the importance of the soundscape as a factor that must be inserted into urban planning and design projects. For instance, Raimbault 
and Dubois (2005) stressed that: “After presenting city-users' experiences of soundscapes, our investigations were therefore concerned by decision-makers' and planners' awareness about the place and utility of the soundscape concept among urban projects" (p. 343). In the same regard, Steele (2018) admitted that "despite the quickly growing body of evidence supporting the potential for improved urban sound quality, virtually no world cities are adopting soundscape planning and design initiatives in earnest, reinforcing a research-practice gap on urban sound" (p. v). Additionally, Steele (2018) insisted on the importance of including the soundscape concept when designing urban spaces:

The soundscape approach, which implies that the sonic environment can have positive and negative aspects, applies to a wide range of urban scales, from individual buildings and parks to the entire city; the approach also applies to plans, designs, and decisions made both before and after an intervention is made. (p. v)

However, while the urban planning and urban design disciplines have been suggested as logical fields for the consideration and implementation of holistic soundscapes in cities, public spaces, and parks, until now these disciplines have not made any substantial contributions. As was mentioned by Raimbault and Dubois (2005): "very few results are known concerning the urban planners' point of view on city soundscapes and how their expert knowledge affects their conception and their work" (p. 341). Now, where to start to address the soundscape within urban design and planning? Since the soundscape is a mixture of pleasant and unpleasant sounds, how should we proceed? 
If we begin with the assumption that planners and policy officials are educated and empowered to review or make recommendations regarding land use codes, with additional knowledge and understanding of a soundscape approach, they could influence current plan making, plan implementation, and noise control practices. The education of practitioners on the principles of the soundscape approach is not a new proposition, given that Kang and Aletta (2018), Aletta et al. (2016), Adams et al. (2009), and Raimbault and Dubois (2005) have already researched this area. Kang and Aletta (2018) explicitly mentioned the importance of training practitioners and providing them with adequate resources, such as labs and software:

There is a need for practical guidance in soundscape design, based on research and successful practical examples... It would be important to develop tools and corresponding software for the design and implementation of soundscapes for use by urban planners and policymakers. Auralisation tools are especially relevant and important for soundscape design. (p. 3)

However, in the United States, the noise management approach still seems to be prevalent. Thus, this study suggests the benefits of combining both approaches to 'educate' practitioners on the benefits obtained from this combination.

\section{Closing the Gaps between Noise Management and Soundscape Approaches}

To incorporate the positive aspects of both approaches, researchers such as Brown (2012) and Truax (1998) have suggested that both fields' contributions could be exploited, closing the gap between sound as waste and sound as resource. Brown (2012) made this difference more evident by proposing the table below: 


\section{Table 1}

The Different Foci of Environmental Noise and Soundscape Approaches

\begin{tabular}{|c|c|}
\hline Environmental Noise Management Approach & Soundscape Approach \\
\hline Sound managed as waste & Sound perceived as a resource \\
\hline Focus is on sounds of discomfort & Focus is on sounds of preference \\
\hline
\end{tabular}

Source. Brown (2012, p. 75)

Brown (2012) pointed out the characteristics around each one of these two approaches: "Sound is conceived as a waste product in the environmental noise field - a waste to be reduced and managed. Such noise reduction or management is at the source, in the propagation path, or at the receiver itself' (p. 75). The noise management approach usually measures sounds, and labels as disagreeable sounds as noise that must be eliminated or mitigated. Conversely, Brown (2010) commented on the soundscape approach, which regards sound largely as a resource-with the same management intent as in other scarce resources such as water, air, and soil: rational utilization, and protection and enhancement where appropriate. Resource management has a particular focus on the usefulness of a resource to humans and its contribution to the quality of life for both present and future generations. (p. 494)

However, the soundscape approach considers sound a resource that offers benefits to a suitable soundscape. In this regard, I talk about closing the gap between these two fields, i.e., creating a zone of mutual understanding where both areas can benefit from each other. As a result of this new zone of understanding, practitioners from both fields 
are merging to combine methodologies and theories and invite other disciplines such as urban planning into the discussion. Yang and Kang (2005) also suggested closing this gap when they proposed that the design of soundscapes should be intentional, and that designing a good soundscape creates more opportunities for urban design. Soundscape researchers can open a line of communication to urban designers because soundscapes fall under the umbrella of urban design, which caters to the concerns of urban space (Steele et al., 2012).

\section{Lessons from the Literature Review}

This chapter reviewed significant literature that included soundscapes, sound and urban planning, noise mitigation in urban areas, the soundscape approach method for planning and designing urban spaces, and the role of the soundwalk methodology.

Although the research presented in this chapter encompasses the nexus of the soundscape and urban planning, it also exposes several knowledge gaps in urban planning theory and practice.

As a critical reflection on the literature about soundscapes studies, the following lessons emerged about current literature on the soundscape.

First, the studies about soundscapes are more developed in European countries than in the United States. However, the studies conducted in the US are reduced and limited to natural spaces (national parks) or the soundscape of marine communities.

Second, many researchers perceive the soundscape as a noise control strategy, i.e., negative sounds must be eradicated. 
Third, the soundscape view, which strikes a balance between positive and negative sounds, has been used sparsely as an approach in the few studies found.

The literature review also supports the direction that this study takes concerning using the soundscape as an approach and using the soundwalk as a tool to assess the soundscape in urban areas. 


\section{Chapter 3: Methodology}

Dubois et al. (2006) observed the subjective character of sounds. Because of the variety of sound interpretations that can be obtained from different people at different hours on the same day, the same phenomenon can be interpreted and understood in different manners, according to the different subjects that live the experience. This belief is aligned with the thinking of Creswell (2003), who pointed out the following concerning qualitative approaches: "The researcher's intent, then, is to make sense (or interpret) the meanings others have about the world" (p. 8). Therefore, I believe that individual subjectivity and interpretation must take center stage in research. This led me to choose a qualitative approach in order to allow individual subjectivities to emerge. Thus, I offer that qualitative approaches, where participants' voices are significant, can offer a better approximation to study the soundscape of urban areas when compared to the traditional use of quantitative methods.

Likewise, qualitative approaches are relevant for my study because of my interest in understanding practitioners' experiences of doing a soundwalk in the park. I envision their sound walk as an immersed situation that requires them to pay attention and focus on the different sounds they perceive in the different sections of the park. My research questions are focused on their impressions and perceptions of listening to the soundscape of the Tom McCall Waterfront Park. In this sense, qualitative approaches are the best to reach my objectives because they allow the participants to express themselves and narrate their subjective experiences in the park. I assume that these practitioners' experiences are valid and valuable expressions of their experience and their narratives are true. 
In this regard, I argue that a soundscape approach should be rooted in a qualitative analysis, which creates opportunities to explore, gain data, and understand how the soundscape is experienced.

\section{Hermeneutic Phenomenology}

Phenomenology is a descriptive research method that "describes the common meaning for several individuals of their lived experiences of a phenomenon" (Creswell, 2014). In this context, a hermeneutic phenomenological approach was used as the methodology for this study. As mentioned by Laverty (2003): "Dasein is translated as "the mode of being human or "the situated meaning of a human in the world"' (p. 24). In this sense, the practitioners in this study must be seen as individuals in continual interaction with the park, considering it as a lived space of life, where it is possible to experience many types of sounds. Every individual's perspective has been influenced by their inner beliefs and values (Cammell, 2015). Phenomenology as a methodology allows us to explore the lived experiences of a human being and examine how and why an individual views their exterior world. The approach provides an understanding of the hidden meanings and essences of experience together, focusing on people's perceptions of the world in which they live and what this world means to them, i.e., the significance of their lived experiences.

Relationality is a term of importance because it represents a personal and subjective story that attributes particular impressions to each person. Similarly, relationality can be understood as a person's history and cultural background that has been constructed upon their daily experiences (Laverty, 2003; Osborne, 1998; Reiners, 2012). Finally, the phenomenological description that was obtained is 'space' where 
structure and texture altogether contribute to give relevance to the final discourse (Wertz et al., 2011).

Every transaction is an encounter to be 'interpreted' by the individual based on their background (Laverty, 2003; Reiners, 2012). Therefore, the relations between the person and their social, economic, and cultural contexts are the most important concerns for the hermeneutic phenomenological approach. In hermeneutic phenomenology, people and their backgrounds are an indissoluble duality that, to some extent, has guided them in their transactions with new experiences, such as the soundscape of Tom McCall Waterfront Park (the park).

In this study, the participants were asked about their lived experiences regarding the soniferous experience of their soundwalk in the park. As the participants visit the park frequently, they are already familiar with the different sounds inside and outside the park. These personal impressions are shaped by their particular values, customs, and beliefs when they accomplish any activity in this area. These perceptions are their 'fore-sight' or 'fore-conception,' i.e., the preconceived knowledge about a phenomenon they possess that is considered through the lenses of their inner beliefs and values (Laverty, 2003; Osborne, 1998; Reiners, 2012). Assuming that their individual soniferous experiences will influence the points of view of the practitioners, such perspectives will be revealed hermeneutically, i.e., the process of understanding the interpretation that individuals make of their phenomenon from their foresight or previous conceptions (Laverty, 2003; Reiners, 2012). In my study, sound is understood as a resource, whether positive or negative, without judgment, and both possibilities are part of the soniferous experience. In this regard, the soundscape as an approach and the soundwalks as a strategy to 
immerse participants in the soundscape of the park are presented below. These are two useful tools that allow participants to enter the soundscape of urban space, knowing that positive and negative sounds compose the soundscape.

Here I return to the study's research questions to confirm that the phenomenological approach is a logical choice:

RQ1: What are the soniferous experiences for practitioners who do a soundwalk of Tom McCall Waterfront Park?

RQ2: How do practitioners who do a soundwalk of the park understand the soniferous experience of Tom McCall Waterfront Park?

RQ3: How does the soniferous experience of practitioners who do a soundwalk of the park inform future planning and design considerations of Tom McCall Waterfront Park?

All my research questions refer to the practitioners' experiences, i.e., how they understand this soniferous experience and how they obtain insightful information from the soundwalk they have realized.

Phenomenology was appropriate for this study because I intended for participants to reveal their lived experiences of the soundscape in the park. Phenomenology was also applicable to this study since it is receptive to both the phenomenon of sound and the individual relationship between the examiner and the examined (Finlay, 2012).

\section{The Soundwalk as a Tool to Assess Soundscapes}

In general, walking is a practical and accessible way to experience the locations where everyday life passes, and to establish a sense of place and a sense for place (Wunderlich, 2008). As Gehl (2013) and others have suggested, test walks are a suitable 
methodology for studying public life and gathering information about a site because they situate the individual in the immersed environment to be tested.

However, Gehl and others do not specifically call out the soundscape as essential information that should be collected. For urban planning and urban design practitioners, walking in any form should be considered a spatial practice that is afforded more importance as part of an overall research methodology. It offers an essential way of identifying factors that play a role in the phenomena of the soundscape in urban places. When coupled with listening to the sonic environment, walking offers a purposeful method that enables practitioners to ignite their sense of hearing alongside their inherent sense of sight. As senses such as hearing become more apparent to urban designers, design decisions related to the soundscape have a better chance of being considered.

\section{A Brief History of the Soundwalk Method}

R. Murray Schafer conceived the soundwalk method during the late 1960s and early 1970s at Simon Fraser University in British Columbia, Canada. According to The Handbook of Acoustic Ecology (1978), a soundwalk is

a form of active participation in the soundscape. Though the variations are many, the essential purpose of the soundwalk is to encourage the participant to listen discriminatively, and moreover, to make critical judgments about the sounds heard and their contribution to the balance or imbalance of the sonic environment. (Truax, 1978)

Schafer utilized this method while documenting changes in the sonic environment during a study known as the World Soundscape Project. This study was conducted with several 
graduate assistants who have since become leaders in acoustic ecology and soundscape studies.

For example, Hildegard Westercamp, an assistant of Schafer, has focused most of her research on the methodology and design of soundwalks. Westercamp (2006) proposed the soundwalk in a straightforward but profound manner by describing it as "any excursion whose main purpose is listening to the environment" (p. 1). The simplicity of her definition is to listen to everything, no matter what it may be or where it may be. Still, the complexity of soundwalks is that we do not typically listen in this manner. Exercising this method of listening may be difficult since we have been subjected to many loud and meaningless sounds on a daily basis. Westercamp (2006) argued that we cannot ignore sound like we can ignore sight because we can close our eyes but not our ears. Sound is vibration, which affects our bodies and minds. Even if we try to tune out unwanted sounds, our brains still want to process the input.

In addition, when we intentionally tune out the sounds around us, we desensitize our listening abilities and hinder our ears from performing their natural function (Westerkamp, 1974). Westercamp (1974) also emphasized that listening without attention increases the probability for subtle and quiet sounds to become unobserved; we become less sensitive to our hearing given the cacophony of mechanized and urban sounds we encounter.

\section{Soundwalks as a Method to Immerse Participants in a Given Soundscape}

Soundwalks are instrumental in immersing a listener into the sonic environment as an active participant to analyze the encompassing nature of sounds. The soundwalk is the chosen method for this study because it provides an opportunity for participants to 
become familiar with the sonic fabric of a place and shift from an inherently visual lens to one that offers a new responsibility and criteria when considering the planning and designing in urban spaces and parks. Practitioners can also use the soundwalk to collect other data about urban forms and architectural details that influence the soundscape (Semidor, 2006).

The soundwalk has also been used to gather soundscape-related data in urban planning and design strategies that aim to modify or restore public spaces. Venot and Sémidor (2006) examined the relationship between the morphology of public spaces and the soundscape to improve tools that urban planners and urban designers can utilize when redeveloping existing sites. By incorporating these tools, urban planners and urban designers will be empowered to consider the sonic phenomena of spaces and prepare for future changes to the spaces if needed. Venot and Sémidor (2006) suggested that the soundwalk method should be conducted before any redevelopment to capture the original location's representation.

The soundwalk can be used in association with other data collection methods such as field recordings of specific sites. Field recordings can aid the urban planner and urban designer in evaluating how their development decisions might transform the soundscape by listening to simulations where other sounds are added to the original recordings.

During the study conducted by Venot and Sémidor (2006), field recordings were performed by soundwalkers to be examined later in a laboratory setting. These recordings allowed the researchers to determine different urban forms. A closed space could be identified by a similarity of two tracks, and an open space such as an outdoor square could be identified by a large difference between the two tracks. The authors point out 
that the soundwalk is an accessible method for city officials, urban designers, and urban planners, and it becomes even more powerful when paired with the soundscape terminology established by R. Murray Schafer. When used together, these methods allow for describing the sonic environment without making judgments about whether a sound is a noise or is an acceptable or desirable part of the soundscape.

Though soundwalks are a common method, comprehensive procedures for conducting soundwalks have yet to be defined (Jeon et al., 2013). Researchers have employed the soundwalk in several ways to conduct soundscape-related studies of urban areas. Most soundwalks are conducted in groups, but there are several advantages of individual soundwalks over group soundwalks. Jeon et al. (2013) proposed individual soundwalks because soundwalking as an individual allows for more time of day and location options when compared to group soundwalks. On an individual soundwalk, there is no need to be consumed with the individual's distance and spacing from others, so listening is not affected. Adams et al. (2008) regarded the soundwalk as an empirical method for identifying a soundscape and components of a soundscape in various locations. In their study to understand people's experiences and perceptions of soundscapes in urban areas, soundwalks were used but altered based on a quantitative framework that took into account professional and personal feedback received from participants. The study participants were sent to urban areas and directed to focus on sounds rather than sights to better understand the dynamics between the soundscape and the built environment.

As an active way to engage the soundscape, soundwalks encourage individuals to listen and critique sounds, which has the potential to determine if a sound is contributing 
to the balance or imbalance of the sonic environment (Adams et al., 2008). Urban design, urban planning, and architecture professionals can work more collaboratively on soundwalks. The researchers and professionals shared and experienced sonic phenomena in the urban areas utilized for the study. Additionally, through using the soundwalk method, this study introduced professionals to a positive sound perspective instead of the regulatory context and negative noise dialogue that most were familiar with through their work.

\section{Study Participants}

The participants for this research were recruited from a population of professionals in Portland responsible for either planning, designing, and maintaining public spaces or regulating the sound that occurs in those spaces. Study participants included the fields of urban planning, parks and recreation, noise management, community engagement, and landscape architecture practitioners. The practitioners were familiar with urban planning and design practice, were aware of the park's history and context, and/or involved in regulating and maintaining the site. This study focused on these specific practitioners rather than non-practitioners because non-practitioners lack the experience and ability to answer specific soundwalk survey questions related to their professional experience.

Participants were recruited through my existing professional networks, phone calls, emails, in-person meetings, and recommendations. The researcher's networks served as bridges to contact the individuals who eventually decided to participate. As an urban planner that has managed a city's livability program, I had personal access to many 
professional networks. The group of participants contacted to join this study included professionals and representatives drawn from the following agencies:

- The City of Portland - Portland Parks \& Recreation

- The City of Portland - Noise Management Office

- The City of Portland - Bureau of Planning and Sustainability

- The City of Portland -Office of Community and Civic Life

- The City of Portland - Bureau of Environmental Services

- The City of Portland - Portland Bureau of Transportation

- The City of Portland - Portland Water Bureau

Other participants included professionals from various urban planning and landscape architecture firms. These participants were invited because they work on various planning and design projects in parks and urban spaces. Government agencies often hire their firms to provide recommendations. As a result, it can be assumed that all the people who participated in this study were knowledgeable persons working in different areas related to policy, noise control, urban planning, and urban design.

Thirty-one (31) practitioners participated in this study. Based on Creswell's (2014) recommendation to select 5 to 25 participants, the initial goal was to recruit at least ten practitioners. I determined that 31 practitioners was a sufficient number to gather a comprehensive understanding and meaning of a phenomenon (Dworkin, 2012). More participants than the original goal of ten proved important to reach saturation, given the researcher's timeline.

A compiled list of potential participants was emailed at the beginning of the study to gauge interest in participating. Participants who were interested were emailed more 
information about the study, followed by a series of emails about participating, a research study overview, and links to a schedule for participation. Participants were not compensated for their participation in the study. Soundwalks started once participants scheduled a day and time to take the soundwalk at the park, completed the digital consent form, received instructions, and agreed to participate in the research.

\section{Site Selection/Setting}

Tom McCall Waterfront

Park in Portland, Oregon was

selected as the study area for this

research because it contains a

diversity of activities, amenities,

and distinct areas that could

easily be divided into quadrants.

Other parks in the Portland area

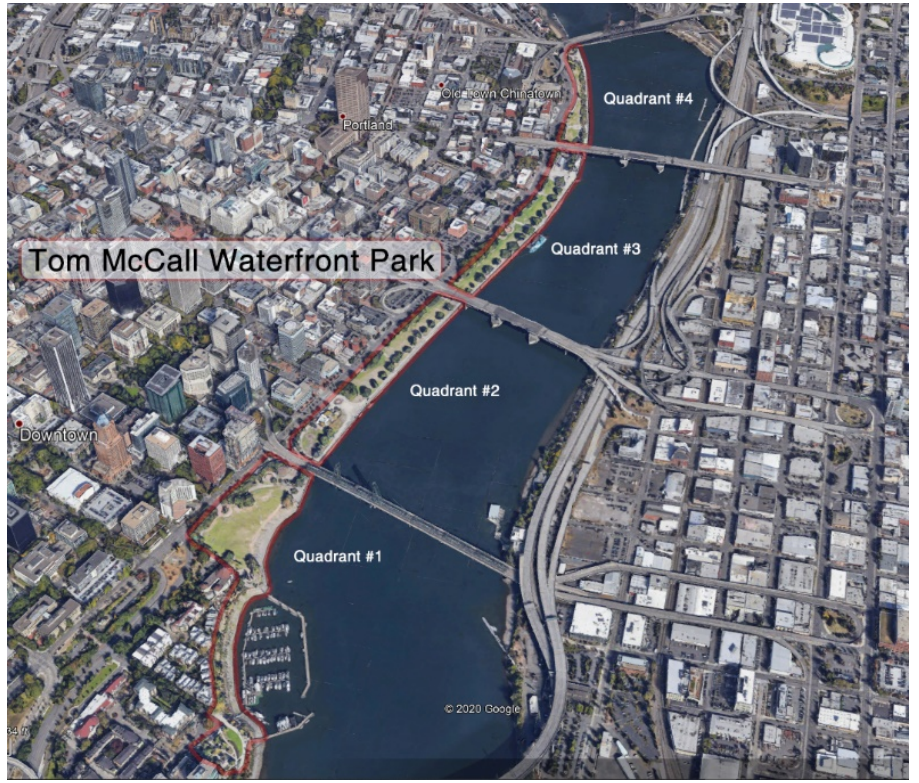

Photo Credit: Google Earth

were considered; however, they

were not centrally located and did not contain a diversity of activities or amenities representing sounds that typically occur in cities and urban spaces. The park's size allowed soundwalks to be conducted in a large city park instead of a smaller park or multiple parks.

The 36-acre park was once the site of the Harbor Drive F. In 1968 a proposed expansion of the freeway was met with opposition from community activists. The freeway expansion was halted by then Governor Tom McCall, who formed a task force to study the freeway's removal (Reclaiming Old West Broad Street, 2014). In 1972, a 
Citizen Advisory Committee was established and made recommendations for the area to be redeveloped, including a waterfront park. The removal of the Harbor Drive Freeway started in 1974, and the park was completed in 1978. The park was renamed for Governor Tom McCall in 1984 (American Planning Association, 2012).

Activities and amenities in the park range from historical plazas, monuments, water features, the Portland Saturday Market, a marina, and many annual events, protests, and festivals. This array of activities made it possible for participants to observe, experience, and document various activities at several locations within the park that could be differentiated for this study. This park was also selected because it contains an assortment of sonic phenomena within its boundaries that comprise the park's soundscape. This was important because this research could provide potential observations about public spaces' overall desirability from a non-visual perspective. This can help various practitioners, including urban planning and public space decisionmakers, to employ new methods and tools to study and value the soniferous experiences of public spaces in Portland, Oregon, and other cities.

For this study, a hypothetical division of the park was made to better analyze each participant's responses regarding a given quadrant. Thus, using the bridges as landmarks, the park was divided into the following four quadrants:

- Quadrant 1: South Waterfront Park Garden to Hawthorne Bridge

- Quadrant 2: Hawthorne Bridge to Morrison Bridge

- Quadrant 3: Morrison Bridge to Burnside Bridge

- Quadrant 4: Burnside Bridge to Steel Bridge 
The Willamette River bounds the park to the east; Naito Parkway borders it to the west; Northwest Glisan Street is to the park's north; and Southwest Harrison Street is to the park's south. Naito Parkway bounded each quadrant to the west and the Willamette River to the east. All North and sound boundaries for each quadrant were bridges, except for the first quadrant where the south boundary was SW Montgomery Street.

\section{Data Collection/Procedures Followed}

For the proposed research, Institutional Review Board (IRB) approval from Portland State University (PSU)'s Human Research Protection Program (HRPP) was requested and approved. The primary data collection instrument for this research was a soundwalk survey and post-soundwalk survey, found in Appendices A and B. Participants registered online to participate in the soundwalk then received instructions via email detailing where to meet and how to complete the soundwalk.

All soundwalk participants met at the same specified location to start their soundwalk. During the soundwalk, the participants navigated through the park via instructions on their mobile devices while answering questions that corresponded with each quadrant. Additionally, soundwalk participants had the opportunity to provide openended comments and descriptions on the survey form at any time during the soundwalk.

After the participants completed the soundwalk, they received an automated email link to the post-soundwalk survey. Participants completed the soundwalk and postsoundwalk surveys on average within one hour each. As a best practice, demographic information was requested as a part of the soundwalk consent form. All soundwalk 
participants were assigned a number and referenced by their assigned number as a measure to protect their privacy.

\section{Data Analysis}

The analysis of the data collected was ongoing. Data were analyzed after each soundwalk, and a sound preference survey was submitted. In keeping with the purposes of the hermeneutical phenomenology, the data analysis first presents a textural description of the practitioners' soniferous experiences. A textural description can be understood as a narration or account where the participants' feelings and emotions need to be considered to approach their lived experience. This includes, for example, a practitioner's workplace and profession, because an urban designer working in an architecture company may not perceive the soundscape in the same way that a park official from Portland Parks \& Recreation or a government official working in the Office of Community \& Civic Life. People do not experience the same sound equally. Our knowledge influences our perceptions, i.e., the professional knowledge of a landscape architect is not the same as that of the urban planner or noise management official. Their professional background is important because it impacts their perceptions about the soundscape of the park.

Next, the survey transcripts allow the researcher to explore how participants interacted with the park and how the soniferous experience shaped the participants' perceptions. Analysis of this data was refined in such a way that it allowed me to explore what the participants understood about the phenomena (the park) that impressed them during their experience in the park, i.e., a textural description (Creswell, 2014). 
The data collected from the soundwalk survey used a classification scheme to label potential categories and subcategories. Preliminary categories and subcategories were based on prominent themes that emerged and possible park activities that influenced the park's soundscape or impacted participants during their soundwalk. The initial code categories changed over time based on the soundwalk survey answers.

After all the surveys were transcribed, thematic content analysis was conducted on each transcription to identify themes from each soundwalk and post-soundwalk survey and patterns of themes among all the study's soundwalk participants.

Additional data collected from the soundwalk survey submitted as open-ended text responses was analyzed to discover the most frequent words used to describe each of the four quadrants experienced by each participant. Open-ended text results were constructed into word cloud visualizations using the Qualtrics survey software to display the most frequently used words, which appear larger and darker than less often used words. Ratings from each quadrant were also collected and analyzed, found in Appendix E.

\section{Ethical Considerations}

Ethical considerations were critical and a priority throughout this study. Participants were asked if they wanted to participate before starting this research study via official email communication. Only participants who wanted to participate received additional information about registering as a participant for the research study. Participation in this study was voluntary, and consent forms were provided to all 
participants before providing any information used for this study. All consent forms were digitally signed and submitted before participants could participate.

The real names of participants were excluded, and each participant was assigned a pseudonym or number. The researcher stayed true to the participants' responses by using verbatim quotes to any open-ended questions and offered member checks. For this research, soundwalk participants were asked only questions that were related to this research study. After the soundwalk and post-soundwalk surveys, participants could read transcripts of their responses and modify their responses if needed.

I took the following steps to ensure data confidentiality and security during collection, analysis, and storage through the following methods:

- All paper forms, including consent forms and completed survey forms, were stored securely in a locked file cabinet.

- All removable media such as portable hard drives and SD cards were stored securely in a locked file cabinet. If media was transferred, media was stored on a password-protected computer and cloud server.

- All electronic files were compressed and encrypted before they were transferred from one location to another.

- Data was not accessed or stored on a laptop or any other connected device to a public Wi-Fi network.

- Once data collection and analysis was complete, all unused or irrelevant data was either shredded or permanently deleted. 
Additionally, I will ensure that all documented materials will be deleted after three years or after the university's retention policy's expiration to lessen any future threats to confidentiality.

\section{Trustworthiness of the Study}

Scholars agree that there are four validation criteria for qualitative-interpretative research: credibility or internal validity, transferability or external validity, reliability, and confirmation (Barbour, 2001; Guba, 1981; Lincoln, 1995). This research's outputs were based on the participant's point of view about the experiences they lived and felt while visiting the park. The paragraphs that follow will discuss each validation criterion and show how each one was achieved.

\section{Credibility}

This criterion was reached by following two strategies - first, the credibility of the participants' statements. The participants were considered qualified individuals with an appropriate educational level and experience in relation to the research concerns. The participants are linked to the public and private sectors of urban planning and urban design and are city officials, policymakers, and maintenance staff. Specifically, the participants were park employees, urban planners and designers, and noise management practitioners. Therefore, the chosen participants were a good source of information, given that they have worked in areas related to policy, planning, design, and maintenance of parks for many years.

Also, to improve credibility, data transcripts and analysis process were reviewed by the supervisor as needed, to confirm that participants' perceptions and points of view 
were correctly reflected in the analysis, and new interpretations were incorporated into the textural and structural descriptions presented in the data analysis section (Guba, 1981; Lincoln 1995).

\section{Transferability}

Transferability is defined by the degree to which this study's outcomes could be adapted to other contexts. One method to establish transferability is to provide a complete description of the park and its setting, including descriptions of the park's urban and geographic limitations (Murphy \& Yielder, 2010). To guarantee this criterion, a description of the park and the surrounding areas around the park was provided in terms of the features that illustrate the park's diverse amenities and activities. Likewise, a thorough description of the participants, including their occupations and their workplaces, was represented.

Finally, the exhaustive and clear description of each stage of the study, through data collection and analysis to the discussion of the results, makes it possible to replicate the study in any future research about soniferous experiences in parks and public spaces. The strategies mentioned above assist the findings' transferability, while considering that qualitative phenomenological results cannot be generalized as in a quantitative approach.

\section{Reliability}

This criterion is related to the coherence between results and study development. In this regard, the writing notes (research field journal) include all the decisions made during the data collection process and the premises that logically emerged during the data analysis. 


\section{Confirmation}

This refers to the possibility of tracking data research to their source (Taylor \& Medina, 2013). I considered that personal biases needed to be minimized. For this, data source triangulation techniques helped to provide responses characterized by the greatest possible objectivity. Thus, it should be noted that I used field notes to keep track of the analysis process, the decisions that I made, and the reasons that led to such decisions. Similarly, the use of a clear and strictly followed data collection and analysis process, such as the hermeneutical phenomenological approach used in this study, confirmed the data interpretations.

\section{Limitations}

Limited transferability will be a limitation of this study because of the uncertainty of applying the soundwalk survey questions and findings to other public spaces. This is based on several factors, including the levels of use of other public spaces or a specific population of participants that utilize public spaces differently than those who plan, design, regulate or maintain public spaces.

Since the soundwalks focused specifically on park employees, urban planners and designers, and noise management practitioners, it may be difficult to generalize or make comprehensive recommendations based on the results of this study. Although this study addressed the soundscape in an urban area, it does not address environmental health impacts or community noise implications related to traffic noise. Additionally, this study occurred during the daytime; therefore, some findings and conclusions may not apply to related studies conducted during nighttime hours. 


\section{Chapter 4: Findings}

\section{Phenomenological Analysis}

The hermeneutic phenomenology research method emphasized individuals' and groups' subjective experiences in order to understand a phenomenon's meanings from individuals' life stories (Todres, 2008; Wertz et al., 2011). In this case, data were collected from individuals who have all experienced the same phenomenon, and the aim is to develop a description of "what" they experienced and "why" they experienced it (Moustakas, 1994). Ultimately, such studies seek to understand what meaning the person attributes to the phenomenon (Moustakas, 1994; Rossman \& Rallis, 2003) that, in this case, refers to the soundscape at Tom McCall Waterfront Park.

There are two guiding questions for this study: a) what do participants experience in terms of Tom McCall Waterfront Park's soundscape, and b) what contexts or situations have typically influenced or affected their experiences of this soundscape? A detailed description of their lived experiences at the park has been collected through the practitioners' survey responses.

A textural description (Appendix: I) is understood as a narration, where the textural qualities of the phenomenon are highlighted (Conklin, 2007; Moustakas, 1994). Conklin (2007) presented that these qualities include visual, auditory, tactile, and olfactory sensations that inform the experiential gestalt. Also included are the meanings of the experience, the awareness of consciousness of having the experience, space/time references, and qualities that emerge from these dimensions that may otherwise be glossed over in the sensory flood of everyday life. The task is to describe just what one 
sees in language that accesses the object under investigation and how the object is captured in the consciousness of the observer. The relationship between the object and the observer, the objective, and the subjective, is critical in collecting a particular instance of the phenomenon. The process of placing the phenomenon in a field of its own as a means of "seeing it again for the first time" removes everything else so that the researcher can focus solely on the phenomenon at hand (Conklin, 2007, pp. 277-278).

Thus, textural descriptions are accurate individual and particular narrations that describe each participant's particular point of view when they are experiencing the phenomenon, i.e., the soundscape of the park. According to Wertz et al. (2011), the aim of such textural descriptions is to

allow readers to develop more embodied understandings of both the texture and structure of each of the phenomena and illustrate the use of the composite account as a way for researchers to understand better and convey the wholeness of the experience of any phenomenon under inquiry. (p. 5882)

Regarding structural descriptions, Conklin (2007) indicated that it can be understood as: the recursive process of identifying the invariant structures from the participants' transcripts. This step returns us to the data in a way that completes the circle of inquiry and contributes to the development of a structural description of the phenomenon... This description emerges from an understanding and appreciation of the identified structural themes of the experience, the bedrock on which the textural elements rest. (p. 279)

Summarizing, the phenomenological approach, which emphasizes the value of the subjective experiences of participants, implies two types of descriptions: a) a textural 
account indicating the qualities observed about the park's soundscape and the meanings that participants give, and b) the structural description which denotes the common/shared structures or aspects mentioned by the participants.

\section{The Data Analysis Process}

This section details the different steps followed for data analysis. The figure below illustrates the data analysis process, the creation of themes, and how themes respond to each of the three research questions.

\section{Figure 6}

The Data Analysis' Process to Answer the Research Questions

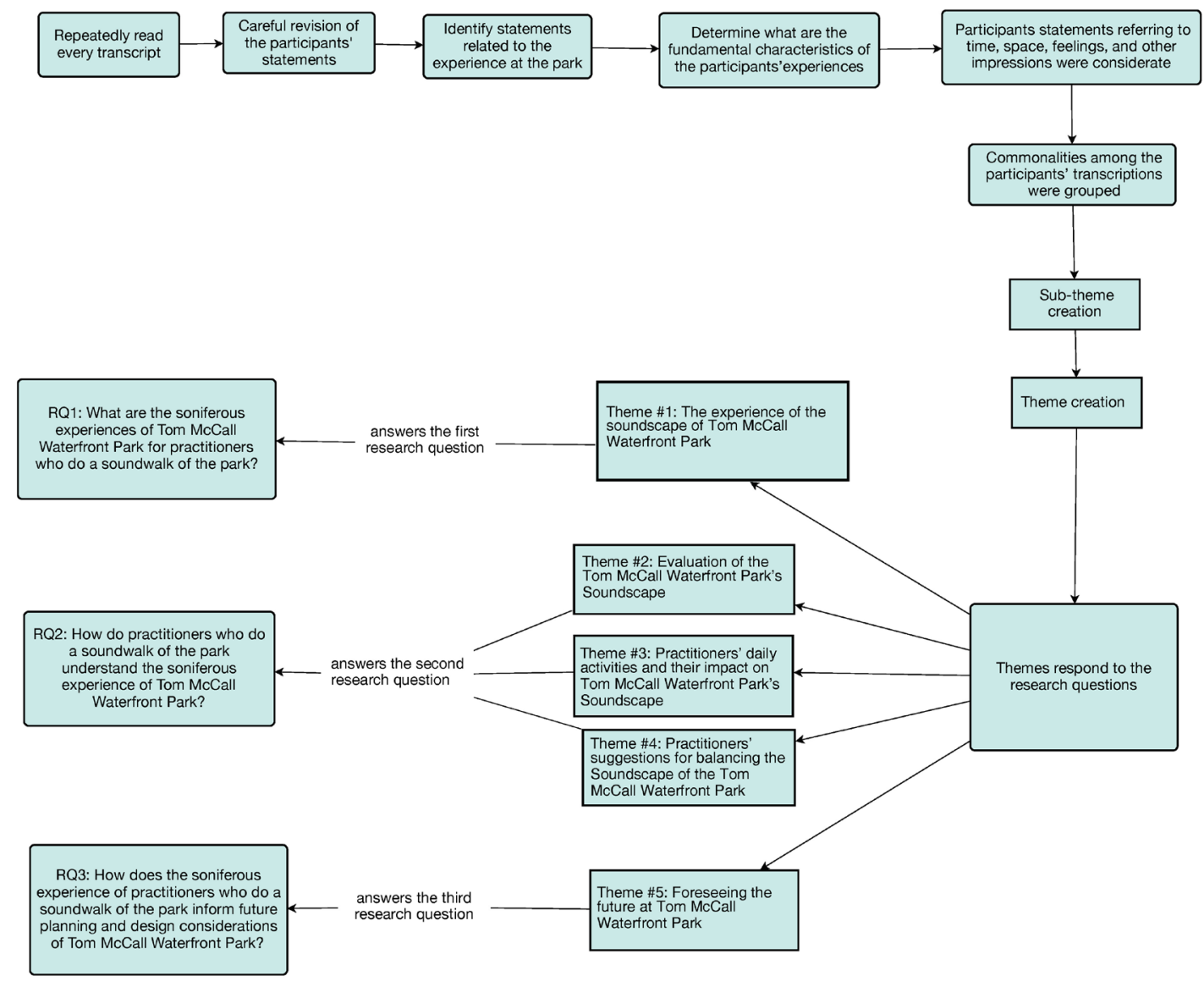


First, I repeatedly read the survey transcripts to be familiar with the participants' comments and opinions. Then, I carefully reviewed the participants' statements to identify statements related to their experiences at the park. The repeated readings allowed me to determine the participants' experiences, which represents the first evidence about the varied dimensions involved in the experience as the participants lived it. I considered participants' details referring to time, space, feelings, and the impressions they obtained through the senses as a whole.

I grouped codes into descriptive categories or sub-themes, which were defined based on the participants' words. I included every definition before the corresponding description of the sub-theme. I determined patterns among the different surveys to create the master themes related to the phenomenon of the soniferous experiences; as mentioned by Smith and Osborn (2004) and Rossman and Rallis (2003), recurring words and phrases generated codes that reflected emergent themes.

I conducted a cross-analysis to search for similarities or differences between participants' observations to generate significant findings about their lived experiences related to the park's soundscape. Finally, I wrote up narrative descriptions that encompassed the textural and the structural descriptions of the themes, with the support of verbatim extracts from the participants' interviews (Smith \& Osborn, 2004).

I continued constructing of themes and sub-themes until I arrived at the point of saturation. Theoretical saturation is defined as the point at which no new information is obtained from interviews, when the participants' declarations begin to overlap and do not add anything new to the created themes (Saunders et al., 2018). In qualitative approaches, the researcher focuses on the meaning given by the participants to the lived experience; I 
was interested in exploring and understanding what was happening, how these practitioners lived the experience, and the different meanings they gave to such experiences. When different features of meanings overlap, it can be said that saturation is achieved.

There was a total of thirty-one (31) participants with the corresponding transcripts. The saturation point arrived in transcript \#17. Thus, in my case, I revised all the interviewees' narrations to ensure that I achieved the saturation point in my analysis and took all the statements into account in the different themes. In short, all the transcripts were analyzed.

\section{Data Presentation}

This section presents the findings that respond to the following research questions:

RQ1: What are the soniferous experiences for practitioners who do a soundwalk of Tom McCall Waterfront Park?

RQ2: How do practitioners who do a soundwalk of the park understand the soniferous experience of Tom McCall Waterfront Park?

RQ3: How does the soniferous experience of practitioners who do a soundwalk of the park inform future planning and design considerations of Tom McCall Waterfront Park?

\section{Theme 1: The Experience of the Soundscape of Tom McCall Waterfront Park}

The theme refers to the practitioners' points of view about the soundscape at the park. Theme 1 allowed me to answer the first research question, which is: 
RQ1: What are the soniferous experiences for practitioners who do a soundwalk of Tom McCall Waterfront Park?

Indeed, this theme reveals how participants perceived the soundscape of the park when doing a soundwalk.

\section{Figure 7}

Theme 1: The Experience of the Soundscape of Tom McCall Waterfront Park.

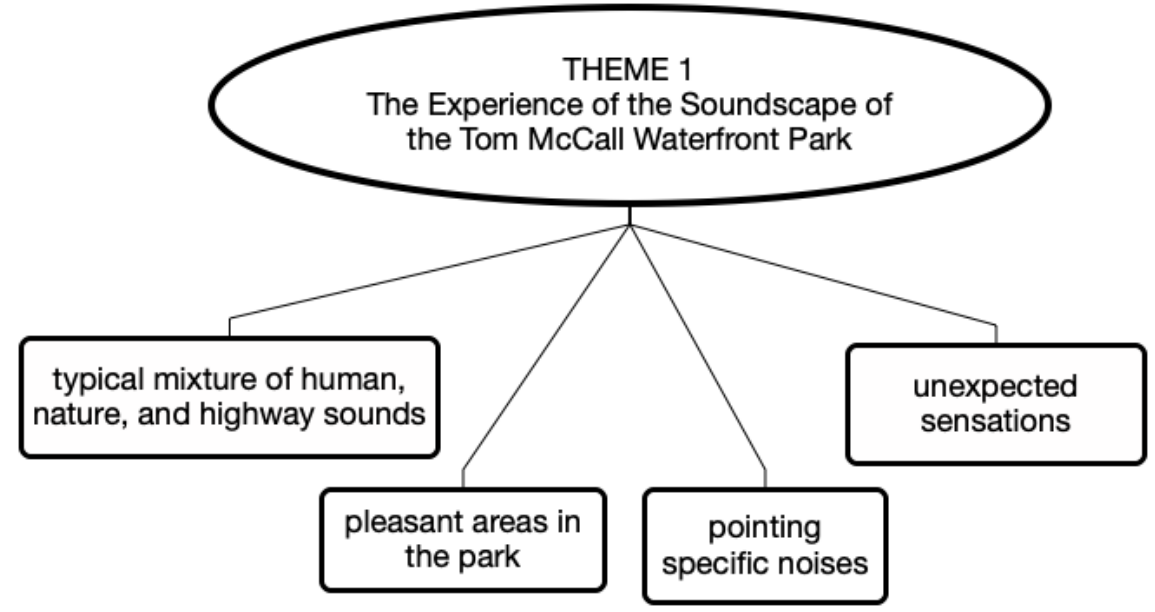

Practitioners perceived the park's soundscape as composed of pleasant and unpleasant sounds, which affirmed that they were immersed in a complex experience without particular valuation about the sounds they referred to: "It is definitely complex, with lots of traffic sounds and also human noises, which can be positive or negative, depending on the circumstance" (P3). Regardless of their background, participants agreed that Tom McCall Waterfront Park has an assorted composition of human 
chatter/conversations, nature sounds, and highway/traffic noises that were equally audible for them. Therefore, the mixture of human, nature, and highway sounds refers to the fusion of sounds that compose the typical soundscape of an urban park.

\section{Sub-Theme 1: Typical Mixture of Human, Nature, and Highway Sounds}

While they were immersed in the soundwalk, participants perceived of the soundscape as a combination of agreeable and disagreeable sounds that they considered the essence of this urban park. For instance, an architect expressed the experience of the soundscape by highlighting the urban character of the Tom McCall Waterfront Park:

"Overall it's a great urban park. I was quite bothered by the white noise of the highway traffic. It's pretty strong at the first quadrant. But I guess that's the nature of urban park" (P26). Meanwhile, another participant working in park maintenance stated:

I would describe the soundscape as a mix of urban and human sounds that can vary each visit (helicopter came in for a landing next to the park on my return walk), and provide positive experiences with or without sounds from around the park. (P13)

Even though the practitioners acknowledged the presence of sounds, sometimes unpleasant or loud from around the park, the practitioners agreed that the park is generally a pleasant place, as shown by sub-theme 2 .

\section{Sub-Theme 2: Pleasant Areas in the Park}

While participants are aware that there are negative sounds around the park, they also remarked on the enjoyable portions of the park marking the relaxed character of the promenade: “The promenade portion is busy, bustling, and enjoyable. It isn't peaceful or 
meditative, but it is relaxing" (P7). Another participant working in maintenance commented:

Tom McCall overall is a very pleasant place to frequent. There are areas that have more noise than others, but there are also areas that allow for you to escape noise as well. Looking back, I think I can appreciate the four quadrants I experienced on my walk. (P11)

For them, the soundscape experience led them to admit that they could escape from the park's general busy environment by searching out those park sections that offer a certain relaxed atmosphere. Still, it is essential to remember that other less quiet sounds commonly invade these areas.

\section{Sub-Theme 3: Pointing to Specific Noises}

Practitioners heard multiple layers of sounds that could be heard when they explored the park: "It is a confluence and collage of water, construction, traffic, and people sounds" (P5), and the practitioners signaled some specific points as the main sources of negative sounds. An official working in the Portland Noise Control Office and an urban planner highlighted some of these sounds:

Pretty much what I would expect with it being in close proximity to main arterial traffic routes in a city center/downtown area of a larger city. It does have a few areas of increased sound - but not unpleasant, with the exception of the area nearest the steel bridge. The unpleasant aspects are the MAX line. (P2)

Freeway white noise gives way to the MAX rumblings and banging at the Steel Bridge at the park's north end. Between these two bridges, there are some nuanced 
differences in sounds, but generally, in addition to the freeway noise, there was a bunch of people chatter. I did the walkthrough at lunchtime, when there may have been a lot more people in the park than normally. (P6)

According to the last quotations, the freeways and the area near the Steel Bridge are key areas where unpleasant sounds are concentrated.

The experience of the soundscape in the park also offered opportunities to remember the particular festivals and celebrations and the sounds these activities usually provoke. Large events occur in specific areas of the park, resulting in loud music and other noises coming from such occurrences.

This park has a lot going on - sometimes more than others, with events. The experience one expects at this park varies depending on when and why one goes. That is, going to have fun at the Blues Festival, one is expecting loud, fun music. Doing the circuit walk of Waterfront Park/Eastbank, one does not, but it is clearly an urban environment. There is not really an expectation of silence, as one might expect from some of our public natural areas. (P13)

Busy with urban sounds, which can be uncomfortable for some but distanced and peppered with some natural noises. The space is also chock full of leisure and enjoyment such as fountains, sport (biking and jogging), boats, and human engagement at a casual or leisure level. (P14)

A kaleidoscope of vibrant possibilities characterized the experiences of these participants, who stressed that such sounds were not a surprise for them: "Most of the sound came from the freeway, and other traffic, including river traffic. None of this was unexpected" (P18). 
Other specific areas were pointed out as sources of negative sounds. Vehicles and construction noises overtook the soundscape at the park, simultaneously dulling the natural sounds: "The presence of vehicle and construction sounds was often too overpowering in general. I kept being drawn to the water and the birds, but absence of related sounds to those features lessened their calming and nurturing impacts" (P21). This comment is complemented by the following one, where the noise coming from the train, traffic, and a helicopter were exposed:

The train and the helicopter tours landing on the parking garage. Bum snores and methastatical tweakers I can deal with (there is a lot of that there too), but the volume from the traffic on the steel bridge and helicopter is not really what I would have in a park. (P2)

However, practitioners from different backgrounds experienced the soundwalk in a singular manner because, for them, the exercise became a noisy and chaotic occurrence: “Tom McCall's soundscape is severely impacted by the overhead roadways at regular intervals, resulting in an overall soundscape that is chaotic" (P20).

The great utility of the soundwalk as a tool to immerse practitioners into the soundscape of the park was evidenced when participants mentioned that the exercise allowed them to become aware of the large number of negative noises that surround this park:

Loud! Mostly transportation noise. Which I realized only after really paying attention to it during this exercise. (P24) 
The freeway noise is much more present than I had thought. It is hard to manage that kind of noise, though. (P6)

I appreciate doing this exercise as I noticed sound much more afterwards and thought about how the wind chimes at the house across the street from me positively impacted my experience walking home. (P21)

The experience of the park is sprinkled with points from which unpleasant sounds emanate, such as traffic, noise near bridges, and nearby building construction. All this soundscape is combined with pleasant sounds from the water, the river traffic, the water fountains, and birdsong.

Despite this often contradictory combination of sounds, the practitioners described the park as a live entity of diverse sounds in continuous interchange with the people. The park is dynamic and active and provokes an exciting experience mainly due to the variety of sounds, some of which are loud and vibrant while others are pleasant; overall this leads to a peaceful experience, all in the same park.

However, particular comments referring to unexpected sensations were identified. As a result, at least half of the participants indicated that the less pleasant elements impacted the park's soniferous experience.

\section{Sub-Theme 4: Unexpected Sensations}

Besides noises, other unwanted sensations sometimes occurred at the park, as stated by P21 and P18. The former highlighted: "encountering campers and people experiencing houselessness felt more threatening than normal due to the absence of sound and activity." Meanwhile, the latest stated: "I would much rather see efforts put into 
dealing with the prevalence of the homeless population, visible public urination, drug and alcohol use, and panhandling" (P18).

To summarize this theme, practitioners have experienced different sounds when doing their soundwalk. The soundscape is a dynamic mixture of sounds that frequently borders on cacophony. These sounds are related to the means of transportation, i.e., traffic, the helicopter, and train services that surround the park. Even if the park offers quiet enjoyment areas, the unpleasant sounds are always present and punctuate the individual's personal experience.

Although some participants found this mixture interesting, the majority concluded that some solutions are needed to mitigate the sounds coming from the freeways, traffic, and helicopter landings and takeoffs in order to diminish the contrast between mechanical, nature, and human sounds.

\section{Answering the First Research Question}

What are the soniferous experiences for practitioners who do a soundwalk of

Tom McCall Waterfront Park? To answer this question, Theme \#1 exposed the experience of the soundscape of the Tom McCall Waterfront Park. According to the practitioners, the soundscape was a mixture of natural sounds combined with human chatter and vehicle noises. Equally, the noise of freeways, traffic, and helicopters landing was mentioned to indicate the over-explanation of contrasting sounds that characterize the soundscape of Tom McCall Waterfront Park. Similarly, noise originating from the freeways, helicopter landings, traffic, and nearby construction contribute to the soundscape and give the park a specific character. 
However, this study indicates that there is potential to balance the soundscape to give the public a better experience when visiting this park. As practitioners, they believe that a more balanced soundscape is achievable. The next theme will explain the participants' suggestions to assess the soundscape of Tom McCall Waterfront Park.

\section{Theme \#2: Evaluation of Tom McCall Waterfront Park's Soundscape}

Once the practitioners finished the soundwalk, they tried to foresee the extent to which they could balance the park's soundscape. However, before thinking in terms of achieving balance, they expressed the necessity to assess the park's soundscape, which led to the second theme, illustrated by the following figure.

\section{Figure 8}

Theme 2: Evaluation of Tom McCall Waterfront Park's Soundscape

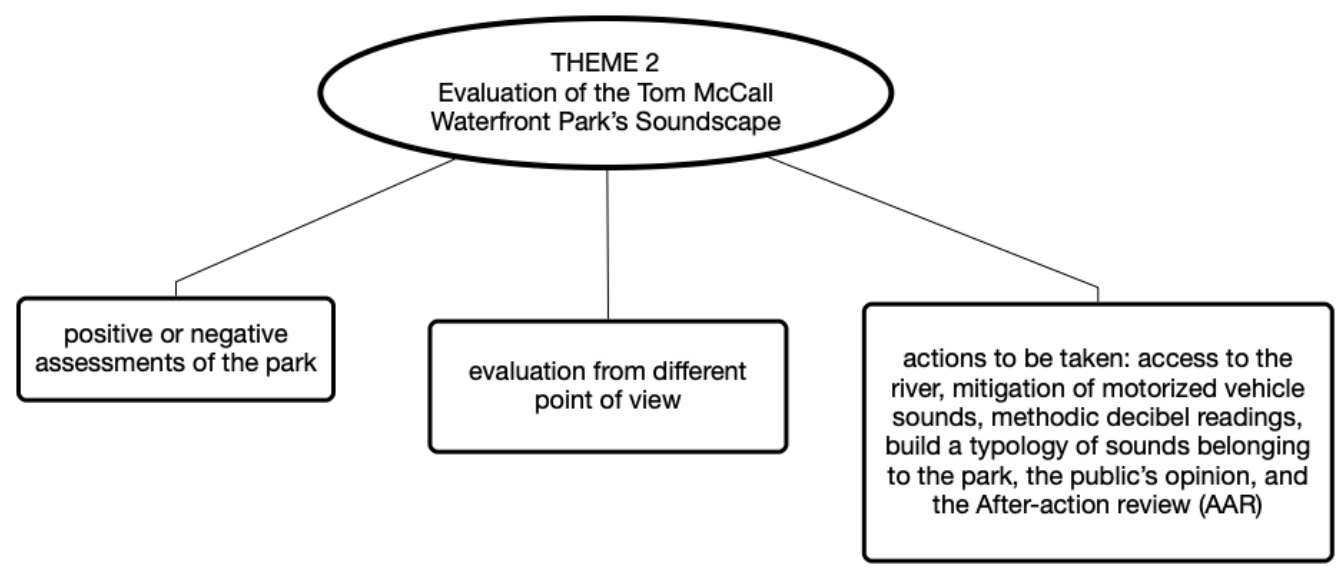

The experience of evaluating the park refers to the processes and actions that practitioners undertook to assess the different sonorous elements that they previously 
identified during their soundwalks. This theme, along with theme \#3 and theme \#4, will allow me to answer the second research question:

RQ2: How do practitioners who do a soundwalk of the park understand the soniferous experience of Tom McCall Waterfront Park?

\section{Sub-Theme 1: Positive or Negative Assessments of the Park}

A quick appreciation of the park's soundscape led some practitioners to evaluate how this urban space is utilized. Besides, the variety of sounds was regarded as positive to the visitors: "I think it is a good example of an urban green space being put to good use" (P10). Likewise, P26 pointed out: "There's diversity in sound, and that is good. There are also a variety of ways to interact with these sounds such as the river, the market, the biking, and the fountains. Wouldn't change those" (P26).

However, other practitioners' reflections led them to expose aspects considered as negatives and in need of an urgent solution. The necessity to solve the problem of the homeless population, as well as look for the efficient resolution of other types of social issues, such as drug use and alcohol consumption occurring in particular zones of the park, were signaled as being of crucial importance.

Besides these short appreciations about the park, a more logical evaluation was developed. Some participants pointed out the importance of looking at Tom McCall Waterfront Park from diverse perspectives to obtain a better assessment.

\section{Sub-Theme 2: Evaluation of Different Points of View}

When discussing the park's soundscape, different points of view emerged, indicating that practitioners have different ways to understand soundscapes. An official working for Tualatin Hills Park \& Recreation District (THPRD) suggested viewing the 
park as an active space, a perspective shared by others: "It's a challenge given the proximity to transportation. May need to view as active space" (P4). Although it is possible to perceive the park as a living entity, more methodic suggestions were exposed, like the hypothetical division of the park into well-defined areas: "As a large area of space, it seems to have several sub-areas to consider. I'm not sure exactly what they all are, but a blanket approach would lose the significant variations /uses down the length of the park" (P12).

Practitioners look at the park as being divided, with every sub-area having its own highlighted sounds; the interrelations among different sub-areas must also be studied and assessed. To achieve such a task, specific actions must be taken.

\section{Sub-Theme 3: Actions to Be Taken}

In their responses, practitioners mentioned dividing and sub-dividing the park into several sections, according to each area's particular activities:

If we were going to complete a redesign of the Tom McCall Waterfront Park, I would divide the park a little more and place public events in quadrant 1 or 4 and develop a quiet space on the opposite end. This would allow for a better transition from one to the other. (P11)

Meanwhile, another participant agreed with the prior statement and added the following: Once the soundscape was determined, I would work with others to plan a desirable soundscape. This would include a buffer from the traffic noise outside the park, more water/fountain noises that connects the park to the river, and play areas for children. (P9) 
Based on the practitioners' reflections about the best manner to assess the soundscape of the park, they commented about building access to the river as a highlighted action that must be achieved: "An attempt should be made to get more access to the water" (P4). Another essential action seems to be the mitigation of motorized vehicle sounds: "On a typical day, it is quite busy, and the paths are crowded. If I could 'manage' the soundscape, I would have less motorized vehicles on the paths" (P16). The participants have also revealed decibel reading as a method to evaluate the sound in different sub-areas of the park:

In a very similar manner to this study: begin in pre-determined area, take some sample readings at different times of day, days of the week, and times of year for longer term stuff. I would also want to break it into easily delineated sections and get readings in the different areas of the park. (P2)

A more efficient suggestion proposed to study the soundscape would consider the diverse types of sounds: "I would assess the soundscape throughout the day at various spots for different types of sounds - nature, human voice, traffic, play, fountains, and transportation in the park" (P9).

Despite that several approaches seem to be adequate, practitioners considered that many of the noises came from outside the park, which make it difficult to have control over them, since they are outside of the purview of the park officials:

I'm not sure. I gather we could take sound readings, to determine the source and level of sounds from various sources. However, my time walking the park for this project led me to recognize that most of the sounds were from beyond the park 
(traffic both above on bridges and from across the river, construction, helicopter landing, etc.) and not really something we can control. (P13)

The experience of the soundwalk placed the practitioners in the soundscape of the park into the same shoes as the general public and how they might perceive it. In consequence, they proposed to explore the public's opinion about their experiences of the park:

I would also talk to my colleagues and perform intercept surveys of users of the park to learn about their experiences. I do not have a lot of experience with managing soundscapes. I imagine this is something very challenging, but it would require continued observation and attention in the least. (P21)

Lastly, practitioners would take the last action regarding the revision or evaluation of the actions accomplished: "I'm also a huge fan of the After-Action Review (AAR) concept and would really like to be able to have an AAR with the involved parties to improve the process for future events" (P3).

A summary of this theme focuses on the actions proposed by the practitioners, which represent the core activities that would guide to obtain a re-assessment of the park. By living this experience, practitioners increased their awareness about how to manage the park in such a way to take into account the different positive and negative sounds they have already identified. These activities manifest to build access to the river from the park, mitigate motorized vehicle sounds, conduct methodical decibel readings, build a typology of sounds belonging to the park, assess the people's opinion about the park experience for the general public, and make reviews after every task has been accomplished. 
It should be noted that Theme 2 provides a partial response to the second research question. For this reason, the second research question will be answered after presenting Themes 3 and 4 , given that these last themes are also part of the response to the second research question.

\section{Theme 3: Daily Activities and Their Impact on Tom McCall Waterfront Park's}

\section{Soundscape}

This theme refers to practitioners' experiences of thinking about how their daily activities could influence the soundscape of the park. Practitioners experienced a kind of self-reflection on how their usual work and tasks impact the park's soundscape. Their conclusions have made them more aware of how their everyday jobs are related to a factor as important as the soundscape, which is sometimes not duly considered when planning urban open spaces. The figure below illustrates this theme.

\section{Figure 9}

Theme 3: Practitioners' Daily Activities and Their Impact on Tom McCall Waterfront Park's Soundscape

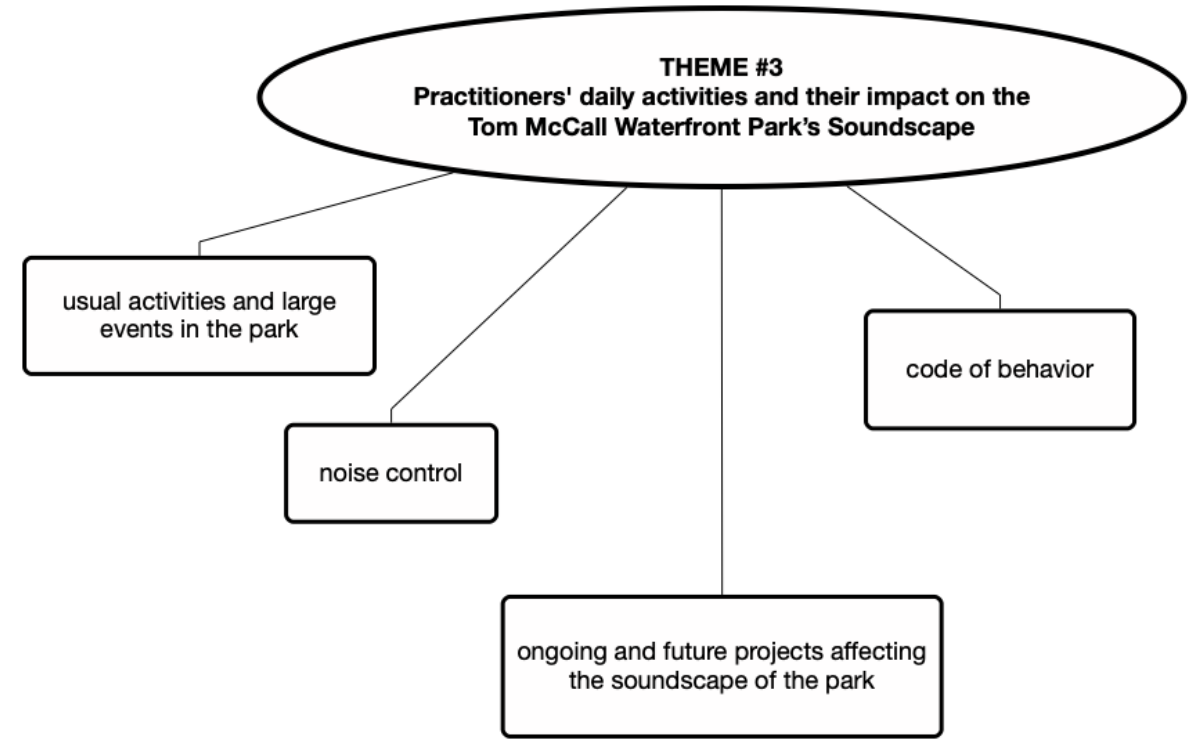




\section{Sub-Theme 1: Usual Activities and Large Events in the Park}

Some activities affecting the park's soundscape are related to the permission officials give to host events in the park. Activities at the park require official authorization, usually granted by one of the practitioners. They reflected on how they permit activities that produce sounds/noises and the global impact on the soundscape of the park: "Some of our roles is in providing the 'permission; for certain activities (e.g., drinking at restaurants or one/time events). Another aspect is supporting community participation and expression" (P12).

Also, large events in the park represent the activities, including the performance of huge events, can influence the park's soundscape. For instance, they suggested the need to modulate the loud volume of some events: "Manage large events that will have amplified sound" (P1).

Practitioners reflected on the importance of controlling the sounds emitted during such large events, as well as their impact on the nearby residential communities outside the park:

Provide permits for high impact sound events with control measures to lessen the impacts on nearby residential use properties, the general public, monitor events, etc. (P2).

In many cases, we are demanding a diverse mix of events to take place in Tom McCall Waterfront Park. Not exactly sure what the 'right' event is but this does influence the soundscape. (P11) 
They concluded that larger events using amplified sound should be regulated to promote an acceptable sound level in the park and the surrounding vicinity.

\section{Sub-Theme 2: Noise Control}

Practitioners also mentioned the necessity of noise control, and they referred to activities they perform to study and regulate noises. For example, they conduct noise studies intend to ensure the assessment of the soundscape in the park, as it was pointed out by (P2): “Assist in conducting noise studies on impacts of planned upcoming events, construction projects, and help to enforce the municipal noise code" (P2). Thus, it can be said that small and larger events must be closely followed to comply with the noise code.

\section{Sub-Theme 3: Projects Affecting the Soundscape of the Park}

Practitioners also reflected on ongoing or future projects that could impact the soundscape of the park. The new infrastructure will support the growing and permanent enjoyment of the park:

I am part of conversations on major pieces of public infrastructure, like freeways, their improvement projects, new bridges, new transit lines and stations, park improvement projects, and the creation of new places and communities around these pieces of infrastructure. I was a part of the technical advisory team for the update to the Tom McCall Waterfront Park masterplan. (P6)

The certainty of future projects that would affect the soundscape of this park arose among the practitioners:

Capital projects have an impact on the park. We have a pump station in the park next to the Burnside Bridge. We don't currently have any projects in the area, but 
we are embarking on a 10-year effort to rehabilitate pipes downtown. This has the potential to impact the park with construction noise quite a bit. (P7)

Specific infrastructure and maintenance projects must be completed, and the impact on the soundscape must be considered: "Continue to build infrastructure that supports growing use and population (bike trails on Naito for commuters, shelter and hygiene services for homeless) and attracts and sustains wildlife (primarily birds)" (P14).

\section{Sub-Theme 4: Code of Behavior}

Practitioners disclosed that some activities are required to enforce compliance with the code of conduct in the park. They referred to the behavior of the public that attends the park. Several of these activities are connected to the park's soundscape, such as the fast cyclists. The code of behavior is a way to try to ensure that park visitors' particular conduct, actions, or performances do not affect the soundscape and the enjoyment of other persons:

I work hard to ensure we have appropriate park rules and education/enforcement of these rules, as we are able. This has focused more in the past decade on the use of bikes in the park and work to help find alternatives for faster bikes (which can impact sound but is more a safety, sense of safety issue) outside the park. (P13)

Finally, practitioners mentioned some specific areas essential for the park's functioning, such as infrastructure maintenance, acoustic studies, and the monitoring of people's behavior at the park. Besides these activities, other concerns are nearby construction projects and developments that can potentially impact the park's soundscape.

Summarizing, practitioners highlighted some of their ongoing tasks, such as authorization for small, middle, and large events; noise control; ongoing and future 
projects; and a code of behavior that could affect the soundscape. These tasks

(authorizations, noise control) are easily manageable, but the unwanted sounds coming

from nearby freeways and construction projects seem to be more difficult to manage.

Theme \#4: Practitioners' Suggestions for Balancing the Soundscape of Tom McCall

\section{Waterfront Park}

The experience of balancing the park's soundscape refers to the practitioners' suggestions to harmonize the current soundscape or mitigate the negative sounds they identified during their soundwalks.

\section{Figure 10}

Theme 4: Practitioners' Suggestions for Balancing the Soundscape of the Tom McCall

\section{Waterfront Park}

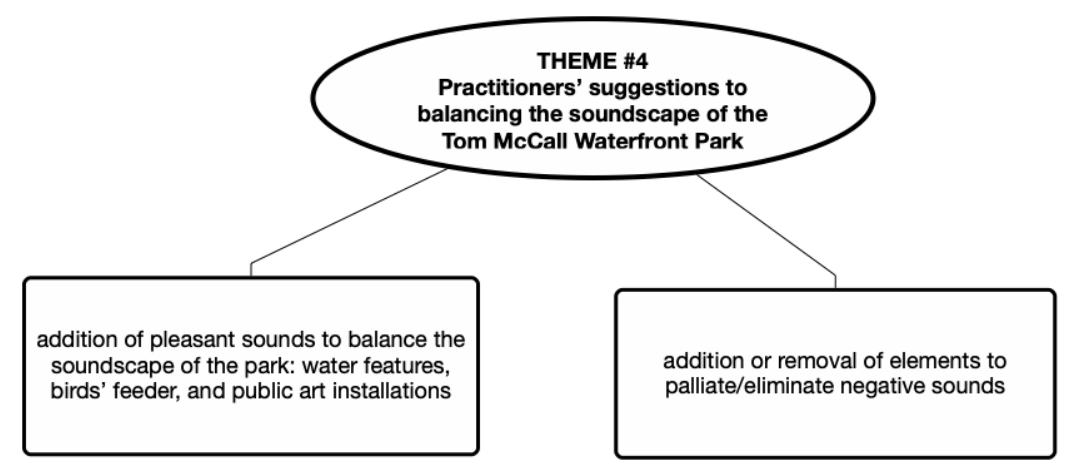

Sub-Theme 1: Addition of Pleasant Sounds to Balance the Soundscape of the Park

Incorporating pleasant sounds into the park was one of the immediate suggestions of the practitioners, who talked about the addition of elements such as water features and songbirds: "Need more songbirds to bring a more pleasant sound" (P4). Participants mentioned the potential of water features to palliate the negative sounds coming from the 
nearby freeways, traffic, and close constructions: "Add more water features which would diffuse some of the traffic and construction noise" (P5). These new positive elements are supposed to generate pleasant sounds from the inside of the park and would be a focus of attention for the public:

I would have more pleasant sounds generated from within the park so that people focus on the sound within the park and not dominated by traffic outside the park. I would add more fountains and water sounds. Activate more spaces for activities both for children and adults. Add trees to buffer the outside noises. (P9) Some peaceful areas would be created through the introduction of more fountains and trees/vegetation: "More fountains that are less noisy, strategically placed vegetation buffers (trees for bridge noise, shrubs or berms for ground/street noise), more attention to varying kinds of nodes in Park so not all one big open space that conducts noise" (P8). Opening contemplative zones were also suggested: "We should look for ways to incorporate places that are more soothing" (P4).

The incorporation of sound art installations was another suggestion coming from the practitioners: "Sound art installations at select points with more frequency could also be done." (P23), and an urban planner shared this idea:

It would require further study, but the addition of public art that makes noises like wind chimes or mimics the sound of water and/or birds would benefit Waterfront Park during those more quiet times. It would have to be tested to understand the impact of these additions during the larger events to minimize conflicts. (P21) 
The installation of some sonorous sculptures was another proposal inspired by what practitioners saw during their soundwalk. The final intention is to provoke the emergence of new sounds through the interaction between the public and the sculptures:

I don't know how we could remove some of the sounds, but we could add some. The Tomodachi Friendship Circle at the north end of the park has a sculpture that I believe is supposed to chime. A kid was making sounds with the sculpture during my walk, by hitting it with a stick... A different additional piece of art that introduced some new sound(s) to the space would be interesting. Perhaps even an interactive thing like some of the sound tubes, or shared xylophone toys we have in our newer parks would be worth considering here. (P13)

The creation of peaceful/contemplative zones, the introduction of more natural sounds, the increment of feeders to attract more birds, and the incorporation of sound art installations and sculptures would balance out the negative sounds heard in the park.

\section{Sub-Theme 2: Addition or Removal of Elements to Palliate/Eliminate Negative Sounds}

When considering how to balance the park's soundscape, some practitioners would like to mitigate the noise, and others would like to remove the elements producing very loud sounds.

Advice to alleviate the negative sounds coming from sources near the park emerged from the analysis. The addition of more water fountains was suggested:

It seems to me that traffic noise is the biggest issue and could use some mitigation. Perhaps more water features? The water feature adjacent to the Burnside Bridge and Salmon Street Springs both helped mask the traffic noise coming from the freeway. (P7) 
Practitioners suggested barriers on and under the bridges because they believe that measures like this would significantly help to ease noise: "I would try to minimize traffic noise. I'm not sure if that's entirely possible, but perhaps noise barriers on/under the bridges and next to the freeway on the east side would help" (P3). This was a shared recommendation from both $\mathrm{P} 6$ and P1: "exploring new ways to mitigate, or at least reduce, the freeway noise would be good. That would have profound effects on the park's soundscape, and perhaps create space for new sounds" (P6). P1 commented: "If there was a way to mitigate highway sound somewhat, the ambient levels would allow people to hear the water and birds more" (P1).

However, other practitioners pointed out that it is necessary to remove the sources of noise, i.e., the freeways: "I would try to remove some of the freeway noise on the east side of the river, but that's a tall order!" (P22). Another suggestion suggested reducing the noise and balancing the park's soundscape by eliminating sounds coming from vehicles:

Removing (or even reducing) auto-related sounds, both from the overhead roadways and from Naito Parkway, would allow the Park soundscape to become calmer and more consistent along the length of the park. Reducing these close, loud sounds would also allow the soundscape to extend, incorporating sounds from across the river, from downtown, and from further along the banks of the park walk. (P20)

Radical actions were also mentioned, even if they do not seem feasible, like retrofitting the bridges or covering the freeway. Practitioners mentioned both recommendations as a way to balance the soundscape of the park: 
Would be amazing to remove the freeway on the Eastside. (P14)

The Steel Bridge MAX line, the rail lines, resurface the Hawthorne Bridge (different quieter decking than steel grate) and the helicopter tours. (P2)

Practitioners were also surprised by the loud sounds caused by the freeway, suggesting covering it in some manner: "The freeway! Cover it, move it, or close it. It was really surprising how loud it is, even on the other side of the river" (P7).

Lastly, practitioners offered a variety of suggestions to remove the loud negative sounds surrounding the park:

Removal: decreasing the particularly loud urban sounds would always be calming but how? A barrier toward the Steel Bridge to reduce train sounds; a big art wall? Dampening a bridge with sound absorption seems silly. Banning helicopters in urban areas below $1000 \mathrm{ft}$ except for landing? Trees as absorbers, probably. (P23) Practitioners believed that removing these elements would modify the park's soundscape: "Freeway and bridge noise! It would significantly improve the park experience and make it more inviting and enjoyable" (P17).

Eliminating loud horns and beeping sounds would also provide a more enjoyable experience of the park: "I would remove the loud horns and beeping sounds from the bridge lifts and construction rigs. Folks enjoying the park could hear each other, and the sounds of the geese, fountains, and other nature sounds more" (P16).

Finally, the creation of special areas for larger events was commented as a measure to concentrate the noise provoked in a particular area of the park: "Make a few places off-limits to amplified events" (P1). 
Although most practitioners were inclined to remove or add elements in the park to balance the soundscape, two practitioners expressed that they would not change anything. In their opinion, they would leave the soundscape of the park as it currently is: "At this point, I would not add or subtract anything. Currently this sounds reflect its (sic) urban/machine, urban/community and natural asset features” (P12).

For these two practitioners (P10 and P11), the park is a sort of hybrid entity that can offer peaceful paths, harmonized by natural sounds, but the park will always remind the public that they are in an urban space, since the transportation sounds evoke the life and the activity of the city.

Initially, I thought I would make several changes to the soundscape. However, after carefully thinking about this over a few days, I don't think I would change anything... There is something for everyone in this public space, and that is what makes it great. (P10, P11)

Summarizing theme \#4, practitioners who want to enhance the park's soundscape experience suggested adding some elements, like water features, birdfeeders, sonorous art installations, and sculptures. Practitioners posited that the exchange between these elements and the public would make the experience more enjoyable. However, other practitioners went directly to the issue of negative sounds, a focus that they suggested alleviating or even eliminating. Finally, a few practitioners determined that the park does not need elements to be added or removed.

Answering the Second Research Question

RQ2: How do practitioners who do a soundwalk of the park understand the soniferous experience of Tom McCall Waterfront Park? 
The answer to this question comes from the last three themes I presented: Theme 2, "Evaluation of the Tom McCall Waterfront Park's soundscape"; Theme 3, "Practitioners' daily activities and their impact on the Tom McCall Waterfront Park's soundscape"; and Theme 4, "Practitioners' suggestions to balance the soundscape of the Tom McCall Waterfront Park.”

The soniferous experience was understood as an initial process of immersion (theme 1) and the subsequent awareness it produced. During their soundwalks, Practitioners became conscious of certain factors impacting the park's soundscape, which can be the source of positive and negative sounds. Under this perspective, practitioners examined their relationship with the soundscape of the park. This is a relationship between two entities: the park as a lived entity and the practitioner as an individual who maintains a relationship with the park. From this point of view, practitioners found it useful to evaluate the park's soundscape by performing some activities allowed them to be more precise and detailed in their assessments. There were enough details to point to the activities they would perform, such as the systematic decibel readings or the park's division in smaller areas. They commented on the classification of sounds according to the zone, as well as the consideration of different perspectives, which allowed me to understand what they lived through this experience.

However, Theme 2 only touched on the relation between the park and the practitioner and how the practitioner's activities affect the soundscape of the park. Practitioners understood that their soniferous experience on the soundwalk led them to question their daily tasks. In this regard, Theme 3 allowed me to support that practitioners increased their awareness about how their daily tasks indirectly and directly impact the 
park's soundscape. The authorization for small and large events, the management of sounds during events, noise control, and ongoing or future projects in the park would have an impact should be considered before the impact occurs.

Finally, Theme 4 completes the response to the second research question because this theme implies what practitioners would do, if possible, to mitigate the negative sounds in the park. Their comprehension of the park's soundscape became more complete because they could argue and discuss what and why they would add or remove elements from the soundscape. In this regard, their opinions were diverse and interesting, ranging from adding more water features and bird feeders to the introduction of sonorous art installations and sculptures. Their broadened comprehension also became evident when they focused on the main sources of noise and suggested different ways to mitigate or even eliminate such sources.

The elimination of the nearby freeways was also proposed. Other ideas emerged about the implementation of some measures following the Master Plan of the park. Nonetheless, in relation to future plans for new public spaces, they all admit that the soundscape must be taken into account when planning and designing parks and other urban spaces.

\section{Theme 5: Foreseeing the Future at Tom McCall Waterfront Park}

The practitioners looked to the future and tried to imagine what they would do if they could improve the current soundscape of the park. The experience of imagining the future placed the practitioners in the hypothetical situation of reflecting on how the park could have been planned, what elements would have been present, what elements would have been avoided, and which others would have been given greater presence. Their 
comments were reunited in the last theme, "Foreseeing the future at Tom McCall

Waterfront Park."

\section{Figure 11}

Theme 5: Foreseeing the Future at Tom McCall Waterfront Park

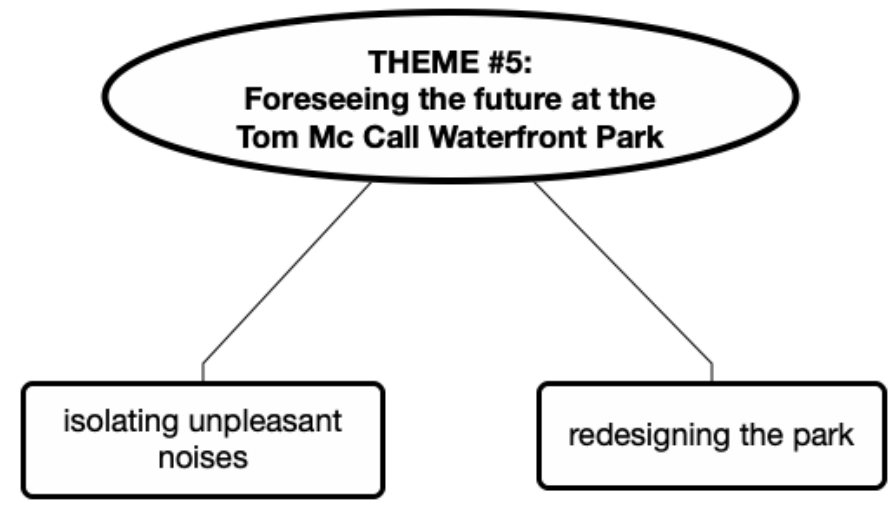

Here I collect answers to the questions: What would the park's features be if the practitioners in the study had the opportunity to rebuild it? What elements would they add or remove? And what would guide the park's design?

\section{Sub-Theme 1: Isolating Unpleasant Noises}

In doing this visualization exercise, practitioners raised concrete ideas about strategies and measures to control or isolate the noise coming from freeways, Naito Parkway, and traffic. One idea considers a vegetation barrier that offers the possibility of isolating people from unpleasant noises: "I would try to ensure Naito Parkway is as far back as possible and given vegetation barriers to help mitigate sound without restricting view and regular access points for pedestrians" (P14). Placing trees as buffers is a 
commonly shared idea among the practitioners: "Add more water features, as well as natural sound barriers and adjusters" (P5).

The benefits of lower but denser trees were also highlighted as a possibility to mitigate the sounds coming from the freeways: "I also found that the lower denser trees (Japanese blossoming cherries?) along the waterfront had a dampening effect on the urban noise that I felt was favorable to the soundscape" (P23).

Another suggestion was to include a sonic buffer and increase the number of trees: "Perhaps the design could incorporate a greater sonic buffer from Naito, perhaps more trees?" (P25). Resting areas was another suggestion in this exercise offered to isolate people from traffic noises and to offer them a number of resting places inside the park:

If I were to work on a park project at the waterfront, I would consider where to place trees and resting areas to keep people as far from the traffic noise as possible and think about introducing more natural sounds... I would focus on how people can interact with the sounds of the river and trees rather than surrounding traffic. (P3)

Another participant added: "Creating topography within the park could add texture to the soundscape and connection to the sounds of the river" (P20).

In the same manner, two interesting suggestions were made by practitioners to achieve the isolation many of them proposed as ideal for balancing the soundscape. The first came from (P2), who suggested a sort of buffer zone to insulate, in an active way, the noises coming from the main freeways around the park: 
Abutting the steel bridge, I'd probably house a facility for grounds crew equipment, barricades, etc., public restrooms, café, some sort of multi-use facility with public services to act as a buffer zone. If it helps shield and/or act as somewhat of a sound deflector for the rail line and provided distance from the sounds of the MAX, even better. Maybe some kind of water feature as well to help with the louder soundscape at that end. (P2)

The second interesting idea came from (P17), who stated:

I might look at adding piped-in, pedestrian-level music like Disney does in their theme parks to drown out the negative sounds of the traffic and freeway. The music could be more ethereal mood music and soft and changing (not standard genres like pop, classical, rock, rap, a/c, etc.) (P17).

Practitioners then suggested covering the sound. They pointed out the water features and the installation of sound-absorbing materials as ways to achieve noise reduction: "water feature to help mask the sound" (P1) and "install sound-absorbing material under the bridges and freeway" (P18).

The noise coming from the I-5 freeway could also be dampened using more water features, as an architect has recommended: "Maybe a water feature to dampen the I-5 traffic..." (P26). Lastly, a park official commented: "I might cap the freeway, so as to eliminate the freeway noise" (P16).

I think I'd offer more opportunities for the natural sounds to come forward, above the traffic noise. For example, should there be bird feeders to enhance different types of birds in the park? Should there be access down to the river (like there is along the Seine) to be able to hear the water? (P22) 
Similarly, the sounds coming from concerts should be controlled, as it was suggested by (P11) who said: "I may add a few sound buffers to redirect concert noise to avoid flooding the entire park."

\section{Sub-Theme 2: Redesigning the Park}

To study the park section by section was another strategy proposed by the practitioners, a strategy that was undertaken by the initial planners. Basically, practitioners proposed approaching the park's new design through the study of what elements would be placed in a specific section and how this section would interact with the others in the same area of the park.

Some comprehensive plans have been pointed by out the practitioners, like those expressed by P7:

1) Work with the community and key stakeholders on a set of design principles that include a vision for the soundscape 2) Develop alternatives that include different 'flavors' of the soundscape based on these principles 3) Test the different 'flavors' by trying out limited interventions in different areas and testing them over time 4) Based on the results, develop a park-wide sound strategy and begin implementing it. (P7)

Another practitioner also proposed a systematic approach to redesign the park. They stated the following:

Waterfront Park is such a large park, it is often broken into sections with each being treated slightly different. I would study the soundscapes by section and through public, stakeholder and staff engagement determine the desired character of each soundscape. It would be great to then challenge artists and designers to 
come up with creative solutions about how to achieve those desired soundscapes. However, one of the greatest things about public space is its unpredictability and dynamism. The lack of control and changing nature of the soundscape would have to be remembered through this process. $(\mathrm{P} 21)$

The river seems to be a zone that would need more development. Many practitioners would revamp this area to get more out of it. A landscape designer commented in this regard: "Put higher noise elements on the street side and quieter elements on the riverside. Have more sections that reach closer to the river. More variety of types of spaces, especially in the central section" (P8).

Concerning the different activities that can be established in the park, the practitioners expressed different points of view. For instance, P12 stated: "I would think about zones for different types of activity and create at least one better performance venue." A park official expressed similar opinions:

I like the notion of integrating small permittable performance/busking stations spaced throughout the park that would be simple, covered, open, easily cleaned maintained, etc. that would be available during times when larger permitted events were not occurring. Mini performance arts spaces curated by...? (P23) Simultaneously, other practitioners were concerned with creating more quiet spaces where events or activities were not allowed: "some quiet areas, like South Waterfront Park, some 'what do you hear?' Signage, and designated areas where large events are not allowed" (P1). The last statement in this manner: "I would think about it, just as I do visual, activities, and open space. It would be an important component of the park and the park experience" (P9). 
To close this theme, it should be noted that several modifications have been mentioned. These adjustments could be considered in the future to improve Tom McCall Waterfront Park's soundscape, but they also could be considered in future plans for other urban spaces. For Tom McCall Waterfront Park, it was suggested to create natural buffer zones, i.e., inserting trees and vegetation to act as buffers to isolate people visiting the park from urban sounds. Also, another suggestion considers a planned development of the river as an attraction of the park, i.e., to develop the river zone to be a point of attraction and enjoyment for the visitors.

Finally, the insertion of quiet spaces, where events are not allowed, represents another consideration that would improve the soundscape experience.

\section{Answering the Third Research Question}

Theme \#5, "Foreseeing the future at Tom McCall Waterfront Park," allows me to answer the third research question:

RQ3: How does the soniferous experience of practitioners who do a soundwalk of the park inform future planning and design considerations of Tom McCall Waterfront Park?

I believe that the soundwalk and the post-soundwalk interviews allowed practitioners to gain insights concerning the future plans for this park or other urban spaces in the future. Practitioners' awareness increased about the complexity of this park's soundscape, and they tried to assess it by proposing different activities.

However, they were also able to interrogate themselves about the daily tasks they usually accomplish and how such activities are related to the park's soundscape. They concluded that even direct or indirect activities as practitioners positively or negatively impact the park's soundscape. The exercise also informs them about the possible 
strategies that they can introduce to mitigate the negative sounds they detected during their soundwalk. Finally, the experience of foreseeing a future plan for this park or for other urban spaces led the practitioners to give a significant value to the soundscape as part of the park's general design.

Some of the previous suggestions should be seriously considered in the future of Tom McCall Waterfront Park. Equally, the practitioners' experiences can inform future projects where: 1) the soundscape will be regarded as an essential element of the planning, 2) an appropriate analysis of the factors affecting or impacting the park and how these elements could impact each other, 3) the planning of more calm and quiet areas could be new incorporations for the current park or in the case of future urban spaces, and 4) special planning of areas for large events, as well as mini-performance spaces for artistic performance. These suggestions were considered as important factors to be included in future planning for Tom McCall Waterfront Park and other public spaces.

So far, I have presented the structural description of the experience lived by practitioners participating in a soundwalk in the park and how these accounts answer my research questions. As this research is a phenomenological study, besides the structural description, a textural account describing the participants' experiences closes the phenomenological analysis. Hermeneutic phenomenology includes a textural narration where feelings and emotions are mixed with the specific experiences obtained from the soundwalk. The final meaningful description or essence of the phenomenon that we have studied, i.e., the soundscape and the practitioners' soniferous experiences while being in Tom McCall Waterfront Park, is located in Appendix I. 


\section{Chapter 5: Discussion}

This chapter will discuss the findings and how these findings relate to the literature reviewed in Chapter 2. This chapter will first list the interpretation of the results, highlighting the aspects that characterize the themes and sub-themes presented in the previous chapter. Next, I will discuss the research outcomes in light of the literature review, which helps me to consider and assess the results. The chapter concludes with a discussion of findings regarding the implications for practice, limitations of the study, and future research recommendations.

Before entering the discussion on the findings, the purpose of the study and the research questions must be restated. The purpose of this phenomenological study was to examine planning practitioners' perceptions about the soundscape of Governor Tom McCall Waterfront Park and the role that the soniferous experience of a public space can play in utilizing and managing the soundscape on behalf of public goals. In this regard, the research questions are as follows:

RQ1: What are the soniferous experiences for practitioners who do a soundwalk of Tom McCall Waterfront Park?

RQ2: How do practitioners who do a soundwalk of the park understand the soniferous experience of Tom McCall Waterfront Park?

RQ3: How does the soniferous experience of practitioners who do a soundwalk of the park inform future planning and design considerations of Tom McCall Waterfront Park? 
Based on the findings of this research, the findings regarding the soniferous experiences of Tom McCall Waterfront Park were comprised of five themes:

Theme 1: The experience of the soundscape of the Tom McCall Waterfront Park

Theme 2: Evaluation of the soundscape of Tom McCall Waterfront Park

Theme 3: Daily activities and their impact on Tom McCall Waterfront Park's soundscape

Theme 4: Practitioners' suggestions for balancing the soundscape of the Tom McCall Waterfront Park

Theme 5: Foreseeing the future at the Tom Mc Call Waterfront Park

\section{Interpretation of the Findings}

The themes that emerged from the data analysis represent the findings that answer the research questions. The participants provided textural and structural accounts based on their lived experiences exploring the park.

\section{Theme 1: The Experience of the Soundscape of Tom McCall Waterfront Park}

Theme 1 revealed the assessments of participants about Tom McCall Waterfront Park. Here, the findings indicated that this soundscape experience was complex compared to the soundscape perceived in natural parks; such complexity is mainly due to the mixed soundscape (sounds and noise) encountered during the soundwalk. Considering that the park is located in downtown Portland, the study's outcomes are consistent with the research of Hedfors (2003), who referred to the soundscape properties of city parks this way: "the sonotope of the city garden was characterised by the sounds of its surroundings" (p.1). This means that sounds coming from elements placed outside 
or near the city garden in Hedfors' study dominated the soundscape: "The location was perceived as a small oasis due to the songs of the birds, but the surroundings dominated the auditory identity" (p. 41).

In the same regard, my findings report that a mixture of human, natural, and highway sounds made up the park's soundscape, which means that the park presents pleasant zones in contrast with other noisier ones. Through the soundwalks used in this study, it was possible to delimit the park's particular zones that evidenced higher/lower levels of pleasant/unpleasant sounds. My results are in line with those reported by Jeon et al. (2013) and Semidor (2006). In particular, Semidor (2006) commented:

The different data... extracted from the soundwalks are examined in order to gather information about the relationship between the urban characteristics, urban activities, and the sound environment... The purpose of this approach is to enable us to evaluate what is pleasant and relevant in an urban sound environment in accordance with activities in the area. (p. 959) My findings are in line with Semidor's arguments concerning the noises and unwanted sensations reported by the participants. Interestedly, results from the surveys indicated that construction noise, traffic, and other mechanical sounds dampened the natural sounds present in Tom McCall Park. Findings from the soundwalk surveys showed that, comparatively, the graph representing the loudest sounds corresponds to traffic (18 people out of 31), despite also being the most distant sound identified by the participants. The sounds resembling natural sounds were overshadowed by traffic sounds, given that natural sounds were the most distant sound. It can be inferred that noise and unwanted sensations coming from traffic, for the most part, dominate the complexity of the 
soundscape of the park. Traffic was also identified as the least favorite sound for participants. Because of the overall sounds coming from traffic, participants did not expect to hear natural sounds from the fountain and birds. The soundscape quality was qualified as moderately positive (14 people out of 31 , or $45 \%$ ) to slightly positive ( 7 people out of 31 , or $23 \%$ ). This result could be interpreted as $63 \%$ of participants (21 people out of 30) feeling that they consider the park to be a moderately pleasant place.

However, Theme 2, Evaluation of the Tom McCall Waterfront Park's soundscape, complements the aspects described above.

\section{Theme 2: Evaluation of Tom McCall Waterfront Park's Soundscape}

Theme 2 explains the participants' suggestions about ways to evaluate the soundscape of the park. The park's positive and negative aspects have been indicated, which is common to encounter in an urban park. This way of raising awareness about the soundscape has also been highlighted in the study of Koutsomichalis (2013), who stated:

Regardless, the project exemplifies what I consider to be the most interesting aspect of soundwalking practices: the intention to provoke an attentional shift towards a more substantial, more dynamic engagement with soundscapes, wherever they may be encountered, and whatever they may be associated with. (p.7)

My study participants also experienced substantial engagement during their corresponding soundwalks, the results of which are discussed below.

Soundwalk surveys reported that Quadrant \#1 (South Waterfront Park Garden to Hawthorne Bridge) represents a mixture of resonances. The dominant sound comes primarily from traffic and secondarily from people chattering. Comparing the responses 
of the survey in this quadrant, 23 participants out of 31 (74\%) qualified the quadrant as being a positive one, with six (6) participants (19\%) indicating negative assessments of the same quadrant.

Quadrant \#2 (Hawthorne Bridge to Morrison Bridge) also presented a mixture of sounds, with bike sounds as a dominant one; this soundscape is very different from Quadrant \#1. The second quadrant seems to be louder than quadrant \#1 because of bikes, bells, traffic, road-noise, jogging, and water. Although this quadrant was experienced as being loud, the overall rate of the quadrant indicated that 24 participants out of $31(77.4$ \%) thought that Quadrant \#2 is a positive area.

Quadrant \#3 (Morrison Bridge to Burnside Bridge) received 35\% of moderately positive responses. However, many statements indicated that traffic was the dominant sound, in addition to a combination of other human-made sounds, such as noises coming from the bridge, traffic, people, the Saturday Market, and water, in this order.

Quadrant \#4 (Burnside Bridge to Steel Bridge) seems to be the loudest quadrant, with the train and the MAX Light Rail as dominant sounds. Mainly due to the humanmade noises produced by the train, MAX, bridge noise, and traffic in this order, this quadrant offered a noisier/louder soundscape. However, 17 out of 31 evaluated the quadrant as being extremely positive/moderately positive/ slightly positive. Nonetheless, 8 out of 31 persons reported the quadrant as having a negative/extremely negative soundscape.

This evaluation of the different quadrants of Tom McCall Waterfront Park allows for the comparison of the primary sounds and characteristics that are dominant in each section of this urban area. 


\section{Figure 12}

Primary Sounds and Characteristics from Each Quadrant

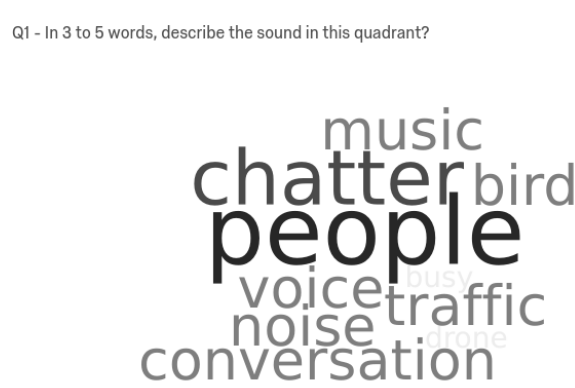

Q3 - In 3 to 5 words, describe the sound in this quadrant?
Q2: In 3 to 5 words, describe the sound in this quadrant?

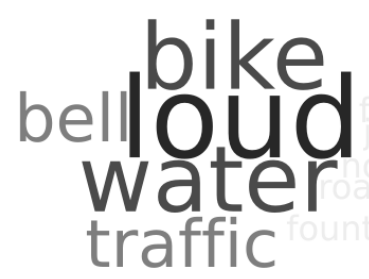

Q4 - $\ln 3$ to 5 words, describe the sound in this quadrant?
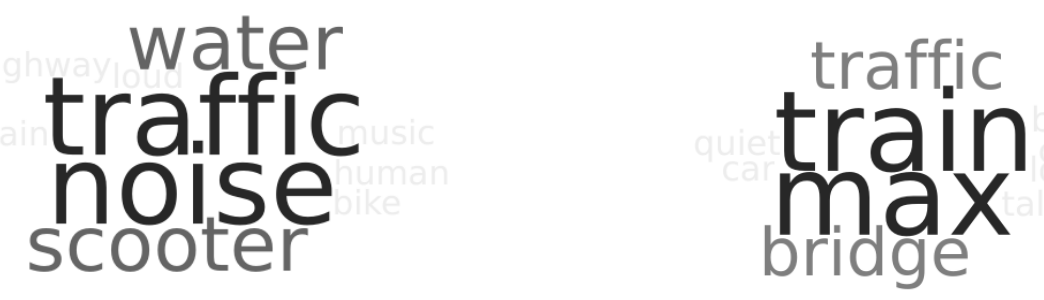

Comparing the four graphs of the soundscape analysis, it can be inferred that traffic is the factor that affects the four quadrants of the park the most. It is noteworthy that traffic sounds are slightly overshadowed by the sounds of people's conversations and music in the first quadrant. In the second quadrant, traffic sounds were also dominated by the sound of bells and bikes, which suggests that Quadrant \# 1 and \# 2 presented a lower level of traffic sound. Looking at this interesting mix of sounds where people chatting seems to overlap traffic sounds, authors Jeon and Hong (2015) stated: "It was revealed that sounds caused by various human activities in parks play an important role to 
influence eventfulness of soundscape perception" (p. 100). This statement clarifies that noise and human activities can also impact people's perception of the soundscape.

It was also noticed that, depending on people's backgrounds, the soundscape differed. As our participants are all practitioners, i.e., people working in the design/planning/managing of urban areas, the general perceptions of soundscapes they provide differ from the perception that everyday citizens may have about the same park (Raimbault \& Dubois, 2005). In our case, most of our participants stated that after the soundwalks, they became more conscious about the role of the soundscape. However, some of their responses, such as "I think it is a good example of an urban green space being put to good use" (P10), indicated an impartial examination of the park, of its quadrants, and the sound sources. These specific responses stressed that it was customary to expect this type of mixture in a downtown urban area.

Examining the park's quadrants, it is noticeable that quadrant \#3 and \#4 present human-made dominant sounds coming from MAX, the train, and traffic, making them the loudest sectors of Tom McCall Waterfront Park. Human-made sounds dominate over the natural sounds (birds, water sounds) and human sounds (conversations, feet jogging) that predominate in quadrant $\# 1$ and $\# 2$.

The presence of both natural and machine-made sounds in an urban park's soundscape is consistent with the outcomes presented by Lobo Soares and Bento Coelho (2016). One of these authors' outcomes is that sounds that are usually considered positive and noises that usually are considered negative are perceived in a different manner, according to the expectation of the people who frequent urban parks. Lobo Soares and Bento Coelho (2016) commented: 
Depending on the park user's expectations and types of activities, the natural sounds of some birds, usually perceived as pleasant, can instead be regarded as unpleasant. The same can be applied to some mechanical sounds, which are not necessarily always perceived as noise. Some traffic sounds can blend nicely with others to convey a notion of liveliness, unless you require calm and tranquility. (p.

Architects, urban planners, and city government officials agree that the park is a good representation of what can be found in an urban space located in the city's downtown. Among my findings, some participants indicated that the park offered natural and mechanical sounds, which were the expected sounds in that area. Some participants did not express displeasure at the combination of natural sounds and human-made noises in Tom McCall Waterfront Park. On the contrary, P26 mentioned that they would not change the soundscape, inferring that this soundscape should and could remain unchanged: "There's diversity in sound and that is good. There are also a variety of ways to interact with these sounds such as the river, the market, the biking, and the fountains. Wouldn't change those" (P26).

Immersed in the soundscape, participants also reported about their different approaches to evaluate the park's quadrants. Alternatively, it seems that executing systematic decibel readings in the park's diverse areas was a popular response for how to evaluate the park; such results are similar to the findings of Jeon et al. (2010). However, I believe that this suggestion to do systematic decibel readings comes from the noise control approach. Obviously, my findings reveal that some human-made sounds can be challenging to mitigate. Raimbault and Dubois (2005) commented: "Analysis of the 
specific answers about soundscapes highlighted that the only matter in engineering noise control remains currently the noise level" (p. 345). My findings are consistent with the mentioned scholars, given that the sound level coming from inescapable sources seems to be difficult to mitigate: "I'd see about dampening the sound under the Hawthorne Bridge. Don't know what one would do about I-5 traffic" (P26).

In contrast, the process of raising awareness implies experimenting and reflecting on a particular soundscape. This type of intimate experience means that the person will feel different sounds/noises and compare the different sensations these sounds carry-on in them. This type of exercise allows practitioners (architects, urban designers/planners, and public officials) to raise awareness concerning the soundscape as a critical factor to consider when planning urban spaces. Although some participants did not seem greatly affected by their soundwalks, a consensus was achieved concerning the need to raise awareness about the soundscape as a factor in the planning of future urban spaces. These findings are in agreement with those of Raimbault and Dubois (2005), who highlighted: "Analysis of the urban planner's point of view about soundscape concepts shows that the consideration of non-acoustic factors causes difficulties in urban noise evaluation and that there is probably no simple answer anyway to soundscape management in cities" ( $\mathrm{p}$. 436).

In my case, I wonder: Can the unique use of objective methods, such as sound level measures, be sufficient to evaluate urban parks? In my study, some participants have suggested employing systematic decibel readings as a unique way to accomplish the soundscape assessment. However, this solution is not enough, according to scholars like Irvine et al. (2009), who stressed the necessity of assessing the soundscape from both 
objective and subjective sides. In this regard, my research mirrors Irvin et al. (2009) study concerning how natural and mechanical sounds are perceived, and general preferences for one over the other. They declared: "The data reveal a prevalence of mechanical sounds and a hierarchy of preference for natural over people and mechanical sounds. There was a link between sound levels, both objective and perceived, and the type of sounds heard" (p. 155). Other holistic approaches that measure sound levels and the overall soundscape used quantitative and qualitative methods to assess the soundscape in urban areas.

Another finding in the present study indicated that practitioners began to be more aware of the difficulties of assessing a park's soundscape through conducting the soundwalk. They suggested approaching this type of varied soundscape by dividing the area into different sections and proceeding with a systematic evaluation of the different sounds in each section, which was done by dividing the park into quadrants. This suggestion is consistent with López Barrio and Carles (1995, in Van Herzele \& Wiedemann, 2003), who stated that "the noise level is the sum of a diversity of sources to which subjective response will be given" (p. 114). Two of the four quadrants (quadrant $\# 3$ and 4) were reported to be louder than the rest of the park, although traffic was the dominant sound in the park. Similar results have been pointed out by Chalas (1998, in Raimbault \& Dubois, 2005), who, when referring to the complexity of some soundscapes, “explains why urban planners need more global and transversal approaches between different partners" (p. 346). Likewise, from my findings, the park's soundscape is dynamic and complicated because of the variety of differences we have already exposed 
in each of the four quadrants. The interaction of the different sounds that converge in the same quadrant gives the park a complex and dynamic atmosphere.

The environmental traits of Tom McCall Waterfront Park are similar to other urban parks, in which soundscapes have been assessed; the results obtained are similar to ours. For instance, Payne et al. (2009) stated the following:

Soundscapes are not perceived in sensory isolation... Many researchers point to the importance of understanding the full environmental and social context for soundscape assessment, the relevance of comparing similar place types, and the effect of moving between one soundscape and another on an assessment. (p.3) Another perspective from my findings suggests the importance of identifying the sources of the different sounds found at Tom McCall Waterfront Park. Additional sources of machine-made sounds like a train, MAX, highways, construction, and traffic have been identified and analyzed as significant sources of unfavorable sounds. This perspective is consistent with Lobo Soares and Bento Coelho's (2016) study concerning the sources of unwanted sounds in the soundscape of urban parks. My findings are also in line with the outcomes exposed by Jeon et al. (2010) concerning sounds and noise sources; in their study, road traffic noise, as well as construction noise, were the primary sources of unwanted sounds:

A laboratory auditory experiment was then conducted to quantify the total annoyance caused by road traffic noise and four types of construction noise. It was shown that the annoyance ratings were related to the types of construction noise in combination with road traffic noise and the level of the road traffic noise. (p. 1357) 


\section{Theme 3: Daily Activities and Their Impact on Tom McCall Waterfront Park's Soundscape}

This theme incorporated every practitioner's reflections on their roles as part of various entities dedicated to maintaining parks and urban spaces in Portland. These individuals are usually the ones who give permissions for small and large events in the park, and others, who work for the Noise Control Office, are charged with controlling noise levels as part of the city's noise policies. All of them noticed that their decisions have an impact on the sonic environment. Thus, the exercise and reflections derived from the soundwalk raised their awareness about their jobs' implications in the resulting soundscape of the park.

The exercise of reflection led practitioners to understand the interconnectivity between their daily activities and the sonic environment of the park. How do decisions coming from the different offices that handle planning, design, and regulation of urban areas such as parks, affect the sonic environment of these urban spaces? My findings reflect the practitioners' full understanding of the extensive relationships among the factors that impact, in one or another way, the sonic environment of Tom McCall Waterfront Park. These results are consistent with other authors who have formulated requests to bring the research on the acoustic environment closer to the entities that design and plan urban cities. In this regard, Raimbault and Dubois (2005) already mentioned that: "In order to develop better skills in treating soundscapes, objective measuring and subjective training research should include far-reaching collaboration between researchers, urban planners, and city-users" (p. 341). My findings are also in line with Steele's (2018) study, who mentioned the importance of creating awareness about 
the interconnected role of all individuals working in or enjoying the open urban space. For instance, Steele (2018) mentioned that:

Growing awareness of the interconnectedness of sound with other factors [is] one of the pillars of the soundscape design strategy. In this context, sound is not just a design and planning resource, but also a way to identify, for example, whether traffic or zoning have been implemented in a way that meets users' complex needs. (p. 40)

Promoting awareness among these practitioners is a principal objective to help practitioners reflect on their role working in areas close to the planning and design of urban spaces.

Besides the noise control activity or permitting events, my findings include the awareness of those who are part of teams in which changes are being planned, both in already existing urban spaces or future projects in which the soundscape is relevant. These practitioners also become more aware of the consequences of the planning they were involved in, and they expressed their concerns regarding the impact that such projects could have on the soundscapes of urban spaces.

\section{Theme 4: Practitioners' Suggestions for Balancing the Soundscape of Tom McCall Waterfront Park}

According to my findings, once the participants finished the soundwalk, they suggested some actions to balance the soundscape. Moreover, Theme \#4, "Practitioners' suggestions for balancing the soundscape of the Tom McCall Waterfront Park," relates to the elements that could be added to the park to improve its soundscape. One of these 
suggested actions was the relocation of some features in the park to achieve a better distribution of sound.

The practitioners identified construction noise as a negative element of the soundscape and they suggested mitigating this noise by adding more water fountains, which would also alleviate the nearby traffic noise. Water fountains are a possible solution that was also suggested by other scholars, like Botteldooren et al. (2008), who stated: "Another example is the sound from water fountains. Altering flow methods and fountain design has proven to provide great potential in shaping the spectrum of water features...making it an ideal instrument for attracting attention and masking traffic noise" (p. 191). In the same regard, the addition of more water sources to mitigate noise has been suggested by Jeon et al. (2010), who stated that "water sounds were determined to be the best sounds to use for enhancing the urban soundscape. The level of the water sounds should be similar to or not less than 3 dB below the level of the urban noises" ( $p$. 1357). Similar results were reported by Botteldooren et al. (2008), who suggested that "altering flow methods and fountain design have proven to provide great potential in shaping the spectrum of water features..., making it an ideal instrument for attracting attention and masking traffic noise" (p. 191). Water sounds could prove to be a simple way to add elements to the soundscape that are generally considered soothing. As in the soundscape approach, agreeable and less-agreeable sounds can coexist. I wondered to what extent my practitioners were aware of the importance of including the soundscape in their practice, both before and after their soundwalk. Once the participants performed the soundwalk, they became more aware of the different sounds that surrounded the park. After this exercise, these practitioners recognized the sounds and 
their sources. They differentiated the natural sounds from the human-made and mechanical sounds that compose the actual soundscape of Tom McCall Waterfront Park. Such results are consistent with Kang and Zhang (2010) and with the described study of Westerkamp (2017) concerning the awareness that soundwalks as a method provide to the participants. In relation to her study with students, Westerkamp (2017) stated: "In developing their perception of the coastal soundscape, through this three-week course, students began to understand sound and its expressions in the interpersonal, social, environmental, anthropological, and artistic realms" (p. 149).

My study's participants came from different professions and possessed different expertise to identify sounds and sources of sound in an urban environment. From this awareness, they were able, with adequate knowledge, to suggest how to incorporate elements that could mitigate the annoying sounds they had identified. The next paragraphs will discuss the proposed elements/items for negative sound mitigation, and the utility of the soundscape as a tool to raise awareness about the multiple sources of sounds in an urban space.

My findings indicate the potential of natural sound barriers, like vegetation and water features, to enhance and balance the park's soundscape. Participants suggested that vegetation could act as a buffer to mitigate noises coming from bridges or traffic. Such findings are in agreement with those reported by Cassina et al. (2017), who mentioned that:

Natural elements such as vegetation and water, but also games for children and anthropic elements, resulted as positive visual factor by over $70 \%$ of interviewees. On the contrary, cars passing, waste and the presence of the construction site have 
been considered negative Environments factors by over $90 \%$ of interviewees. (pp. 7-8)

The findings of Irvine et al. (2009) also aligned with my findings. Their interesting outcomes related to the use of vegetation to attract new birds:

Our data... suggest that species-rich bird communities impact directly on the quality of the soundscape in urban parks, in an effect mediated by vegetation structure. The greater level of biodiversity appears to contribute to a soundscape more distinctive of natural sounds... This suggests ways in which the design of urban parks might influence soundscapes indirectly via its effects on biodiversity as well as directly through modification of physical buffers. (p. 169)

My findings also suggested that new trees and vegetation buffers could be utilized to soften the soundscape in Tom McCall Waterfront Park. Participants also suggested incorporating feeders to attract bird-diversity, which can be another source of natural sounds, all of which is consistent with the findings of Irvine et al. (2009).

Likewise, my results suggested creating new areas in the park for contemplative purposes, as well as the design of specific zones to host large, well-attended events, like music festivals. These suggestions made by our practitioners are consistent with the findings made by Van Herzele and Wiedemann (2003) that:

With respect to the experience of quietness, the distance of the auditory space between sound events is a relevant criterion, which can be reflected by statistical noise levels. Noise level, although important, is not the only variable determining the experience of the acoustic environment. (p. 114) 
Similar results have also been reported by Oberman (2017, cited in Oberman, 2020), which mentioned that "a significant shift towards 'positive soundscape descriptors' when generic music was introduced during the festive season in urban open spaces is otherwise monotonous and characterized mainly by traffic noise" (p. 3).

Focusing people's attention on the interior of the park was also suggested. My findings indicated that more pleasant sounds coming from the park's interior could balance out the park's soundscape. Doing this will activate more spaces for adult/children activities and add trees to buffer the noise from the park's exterior. Such suggestions are consistent with scholars as Irvine et al. (2009) when they exposed the utility of concentrating the public's attention on the interior zones of the park, especially for those parks located in downtown areas:

The structure of the green space's habitat not only provides a supportive habitat for important aspects of biological diversity, but it also has the potential to attenuate sounds generated outside of the space. In the outer-edge green space, hedges and trees as well as homes and gardens acted as a buffer, effectively minimizing the impact of continuous and monotonous external sounds into the green space... The availability of buffers may help maximize the ability of park users to hear sounds emanating internally and can promote 'hi-fi' rather than 'lofi' soundscapes. (p. 169)

Another suggestion in my findings was to add "wind chimes or mimics the sound of water and birds would benefit Waterfront" (P21). The incorporation of sound art installations could focus the public's attention on the center of the park and direct their attention from the outside noise produced by traffic, bridges, or highways. The addition 
of sculptures and other art installations has been recently studied by Oberman et al. (2020), whose studies revealed that adding installations leads to a quieter urban environment. They found that "only from the "quiet side" of the [public] space, the questionnaires revealed a significant lowering of perceived loudness" (p. 6). Moreover, these scholars insisted on the importance that such interventions have on the design and planning of urban spaces:

On both theoretical and practical grounds, this work shows the potential benefits for cities and other professionals of the built environment to bring sound expertise to the table and to consider the role of sound art in enhancing their spaces and supporting intended design goals. The results further support the practical implication that that comparatively low-cost audio installations are capable of improving the perceived sound environment. Interventions like these could be considered alongside more resource-intensive (infra)structural elements, such as noise barriers, to purposefully shape the sound environment in public spaces. (p.7)

Concerning sound expertise, it should be noted that increased awareness among practitioners is among the first actions to promote relevant interventions when practitioners plan new urban green spaces or try to improve some already established urban soundscapes. As Oberman et al. (2020) suggested, even simple and inexpensive interventions can make a big difference.

\section{Theme 5: Foreseeing the Future at Tom McCall Waterfront Park}

Once the soundwalk was completed, my findings showed that practitioners evidenced their consciousness by proposing new ideas to balance the soundscape, which were not present in the pre-sound walk survey. The practitioners suggested 
complementing the park's soundscape by incorporating different elements, such as adding more water fountains. The final goal was to mitigate the sounds coming from the highway and the nearby street traffic. As a solution to mitigate mechanical sounds, installing more water fountains (or the sound coming from natural water sources) have also been pointed out by many scholars, like Massulo et al. (2016), Jeon et al. (2010, 2012), Watts et al. (2009), and Yang and Kang (2005). According to these scholars, a water fountain is a positive element to mitigate traffic and other human-made sounds. The results reported by Masullo et al. (2016), for instance, indicated: "The results confirm that the informational masking with water's sounds at levels $3 \mathrm{~dB}$ lower than the road-traffic background noise, provides a general enhancement of the subjective perception of the environmental quality of an urban park" (p. 5). Moreover, Jeon et al. (2012) described the positive effects of different types of water features: "the sounds of falling water with different spectra were introduced as maskers for road traffic noise, and it appeared that the subjective tranquility was affected by the spectral characteristics of water sounds" (p. 2101).

Besides the water fountains, findings suggest installing more bird feeders to attract more birds around the park. Similarly, more vegetation was suggested, assuming that adequate vegetation and trees can act as buffers to unwanted sounds (Kalansuriya et al., 2009; Ow \& Ghosh, 2017). Also, vegetation (trees) has been proposed as a measure to isolate people from unpleasant traffic and highway sounds. These recommendations are consistent with Ow and Ghosh (2017), who stressed the following:

The traffic noise was reduced by $50 \%$ when vegetation was enhanced from a minimal to moderate planting intensity, and no enhancement in noise reduction 
was observed as the vegetation was further increased to a dense intensity. A $5 \mathrm{~m}$ depth of vegetation barrier was found to be an ideal depth for traffic noise reduction. (p. 15)

A similar statement was made by Kalansuriya et al. (2009), whose study's outcomes concluded that:

The results show that higher frequency noise (above $4 \mathrm{kHz}$ ) is heavily attenuated by the vegetation barriers with virtually no attenuation for low-frequency noise (below $100 \mathrm{~Hz}$ ). The width of the vegetation barrier is linearly proportional to the amount of sound absorption. (p. 1)

Among the suggestions made by the participants, our findings also mentioned the use of pedestrian-level music as a way to lessen the impact of mechanical sounds in urban spaces. Such suggestions have also been proposed by Kang et al. (2016), who mentioned that

in cases where poor acoustic design is pre-existing added sounds or music may be the most pragmatic soundscape design intervention, but active systems (e.g., loudspeakers) should not be the default solution in urban public spaces or act as a substitute for good design. (p. 26)

Likewise, the study reported by Easteal et al. (2016) indicated that the use of urban sound planning was a valuable approach to mitigate unwanted sounds in public spaces and gave excellent results. Perhaps, adding music in open urban areas can prevent traffic annoyances and other unwanted sounds. Easteal et al. (2016) offered that:

Urban Sound Planning [is] a credible and valuable discipline, to work alongside design and management professionals of public spaces. In Brighton, the 
SONORUS project compliments traditional disciplines in the planning process and delivers the benefits of integrating sound planning in public realm development projects. (p. 1)

Finally, my findings also demonstrated the important role of what can be named "the sense of place," i.e., the expected sounds of a given place. In this regard, the soundscape approach offers a valuable frame, which can support both agreeable and disagreeable sounds. It allows us to interpret and understand that some people found the soundscape in Tom McCall Waterfront Park to include the "right" sounds that should be expected from an urban space near downtown Portland. Specifically, one participant highlighted the unlimited possibilities delivered by this public park: "after carefully thinking about this over a few days, I don't think I would change anything... There is something for everyone in this public space, and that is what makes it great" (P10). My findings reinforce the idea proposed by Steele (2018) that "soundscapes contribute to a sense of place and encourage activities appropriate for the environment (e.g., marketplace sounds encouraging conversation and purchasing)" (p. v). The soundscape approach enhances the role of sounds when sounds affect the meanings people accord to different places.

\section{Implications for Theory and Research}

My findings have several implications for how soundscapes can be better incorporated in the creation and adaptation of public urban spaces. First, my findings demonstrated that sound needs to be part of the planning process and not an afterthought. Furthermore, using the soundscape approach raised awareness among the practitioners 
regarding the role sound plays in urban spaces, such as public parks. Without question, after the soundwalk exercise, practitioners revealed their opinion that the soundscape should be taken into account before and during the planning process. They experienced the variations of soundscape that occurred in Tom McCall Waterfront Park through the experience of the soundwalk. In particular, it should be noted that $84 \%$ (26 out of 31 ) of the participants indicated they recognized their perceptions about the soundscape and its role in the park's overall soundscape had changed.

In my case, the findings indicated that human-made sounds from transportation (traffic, highways, bridges, helicopter, and construction sites), as well as natural sounds from river, birds, or fountains, are combined to characterize the expected soundscape of a public place, such as the Tom McCall Waterfront Park. In other words, sounds contribute to the characterization of places (Lercher \& Schulte-Fortkamp, 2003), which is provided by generally considering the soundscape. Therefore, the soundscape of a particular area is characterized by a wide variety of typical sounds, as in the example of the marketplace sounds mentioned by Steele (2018).

Next, my findings lead me to argue that the soundscape approach allows for emphasizing the close relationship among sounds and people, as mentioned by Lercher and Schulte-Fortkamp (2003): “The interaction of people and sound, the way people consciously perceive their environment" (p. 1) is highlighted through the use of the soundscape approach. As the soundscape approach considers both pleasant and unpleasant sounds; it does not mask or mitigate noise. In doing this, the exchange 
between people and places is complete. This argument is supported by Lercher and Schulte-Fortkamp (2003), who declared:

This lack of masking allows full interaction with the physical and social environment and leads to 'acoustic coloration,' which provides significant information to the listener and fosters a sense of place for those living in the area. On the opposite side, in 'low-fi' soundscapes, meaningful sounds are masked to such an extent that an individual's 'aural space' is shrunk, and the listener is isolated from the environment. (p. 2)

The expression "acoustic coloration" mentioned above is a notion that should be employed during the urban design and planning of urban places because it represents the soniferous experience that will also encompass people in the location.

Finally, it should also be noted that sounds inspire actions, i.e., sounds encourage activities. For instance, the sound of water may encourage a boat tour around the river area; birds and fountain sounds may inspire relaxation and contemplation; traffic and highway sounds may bring about the feeling of agitation or a need to accelerate the pace.

\section{Soundwalks as a Tool for Assessing Soundscapes: Theoretical Implications}

Soundwalks have been revealed as an excellent tool for in situ evaluating the soundscape of urban spaces in a qualitative way. The choice I made in my study is in line with numerous scholars' recommendations in relation to studying the soundscape (Adams et al., 2008; Cassina et al., 2018; Jeon et al., 2013). For instance, Cassina et al. (2018) mentioned that "from a qualitative [approach] through soundwalks performed in order to study the soundscape, i.e., the "acoustic environment as perceived by people in context" (p. 2). These authors highlighted the relevance of using soundwalks to allow participants 
to experience different sounds and identify the sources. Participants realized the importance of the variation and dominance of individual sounds in the soundscape in Tom McCall Waterfront Park through their individual soundwalks. As the study participants were professionals from different disciplines, such as architects, urban planners/designers, and park officials, their increased awareness was significant since their pre-existing knowledge allows them to more fully understand the reasons for the variations in the soundscape in the park. The interdisciplinarity in the group of practitioners participating in a soundwalk was in agreement with the recognition offered by Oberman et al. (2018) that the "planning practice is strongly interdisciplinary, and besides the planning and design professions, it involves politics, economy, and sociology, among others, and relies on research ranging from ecology to environmental psychology" (p. 336).

Soundwalks allowed practitioners to perform an attentive listening, in situ, allowing them to detect key factors that affect the soundscape of the studied urban space in a positive or negative manner. In this regard, Oberman et al. (2018) stated: “critical listening within a soundwalk in situ ensures the most comprehensive, relevant research environment but rarely offers the opportunity to observe key design factors closely, such as the precise distance from the sound sources simultaneously with the exact vista" (p. 318).

Some scholars, such as Koutsomichalis (2013), are skeptical about the use of soundwalks. In his opinion, a soundwalk performed in a group does not allow an individual to experience the soundscape directly due to the group's interference. According to Koutsomichalis (2013), it is difficult to make a correct exposition of the 
different sounds encountered: "Another somewhat common approach these days is that of soundwalking... I am very skeptical about soundwalking in its various social forms, as whenever I happened to participate, I found it overwhelmingly difficult to focus on the actual listening" (p. 7). However, in my study, participants performed soundwalks individually, allowing them to realize the principal sounds perceived in every section of the park. In my opinion, soundwalks are an important tool that scholars can use to evaluate in situ soundscapes, and each researcher should decide the benefits of individual versus group soundwalks.

\section{Implications for Practice}

Based on my findings, I have formulated some conclusions concerning the practical aspects of the soundscape in urban spaces. During the planning phase, urban spaces, parks, and other public areas will benefit from incorporating the soundscape approach, which considers the soundscape as an all-encompassing element that affects all the people living around and passing through an urban park. Such a proposition is not new, given that scholars like Adams et al. (2009) have already highlighted the importance of incorporating the soundscape approach into the planning phase of urban spaces. Adams et al. (2009) made the following suggestion to urban planners and designers: Incorporating the concept of soundscape into Planning Policy Guidance would make it a factor that had to be considered when designing or developing an urban environment. So, in contrast to the current situation where the impact of noise is a material consideration in the determination of planning applications, the impact of a change of soundscape could be a material consideration. (p. 9) 
Incorporating the soundscape approach into the planning phase of urban spaces implies a different way of foreseeing the arrangement of these areas. As an element in the planning phase, the soundscape approach implies that urban planners have adopted different ways of perceiving and conceiving their design and planning work to include sounds as integral. This approach is different because it involves considering unwanted sounds and pleasant ones to reach an acoustic balance when planning open urban public areas. Also, adopting the soundscape approach into the designing plans implies that the former traditional approach to controlling noise gives way to a more holistic conception of the soundscape, which can play a role in the enjoyment of open public spaces.

A balance in the combination of visual and sonic environments assures people's pleasure and offers a fuller sense of place that parks can provide to the public. Such belief is shared and supported by the study of Eastel et al. (2014), who asserted:

The current approach to the acoustic environment -based on sound levels and noise mitigation- needs to be complemented with urban sound planning that acknowledges the acoustic environment's positive aspects. Urban sound planning has a significant potential for city administrations as a complement to traditional noise mitigation strategies. Brighton and Hove City's foresight and commitment shows how practical approaches towards better local soundscapes can be integrated into policy at a local administrative level. (p. 6) 


\section{Limitations and Future Research}

\section{Limitations}

Although this study's results provided a snapshot of practitioners' lived experiences as they explored and perceived the soundscape of Tom McCall Waterfront Park, this study has limitations that should be considered for future research. The study focused on a specific sample of practitioners. Thirty-one practitioners were identified from the disciplines of urban planning, urban design, architecture, landscape architecture, noise management, and other practitioners who possess agency and decision-making influences regarding the use and management of public space use. Therefore, the study results are from the practitioners' perspective and not the general public, whose perspectives should also be considered in future studies.

This research's results are limited by weather and time of day, since this study was primarily conducted during daylight hours and good weather months in Portland, Oregon. The study results could be entirely different if conducted at night or on days with inclement weather. Variables such as construction noise, the number of people, the lack of traffic, and night activities were not captured due to this study happening during the daytime.

\section{Future Research}

The interest in incorporating soundscape approaches will increase worldwide and particularly in the United States, as more attention is paid to the livability of growing urban areas. More practitioners should challenge antiquated noise control methods. Incorporating a soundscape approach is an opportunity for urban planners and urban designers, in particular, to lead a paradigm shift in considering the soundscape and the 
soniferous experience when planning and designing cities and public spaces. The following areas are suggested for future research consideration: a) examining the impacts of antiquated noise codes and regulations; b) studying how people perceive the soniferous experience of urban spaces at night; c) investigating the contrast in perceptions between practitioners and the general public; and d) investigating how equitable is the complaintdriven noise control model.

Future studies should explore if out-of-date noise codes and regulations impact cities and community members, and if so, how a soundscape approach could be used instead. Several cities, notably Portland, Oregon, have antiquated noise codes that are not enforceable. These codes are pillars of a complaint-driven system that some community members weaponize, even though very few noise violations improve the sources of sound. In most cases, this creates an adversarial back and forth between neighbors that divides rather than builds community.

For future research, it would be essential to expand this study beyond daylight hours and explore how people perceive the sonic environment of urban spaces after dark. Studying the nightlife soundscape could provide valuable data that could be utilized to determine if typical daytime activities, i.e., construction, are extended after-hours and the impacts of these activities. This research may lead to different outcomes regarding how the soundscape of public spaces is perceived. It would also be necessary for a study of this type to incorporate various weather conditions.

Another consideration for future research is to investigate the contrast between practitioners and the general public, and how they perceive the soundscape of public spaces. This study only focused on how practitioners perceived the soundscape of Tom 
McCall Waterfront Park; however, to equitably incorporate a soundscape approach when planning an urban space, the general public's lived experiences of using these spaces on a day-to-day basis must be considered. The data that emerges from the general public's perspective could be compared and contrasted with the findings from a study of just practitioners to develop additional themes about an urban space's sonic phenomena.

Finally, future research should explore how equitable the complaint-driven noise control model is. Many cities have gentrified and diversified in the past decade, even though the complaint-driven noise control model has not evolved. In many cases, city codes and regulations that support complaint-driven noise control models were implemented in cities that did not have diverse populations at the time of adoption. Consequently, these codes contain bias and only reflect the values of the dominant culture. These noise codes and regulations are also written and enforced by code enforcement officers who do not reflect some cities' diversity. Although many of these codes and ordinances are selectively enforced, when they are enforced, they potentially create hardships for some community members, mostly minority business owners and immigrant and refugee community members. Revealing the complaint-driven noise control model's inequities would serve as an additional goal for urban planners and policymakers to implement a soundscape approach. 


\section{Chapter 6: Conclusions}

The results of this study suggest that there are five themes related to the soniferous experiences of Tom McCall Waterfront Park. Theme \#1, "The experience of the soundscape of the Tom McCall Waterfront Park," answered the first research question about the soniferous experiences of Tom McCall Waterfront Park for practitioners who do a soundwalk of the park. The soundscape was a mixture of natural sounds combined with human chatter and vehicle noise. Equally, the noise of freeways, traffic, and helicopters landing was mentioned to indicate contrasting sounds that characterize the soundscape of the park. Similarly, noise originating from the freeways, helicopter landings, traffic, and nearby construction contribute to the soundscape and give the park a specific character. However, this study indicated that the soundscape must be balanced to obtain the public's best experience when visiting this park.

The second research question is about practitioners who completed the soundwalk understand the soniferous experience of Tom McCall Waterfront Park. The answer to this question came from three themes, including Theme 2, "Evaluation of the Tom McCall Waterfront Park's soundscape," Theme 3, "Daily activities and their impact on the Tom McCall Waterfront Park's soundscape," and Theme 4, "Practitioners' suggestions to balancing the soundscape of the Tom McCall Waterfront Park.”

Participants argued that it would be useful to harmonize the park's soundscape by incorporating more natural sounds, i.e., attracting birds and adding water features to help balance the noise coming from traffic and nearby arterials. Other than bird feeders and water features, practitioners suggested art installations and sculptures that produce sound 
as a method to mitigate vehicular noise. Also, they proposed the elimination, if possible, of the freeways.

Other ideas emerged about the implementation of some measures following the Master Plan of the park. Nonetheless, for future plans for new public spaces, most agreed that the soundscape is an element that must be taken into account when planning and designing parks and other urban spaces.

The third research question was how the soniferous experience of practitioners who soundwalk the park can inform future planning and design considerations of Tom McCall Waterfront Park. Future plans were undoubtedly expressed as previsions in Theme 5, "Foreseeing the future at the Tom McCall Waterfront Park." Some of the previous suggestions can be seriously considered in the future of Tom McCall Waterfront Park. Equally, their experiences will inform future projects where: 1) the soundscape will be regarded as an essential element of the planning, 2) there is an appropriate analysis of the factors affecting or impacting the park and how these elements could impact each other, 3) more calm and quiet areas are considered as new incorporations for the current park or in the case of future urban spaces, and 4) there is special planning of areas for large events, as well as mini-performance spaces for artistic performance. These suggestions were considered as important factors to be included in future planning for Tom McCall Waterfront Park and other future public spaces.

Several conclusions emerge from this study. First, using the traditional noise control and mitigation approach to control sound does not align with the participants' expected outcomes. Noise control approaches limit the options to balance or enhance the soniferous experience in urban spaces. 
Second, employing a soundwalk as a tool for exploring a place's soniferous experience could help practitioners increase their understanding and awareness about urban areas and cities' soundscapes before and during the design and planning process.

Finally, when utilizing the soundscape approach, there are no good or bad sounds but a sonorous ensemble that can be balanced by enhancing some aspects of the soundscape over others so that it offers a diversity of dynamic areas for a variety of community members to experience the soundscape.

\section{Concluding Remarks}

Although the literature is limited but growing, the soundscape approach has been well established for several years outside the United States. As an American acoustic ecologist and urban planner, I have been globally engaged for many years with other likeminded practitioners, harvesting whatever knowledge I can to increase awareness of the soundscape approach here in the United States. To date, there have been few attempts to implement this approach, at least amongst those best positioned to do so- urban planners, landscape architects, urban designers, and others involved in the planning and design of the built environment (Brown, 2004). My curiosity and passion for cities and what they sound like have kept me determined to work at the nexus of urban planning and acoustic ecology. For urban planners, urban designers, and policymakers to incorporate a soundscape approach into the current practice and discourse of planning, an increase in soundscape awareness and sonological competency must be achieved through education, multi-disciplinary partnerships, and exploring non-traditional methods. When planning and designing urban spaces and cities, practitioners should become aware of 
how the soundscape and soundscape principles can increase livability. These practitioners should work in unison with urban planners, urban designers, and others who have traditionally been responsible for creating and maintaining a sense of place in urban spaces.

As I reflect on this research journey and the more than 100 soundwalks I have taken through Tom McCall Waterfront Park, the one most obvious thing is that this park's sensory experience is rich and continually changing. The soundscape, the vibrancy, the quiet, the chaos, the familiar strangers, and so much more were addictive changes I looked forward to each visit.

I experienced this park as an expecting dad, a new dad, a black man in a white city, during protests and social unrest, and now during a global pandemic. Our cities and public spaces will always change, and through these changes, I have acquired more awareness and soniferous experiences of these circumstances and places. Consequently, I invited other practitioners on this journey to understand this particular place so that they are more aware of their soniferous experiences the next time they are tasked with considering how to design, plan, or maintain public spaces. 


\section{References}

Adams, M. D., Davies, W.J., \& Bruce, N. S. (2009). Soundscapes: An urban planning process map. Conference or Workshop Item. Inter.Noise: Innovation in Practical Noise Control, Ottawa, Canada. http://usir.salford.ac.uk/2465/

Adams, M., Neil, B., William, J. D., \& Christopher, P. (2008). Soundwalking as a methodology for understanding soundscapes. Institute of Acoustics Spring Conference, Reading, UK. http://usir.salford.ac.uk/2461/1/Adams_etal_2008_Soundwalking as_Methodology.pdf

Adams, M., Cox, T., Moore, G., Croxford, B., Refaee, M., \& Sharples, S. (2006). Sustainable soundscapes: Noise policy and the urban experience. Urban Studies, 43 (13), 2385-2398. doi:10.1080=00420980600972504

Aletta, F., Oberman, T., \& Kang, J. (2018). Associations between positive health-related effects and soundscapes perceptual constructs: A systematic review. International Journal of Environmental Research and Public Health, 15, 2392. doi:10.3390/ijerph15112392

Aletta, F., Kang, J., \& Axelsson, Ö. (2016). Soundscape descriptors and a conceptual framework for developing predictive soundscape models. Landscape and Urban Planning, 149, 65-74. doi:10.1016/j.landurbplan.2016.02.001

Alves, S., Estévez-Mauriz, L., Aletta, F., Echevarria-Sanchez, G. M., \& Puyana Romero, V. (2015). Towards the integration of urban sound planning in urban development processes: The study of four test sites within the SONORUS project. Noise Mapping, 2(1), 57-85. 
Alves, S., Altreuther, B., \& Scheuren, J. (2014). Holistic concept for urban sound planning applied to real sites. Proceedings of Forum Acousticum Conference. American Planning Association. (2012). Governor Tom McCall Waterfront Park: Portland, Oregon. https://www.planning.org/greatplaces/spaces/2012/tommccal.htm Aravot, I. (2002). Back to phenomenological placemaking. Journal of Urban Design, 7, 201-212.

Assem Al-Hajj, I. E. (2014). Sustainable town square for the United Arab Emirates city. In A. Okeil (Ed.), Smart, sustainable and healthy cities (pp. 79-95). The First International Conference of the CIB Middle East and North Africa Research Network.

Aspuru, I., Fernandez, M., García, I., \& Herranz-Pascual, M. K. (2013). Soundscape within the strategy of Bilbao City to improve quality of public spaces. Proceedings of the NAG-DAGA.

Atkinson, R. (2007). Ecology of sound: The sonic order of urban space. Urban Studies, 44(10), 1905-1917. doi:10.1080/00420980701471901.

Bild, E., Coler, M., Pfeffer, K., \& Bertolini, L. (2016). Considering sound in planning and designing public spaces: A review of theory and applications and a proposed framework for integrating research and practice. Journal of Planning Literature, 31(4), 419-434. doi:10.1177/0885412216662001

Botteldooren, D., De Coensel, B., Van Renterghem, T., Dekoninck, L., \& Gillis, D. (2008). The urban soundscape: A different perspective. Duurzame mobiliteit Vlaanderen de leefbare stad, 177-204. 
Brambilla, G., Gallo, V., \& Zambon, G. (2013). The soundscape quality in some urban parks in Milan, Italy. International Journal of Environmental Research and Public Health, 10(6), 2348-2369. https://doi.org/10.3390/ijerph10062348

Brambilla, G., \& Maffei, L. (2010). Perspective of the soundscape approach as a tool for urban space design. Noise Control Engineering Journal, 58(5), 532-539. https://doi.org/10.3397/1.3484180

Brown, A. L. (2010). Soundscapes and environmental noise management. Noise Control Engineering Journal, 58, 493-500.

Brown, A. L. (2011). Advancing the concepts of soundscapes and soundscape planning. The Australian Acoustical Society, Gold Coast, Australia.

Brown, A. L. (2012). A review of progress in soundscapes and an approach to soundscape planning. International Journal of Acoustics and Vibration, 17(2), 7381. https://doi.org/10.20855/ijav.2012.17.2302

Brown, A. L., Kang, J., \& Gjestland, T. (2011). Towards standardization in soundscape preference assessment. Applied Acoustics, 72(6), 387-392. https://doi.org/10.1016/j.apacoust.2011.01.001

Brown, A. L., \& Muhar, A. (2004). An approach to the acoustic design of outdoor space. Journal of Environmental Planning and Management, 47(6), 827-842.

Bruce, N. S., \& Davies, W. J. (2014). The effects of expectation on the perception of soundscapes. Applied Acoustics, 85, 1-11. http://doi.org/10.1016/j.apacoust.2014.03.016. 
Cammell, P. (2015). Relationality and existence: Hermeneutic and deconstructive approaches emerging from Heidegger's philosophy. The Humanistic Psychologist, 43(3), 235-249.

Cassina, L, Fredianelli, L., Menichini, I, Chiari, C., \& Licitra, G. (2018). Audio-visual preferences and tranquility ratings in urban areas. Environments, 5, 1-17. doi:10.3390/environments5010001

Cerwen, G. (2017). Sound in landscape architecture: A soundscape approach to noise [unpublished dissertation]. Swedish University of Agricultural Sciences.

Conklin, T. (2007). Method or madness: Phenomenology as knowledge Creator. Journal of Management Inquiry, 16, 275. doi: 10.1177/1056492607306023

Creswell, J. W. (2014). Qualitative inquiry \& research design: Choosing among five approaches. Sage Publications.

De Coensel, B., Bockstael, A., Dekoninck, L., Botteldooren, D., SchulteFortkamp, B., Kang, J., \& Nilsson, M. E. (2010). he soundscape approach for early stage urban planning: a case study. Proceeding of Inter noise, Lisbon, Portugal, Proceeding CD Rom, 10 pages.

Dessein, J., Soini, K., Fairclough, G., \& Horlings, L. (Eds.) 2015. Culture in, for and as sustainable development. Conclusions from the COST Action IS1007 Investigating Cultural Sustainability. University of Jyväskylä, Finland.

Dubois, D., Guastavino, C., \& Raimbault, M. (2006). A cognitive approach to urban soundscapes: Using verbal data to access everyday life auditory categories. Acta Acustica United with Acustica, 92, pp. 865-874. 
Dworkin, S. (2012). Sample size policy for qualitative studies using in-depth interviews. Archives of Sexual Behavior, 41. Doi:10.1007/s10508-012-0016-6.

Easteal, M., Bannister, S., Kang, J., Aletta, F., Lavia, L., \& Witchel, H. (2014). Urban sound planning in Brighton and Hove. Proceedings of the Forum Acusticum 2014 Conference.

Eldien, H. H. (2014). Soundscape approach as a tool to evaluate the acoustic comfort in urban open spaces.

Friedmann, J. (2010). Place and place-making in cities: A global perspective. Planning Theory \& Practice, 11(2), 149-165. doi:10.1080/14649351003759573

Ge, J., \& Hokao, K. (2005). Applying the methods of image evaluation and spatial analysis to study the sound environment of urban street areas. Journal of Environmental Psychology, 25(4), 455-466.

Guastavino, C., \& Dubois, D. (2006). From language and concepts to acoustics: How do people cognitively process soundscapes? Retrieved from http://mil.mcgill.ca/docs/GuastavinoDubois2006InternoiseSS17-2.pdf

Guba, E. G. (1981). Criteria for assessing the trustworthiness of naturalistic inquiries. Educational Technology Research and Development, 29, 75-91.

Hedfors, P. (2003). Site soundscapes: Landscape architecture in the light of sound [unpublished doctoral thesis]. Swedish University of Agricultural Sciences Uppsala. Herranz-Pascual, K., Aspuru, I., \& García, I. (2010). Proposed conceptual model of environmental experience as framework to study the soundscape. Inter-Noise, Lisbon. Irvine, K. N., Devine-Wright, P., Payne, S. R., Fuller, R. A., Painter, B., \& Gaston, K. J. (2009). Green space, soundscape and urban sustainability: An interdisciplinary, 
empirical study. Local Environment, 14(2), 155-172.

https://doi.org/10.1080/13549830802522061

Jeon, J. Y., \& Hong, J. Y. (2015). Classification of urban park soundscapes through perceptions of the acoustical environments. Landscape and Urban Planning, $141,100-111$.

Jeon, J. Y., Hong, J. Y., \& Lee, P. J. (2013). Soundwalk approach to identify urban soundscapes individually. Journal of the Acoustical Society of America, 134(1), 803812. https://doi.org/10.1121/1.4807801

Jeon, J. Y., Lee, P. J., You, J., \& Kang, J. (2010). Perceptual assessment of quality of urban soundscapes with combined noise sources and water sounds," Journal of the Acoustical Society of America, 127, 1357-1366.

Jeon J. Y., Lee, P. J., You J., \& Kang, J. (2012). Acoustical characteristics of water sounds for soundscape enhancement in urban open spaces. Journal of the Acoustical Society of America 131(3), 2101-2109.

Job, R. F. S., \& Hatfield, J. (2001). The impact of soundscape, enviroscape and psychscape on reaction to noise: Implications for evaluation and regulation of noise effects. Noise Control Engineer Journal, 49, 120-124.

Joo, W., Gage, S. H., \& Kasten, E. P. (2011). Analysis and interpretation of variability in soundscapes along an urban-rural gradient. Landscape and Urban Planning, 103, 259-276. doi:10.1016/j.landurbplan.2011.08.001.

Kalansuriya, C. M., Pannila, A.S., \& Sonnadara, D. U. J. (2009). Effect of roadside vegetation on the reduction of traffic noise levels. Proceedings of the Technical Sessions, 25. 
Kang, J., \& Aletta, F. (2018). The impact and outreach of soundscape research. Environments, 5(58). doi:10.3390/environments5050058

Kang, J., Aletta, F., Gjestland, T. T., Brown, L. A., Botteldooren, D., SchulteFortkamp, B., Lercher, P., van Kamp, I., Genuit, K., Fiebig, A., Bento Coelho, J. L., Maffei, L., \& Lavia, L. (2016). Ten questions on the soundscapes of the built environment. Building and Environment, 108, 284-294.

Kang, J., \& Zhang, M. (2010). Semantic differential analysis of the soundscape in urban open public spaces. Building and Environment, 45(1), 150-157. https://doi.org/10.1016/j.buildenv.2009.05.014

Karahan, E. S. (2019). Social reproduction of space and soundscapes. Inter-Noise and Noise- Control for a Better Environment. http:www.ingentaconnect.com. Knox, P. L. (2005). Creating ordinary places: Slow cities in a fast world. Journal of Urban Design,10(1), 1-11.

Koutsomichalis, M. (2013). On soundscapes, phonography, and environmental sound art. Journal of Sonic Studies, 4(1). http://journal.sonicstudies.org/vol04/nr01/a05

Kuehne, L. M., Padgham, B. L., \& Olden, J. D. (2013). The soundscapes of lakes across an urbanization gradient. PLOS One, 8, e55661. doi:10.1371/journal.pone.0055661

Kurakula, V. K., \& Kuffer, M. (2008). 3D noise modeling for urban environmental planning and management. In M. Schrenk, V. V. Popovich, D. Engelke, \& P. Liseli (Eds.), REAL CORP 008 Proceedings.

Kurakula, V., Skidmore, A., Kluijver, H., Stoter, J., Dabrowska-Zielinska, K., \& Kuffer, M. (2007). A GIS-based approach for 3D noise modelling using 3D city models [Unpublished MSc proposal]. University of Southampton. 
Laverty, S. (2003). Hermeneutic phenomenology and phenomenology: A comparison of historical and methodological considerations. International Journal of Qualitative Methods, 2(3), 21-35.

Lercher, P., \& Schulte-Fortkamp, B. (2003). The relevance of soundscape research to the assessment of noise annoyance at the community level. In ICBEN 8th International Congress on Noise as a Public Health Problem.

Lillis, A., Caruso, F., Mooney, T. A., Llopiz, J., Bohnenstiehl, D., \& Eggleston, D. B. (2018). Drifting hydrophones as an ecologically meaningful approach to underwater soundscape measurement in coastal benthic habitats. Journal of Ecoacoustics, 2, 1. https://doi.org/10.22261/JEA.STBDH1

Lincoln, Y. (1995). Emerging criteria for quality in qualitative and interpretive research. Qualitative Inquiry, 3, 275-289.

Lobo Soares, A. C., \& Bento Coelho, J. L. (2011). An investigation on the soundscape of public parks in the city of Belém, Brazil. $18^{\text {th }}$ International Congress on Sound and Vibration, Rio de Janeiro, Brazil.

Lobo Soares, A. C., \& Bento Coelho, J. L. (2016). Urban park soundscape in distinct sociocultural and geographical contexts. Noise Mapping, 3, 232-246. doi:10.1515/noise-2016-0016

Luzzi, S. (2013). Urban noise management and its practical implementation. Proceedings of the 20th International Congress on Sound and Vibration.

Madanipour, A. (1999). Why are the design and development of public spaces significant for cities? Environment and Planning B: Planning and Design, 26(6), 879-891. 
Matos, Wunderlich, F. (2008). Walking and rhythmicity: Sensing urban space. Journal of Urban Design, 13(1), 125-139. https://doi.org/10.1080/13574800701803472Miller, N. P. (2008). US national parks and management of park soundscapes: A review. Applied Acoustics, 69, 77-92.

Metropolitan Planning Commission. (2014, September 8). Reclaiming Old West Broad Street. https://reclaimingoldwestbroad.org/case-studies/portland-harbor-driv Moustakas, C. (1994). Phenomenological research methods. Sage Publications. Murphy, F. J., \& Yielder, J. (2009). Establishing rigour in qualitative radiography research, Radiography. doi:10.1016/j.radi.2009.07.003

Oberman, T, Jambroši'c, K., Horvat, M., \& Obad Š́ citaroci, B. B. (2020). Using virtual soundwalk approach for assessing sound art soundscape interventions in public spaces. Applied Sciences, 10, 2102. doi:10.3390/app10062102

Oberman, T., Bojani'c Obad Šćitaroci, B., Jambrošić, K., \& Kang, J. (2017). Winter buzz and summer siesta in Zagreb-Perceptual differences in soundscape of the sequence of urban open spaces. Instituto de Geografia e Ordenamento do Territorio: Lisbon, Portugal, 2017

Oberman, T., Obad Šćitaroci, B. B., \& Jambrošić, K. (2018). Towards a virtual soundwalk. In F. Aletta J. Xiao (Eds.), Handbook of research on perception-driven approaches to urban assessment and design.

Osborne, J. (1998). Some similarities and differences among phenomenological and other methods of psychological qualitative research. Canadian Psychology, 35(2), 167189. 
Ow, L. F., \& Ghosh, S. (2017). Urban cities and road traffic noise: Reduction through vegetation. Applied Acoustics, 120, 15-20. https://doi.org/10.1016/j.apacoust.2017.01.007

Palermo, P. C., \& Ponzini, D. (2015). Place-making and urban development: New challenges for contemporary planning and design. Routledge.

Payne, S. R., Davies, W. J., \& Adams, M. D. (2009). Research into the practical and policy applications of soundscape concepts and techniques in urban areas.

Department of Environment Food and Rural Affairs. http://usir.salford.ac.uk/27343/.

Raimbault M., \& Dubois, D. (2005). Urban soundscapes: Experiences and knowledge. Cities, 22, 339-350.

Reiners, G. (2012). Understanding the differences between Husserl's (descriptive) and Heidegger's (interpretive) phenomenological research. Journal of Nursery Care, $1(5)$.

Rossman, G., \& Rallis, S. (2003). Learning in the field: An introduction to qualitative research. (2nd ed.). Sage Publications.

Saunders, B., Sim, J., Kingstone, T., Baker, S., Waterfield, J., Bartlam, B., Burroughs, H., \& Jinks, C. (2018). Saturation in qualitative research: exploring its conceptualization and operationalization. Qual Quant, 52, 1893-1907. https://doi.org/10.1007/s11135017-0574-8

Schafer, R. M. (1969). The new soundscape: A handbook for the modern music teacher. BMI Canada Limited.

Schafer, R. M. (1977a). The tuning of the world. Knopf. 
Semidor, C. (2006). Listening to a city with the soundwalk method. Acta Acustica United with Acustica, 92(6), 959-964.

Smith, J., \& Osborn, M. (2004). Interpretative phenomenological analysis. In G. M. Breakwell (Ed.), Doing social psychology research. The British Psychological Society and Blackwell Publishing.

Southworth, B. (2003). Urban design in action: The City of Cape Town's Dignified Places Programme - implementation of new public spaces towards integration and urban regeneration in South Africa. Urban Design International, 8. 119-133.

Steele, D. (2018). Bridging the gap from soundscape research to urban planning and design practice: how do professionals conceptualize, work with, and seek information about sound? [unpublished dissertation]. McGill University.

Steele, D., Legast, É., Trudeau, C., Fraisse, V., \& Guastavino, C. (2019). Sounds in the city: Improving the soundscape of a public square through sound art. Proceedings of the ISCV 26.

Steele, D., Dumoulin, R., Kerrigan, C., \& Guastavino, C. (2017). Sounds in the city workshops: Integrating the soundscape approach in urban design and planning practices. Proceedings of the AESOP 2017 Conference.

Steele, D., Krijnders, D., \& Guastavino, C. (2013). The sensor city initiative: Cognitive sensors for soundscape transformations. GIS Ostrava.

Steele, D., Luka, N., \& Guastavino, C. (2012). Constructing ideal soundscapes: A practical study on closing the gaps between soundscape studies and urban design. Acoustics 2012, Nantes, France. http://hal.archives-ouvertes.fr/hal-00811341/. 
Taylor, P. C., \& Medina, M. N. D. (2013). Educational research paradigms: From positivism to multiparadigmatic. Journal for Meaning-Centered Education, 1. doi: $10.13140 / 2.1 .3542 .0805$

Todres L. (2008). Being with that: The relevance of embodied understanding for practice. Qualitative Health Research, 18(11), 15661573.

Toolis, E. E. (2017). Theorizing critical placemaking as a tool for reclaiming public space. American Journal of Community Psychology, 59, 184-199. doi:10.1002/ajcp.12118

Truax, B. (1992). Composing with time-shifted environmental sound. Leonardo Music, 2, 37-40.

Truax, B. (1996). Soundscape, acoustic communication and environmental sound composition. Contemporary Music Review, 15(1), 47-63.

Truax, B. (1998). Models and strategies for acoustic design. "Stockholm, Hey Listen!", The Royal Swedish Academy of Music.

Truax, B. (2007). The World Soundscape Project. Simon Fraser University. http://www.sfu.ca/ truax/wsp.html.

Tse, M. S. \& Chau, C. K. (2012). Perception of urban park soundscape. The Journal of the Acoustical Society of America 131 (2762). https://doi.org/10.1121/1.3693644

Van Herzele, A., \& Wiedemann, T. (2003). A monitoring tool for the provision of accessible and attractive urban green spaces. Landscape and Urban Planning, 63, 109-126.

Venot, F., \& Sémidor, C. (2006). The soundwalk as an operational component for urban design. In Proceedings of the 23rd Conference on Passive and Low Energy 
Architecture (pp. 619-624). http://plea-

arch.org/ARCHIVE/2006/Vol2/PLEA2006_PAPER867.pdf

Vernon, B., \& Tiwari, R. (2009). Place-making through water sensitive urban design. Sustainability, 1(4), 789-814.

Vickers, P. (2011). Sonification for process monitoring. In T. Hermann, A. Hunt, \& J. G. Neuhoff (Eds.), The sonification handbook (pp. 455-491). Logos Publishing House.

Watts, G., Pheasant, R., Horoshenkov, K., \& Ragonesi, L. (2009). Measurement and subjective assessment of water generated sounds. Acta Acustica United with Acustica, 95, 1032-1039.

Wertz, M. S., Nosek, M., McNiesh, S., \& Marlow, E. (2011), The composite first person narrative: Texture, structure, and meaning in writing phenomenological descriptions, International Journal of Qualitative Studies on Health and Wellbeing, 6(2), 5882. doi: $10.3402 / \mathrm{qhw} . v 6 \mathrm{i} 2.5882$

Westerkamp, H. (1974, Revised 2001). Soundwalking. http://www.sfu.ca/ westerka/writings\%20page/articles\%20pages/soundwalking.html Westerkamp, H. (1996). Transformations, empreintes DIGITALes Compact Disc (Montreal, 1996). 1

Westerkamp, H. (2002). Linking soundscape composition and acoustic ecology. Organised Sound: An International Journal of Music and Technology, 7(1).

Westerkamp, H. (2006). Soundwalking as ecological practice: Writing by Hildegard Westerkamp. https://www.hildegardwesterkamp.ca/writings/writingsby/?post_id=14\&title=\%E2\% 80\%8Bsoundwalking-as-ecological-practice 
Westerkamp H. (2017). The natural complexities of environmental listening: One soundwalk, multiple responses. BC Studies, 194, 149-162.

Wirth, L. (1938). Urbanism as a way of life. American Journal of Sociology, 44(1), 1-24.

World Soundscape Project. (1978). The World Soundscape Project's handbook for acoustic ecology (The Music of the environment series) (1st ed.). A.R.C. Publications.

Wothge, J., Belke, C., Möhler, U., Guski, R., \& Schreckenberg, D. (2017). The combined effects of aircraft and road traffic noise and aircraft and railway noise on noise annoyance-An analysis in the context of the Joint Research Initiative NORAH. International Journal of Environmental Research and Public Health, 14, 871.

Wrightson, K. (2000). An introduction to acoustic ecology. Soundscape: The Journal of Acoustic Ecology, 1(1), 10-13.

Yang, W., \& Kang, J. (2005) Acoustic comfort evaluation in urban open public spaces. Applied Acoustics, 66, 211-229.

Yang, W., \& Kang, J. (2005). Soundscape and sound preferences in urban squares: A case study in Sheffield. Journal of Urban Design, 10(1), 61-80. https://doi.org/10.1080/13574800500062395

Zardini, M. (2012). Toward a sensorial urbanism. Ambiances in action / Ambiances en acte(s): International Congress on Ambiances, Montreal, Canada. 


\section{Appendices}

\section{Appendix A: Pre-Sound Walk Survey}

The Soniferous Experience of Public Space: A Soundscape Approach

\section{INTRODUCTION}

You are being asked to participate in a research study that is being done by Kenya Williams as part of his research towards receiving his doctoral degree from the Nohad

A. Toulan School of Urban Studies \& Planning, at Portland State University in Portland, Oregon. This research is studying the soundscape of Tom McCall Waterfront Park, its meaning to practitioners and policy officials, and how their assessment and management of the soundscape could be incorporated on behalf of public goals.

You are being asked to participate in this study because as an urban planner, policy official, city employee, landscape architecture or noise management professional, you have agency and a responsibility to either plan, design, and maintain public spaces or regulate the sound that occurs in those spaces. Your opinions are critical to the future implementation of a soundscape approach in urban planning practice as well as the soundscape preferences of everyday park users.

\section{CONSENT}

You are making a decision whether to participate in this study. Your signature below indicates that you have read the information provided (or the information was read to you). By signing this consent form, you are not waiving any of your legal rights as a research participant. 
You have had an opportunity to ask questions and all questions have been answered to your satisfaction. By signing this consent form, you agree to participate in this study.

First Name: Last Name:

X Sign Here:

\section{Participant information:}

First Name:

Last Name:

Title/Position:

Organization/Company:

Email Address:

Please indicate your occupation/industry:

Architect

Urban Planner

Urban Designer

Landscape Designer

Landscape Architect

Maintenance/Facilities 


\section{City/Government Official}

Noise Control/Management

Urban Planning Graduate Student

Citizen Noise Advisory Committee

Other:

A soundwalk is a walk with a focus on listening to the environment.

\section{Soundwalk Instructions:}

The instructions for a soundwalk, are relatively simple, just walk and observe the sounds you hear. Maintaining silence and active listening is vital.

Before you start your soundwalk, take a moment to settle and center yourself. Once you start your soundwalk, explore each designated research quadrant at will taking as much time as needed to listen and then answer the questions that correspond to each quadrant before moving on to the next quadrant.

Be sure to explore each of the following quadrants:

Quadrant 1: South Waterfront Park Garden to Hawthorne Bridge

Quadrant 2: Hawthorne Bridge to Morrison Bridge

Quadrant 3: Morrison Bridge to Burnside Bridge

Quadrant 4: Burnside Bridge to Steel Bridge 
After you complete your examination of this quadrant, walk back in the direction of the first quadrant and reflect on your listening experience to answer the next series of questions about the overall soundscape of Tom McCall Waterfront Park.

Quadrant 1: South Waterfront Park Garden to Hawthorne Bridge

This is the first of four quadrants ( 1 of 4 ) that you will be surveying during your soundwalk of Tom McCall Waterfront Park.

Take as much time as needed to explore this quadrant while listening and then answer the questions that correspond to this quadrant before moving on to the next quadrant.

In $\mathbf{3}$ to $\mathbf{5}$ words, describe the sound in this quadrant?

What do you feel or think about the sound in this quadrant? 


\title{
Rate the overall soundscape of this quadrant:
}

\author{
Extremely positive \\ Moderately positive \\ Slightly positive \\ Neither positive nor negative \\ Slightly negative \\ Moderately negative \\ Extremely negative
}

Please explain your rating for this quadrant: 
Quadrant 2: Hawthorne Bridge to Morrison Bridge

This is the second of four quadrants ( 2 of 4$)$ that you will be surveying during your soundwalk of Tom McCall Waterfront Park.

Take as much time as needed to explore this quadrant while listening and then answer the questions that correspond to this quadrant before moving on to the next quadrant.

In 3 to 5 words, describe the sound in this quadrant?

What do you feel or think about the sound in this quadrant? 
Rate the overall soundscape of this quadrant:

Extremely positive

Moderately positive

Slightly positive

Neither positive nor negative

Slightly negative

Moderately negative

Extremely negative

Please explain your rating for this quadrant: 


\section{Quadrant 3: Morrison Bridge to Burnside Bridge}

This is the third of four quadrants ( 3 of 4 ) that you will be surveying during your soundwalk of Tom McCall Waterfront Park.

Take as much time as needed to explore this quadrant while listening and then answer the questions that correspond to this quadrant before moving on to the next quadrant.

In $\mathbf{3}$ to $\mathbf{5}$ words, describe the sound in this quadrant?

What do you feel or think about the sound in this quadrant? 
Rate the overall soundscape of this quadrant:

Extremely positive

Moderately positive

Slightly positive

Neither positive nor negative

Slightly negative

Moderately negative

Extremely negative

Please explain your rating for this quadrant: 


\section{Quadrant 4: Burnside Bridge to Steel Bridge}

This is the last quadrant ( 4 of 4 ) that you will be surveying during your soundwalk of Tom McCall Waterfront Park.

Take as much time as needed to explore this quadrant while listening and then answer the questions that correspond to this quadrant before moving on to the next quadrant.

After you complete your examination of this quadrant, walk back in the direction of the first quadrant and reflect on your listening experience to answer the next series of questions about the overall soundscape of Tom McCall Waterfront Park.

In 3 to 5 words, describe the sound in this quadrant?

What do you feel or think about the sound in this quadrant? 
Rate the overall soundscape of this quadrant:

Extremely positive

Moderately positive

Slightly positive

Neither positive nor negative

Slightly negative

Moderately negative

Extremely negative

Please explain your rating for this quadrant: 
Take as much time as you need to reflect on your overall listening experience of Tom McCall Waterfront Park.

After your reflection, answer the following questions:

\section{The loudest sound I heard in the park today was? (Select one)}

Natural sounds (e.g., natural sources, bird sounds, etc.)

Human sounds (e.g., human activities, people, etc.)

Technological sounds (e.g., artificial sounds, cell phones, etc.)

Mechanical sounds (e.g., machine-related sounds, etc.)

Traffic (e.g., cars, public transportation, road sounds, etc.)

Music (e.g., from event, PA system, street performance, etc.)

Construction sounds

Voices (e.g., conversations, etc.)

Children (e.g., voices, playing, etc.)

Barking dogs

Event sounds (e.g., concert, special event, etc.)

Water Feature (e.g., fountain, public art, etc.)

Weather (e.g., rain, wind, etc.)

Other

The most distant sound I heard in the park today was? (Select one)

Natural sounds (e.g., natural sources, bird sounds, etc.) 
Human sounds (e.g., human activities, people, etc.)

Technological sounds (e.g., artificial sounds, cell phones, etc.)

Mechanical sounds (e.g., machine-related sounds, etc.)

Traffic (e.g., cars, public transportation, road sounds, etc.)

Music (e.g., from event, PA system, street performance, etc.)

Construction sounds

Voices (e.g., conversations, etc.)

Children (e.g., voices, playing, etc.)

Barking dogs

Event sounds (e.g., concert, special event, etc.)

Water Feature (e.g., fountain, public art, etc.)

Weather (e.g., rain, wind, etc.)

Other 


\section{Overall, my favorite sound heard in the park today was? (Select one)}

Natural sounds (e.g., natural sources, bird sounds, etc.)

Human sounds (e.g., human activities, people, etc.)

Technological sounds (e.g., artificial sounds, cell phones, etc.)

Mechanical sounds (e.g., machine-related sounds, etc.)

Traffic (e.g., cars, public transportation, road sounds, etc.)

Music (e.g., from event, PA system, street performance, etc.)

Construction sounds

Voices (e.g., conversations, etc.)

Children (e.g., voices, playing, etc.)

Barking dogs

Event sounds (e.g., concert, special event, etc.)

Water Feature (e.g., fountain, public art, etc.)

Weather (e.g., rain, wind, etc.)

Other 


\section{Overall, my least favorite sound heard in the park today was? (Select one)}

Natural sounds (e.g., natural sources, bird sounds, etc.)

Human sounds (e.g., human activities, people, etc.)

Technological sounds (e.g., artificial sounds, cell phones, etc.)

Mechanical sounds (e.g., machine-related sounds, etc.)

Traffic (e.g., cars, public transportation, road sounds, etc.)

Music (e.g., from event, PA system, street performance, etc.)

Construction sounds

Voices (e.g., conversations, etc.)

Children (e.g., voices, playing, etc.)

Barking dogs

Event sounds (e.g., concert, special event, etc.)

Water Feature (e.g., fountain, public art, etc.)

Weather (e.g., rain, wind, etc.)

Other 


\section{What sounds did you not expect to hear in the park today? (Check all that apply)}

Natural sounds (e.g., natural sources, bird sounds, etc.)

Human sounds (e.g., human activities, people, etc.)

Technological sounds (e.g., artificial sounds, cell phones, etc.)

Mechanical sounds (e.g., machine-related sounds, etc.)

Traffic (e.g., cars, public transportation, road sounds, etc.)

Music (e.g., from event, PA system, street performance, etc.)

Construction sounds

Voices (e.g., conversations, etc.)

Children (e.g., voices, playing, etc.)

Barking dogs

Event sounds (e.g., concert, special event, etc.)

Water Feature (e.g., fountain, public art, etc.)

Weather (e.g., rain, wind, etc.)

Other 
Overall, how do you rate the quality of the soundscape in the park?

Extremely positive

Moderately positive

Slightly positive

Neither positive nor negative

Slightly negative

Moderately negative

Extremely negative

Has this soundwalk changed your perception or understanding of sound in parks and urban spaces?

No

Yes 


\section{About You:}

What is your age?

Under 18

$18-24$

$25-34$

$35-44$

$45-54$

$55-64$

$65+$

What best describes your gender?

Male

Female

Prefer to self-describe:

Prefer not to say 
What best describes your ethnicity?

Asian

White

Hispanic or Latino

Black or African American

American Indian or Alaska Native

Native Hawaiian or Pacific Islander

Prefer to self-describe:

Prefer not to say

What is the highest degree or level of school you have completed?

Less than a high school diploma

High school degree or equivalent (e.g. GED)

Some college, no degree

Associate degree (e.g. AA, AS)

Bachelor's degree (e.g. BA, BS)

Master's degree (e.g. MA, MS, MEd)

Professional degree (e.g. MD, DDS, DVM)

Doctorate (e.g. PhD, EdD)

Prefer not to say 


\section{Appendix B: Post-Soundwalk Survey Questions}

The Soniferous Experience of Public Space

\section{Q1}

As a practitioner with agency and a responsibility to either influence policy, plan, design, and maintain public spaces or regulate the sound that occurs in those spaces, your opinion is critical to the future implementation of a soundscape approach in urban planning practice as well as urban spaces and parks.

Now that you have completed your soundwalk of Tom McCall Waterfront Park, please answer the following questions.

Q2 Participant Information:

First Name:

Last Name:

Title/Position:

Organization/Company:

Email Address: 
Q3 Describe your experience of becoming a practitioner with knowledge and skills about urban spaces and parks?

Q4 Do you incorporate sound in your practice? Why or why not? If so, how? If not, under what circumstances might it be relevant?

Q5 How would you describe the soundscape of Tom McCall Waterfront Park? 
Q6 What do you do as a practitioner that influences the soundscape of Tom McCall Waterfront Park?

Q7 How would you assess and manage the soundscape of Tom McCall Waterfront Park?

Q8 What sound would you add or remove in Tom McCall Waterfront Park and how would that change the soundscape? 
Q9 If you were planning and designing Tom McCall Waterfront Park today, how would you incorporate the soundscape? 


\section{Appendix C: Participant Narrations}

\section{NARRATIVE OF P1}

Pl has been working in the Noise Office for the City of Portland for four years. Their main concern is to guide community members to understand the differences between noises that violate the Noise Code (Title18) and simple annoyances. Part of their job is to differentiate sounds that are permitted, such as events, festivals, and sounds that violate the City's noise ordinance. Also, they work to regulate sounds that could negatively impact the community. They consider the soundscape of the park to be typical to what can be expected from an area situated in the heart of the city, i.e., an urban area that is comprised of humans, nature, and mechanical sounds. Since they have permitted many events, they suggest creating spaces, specifically planned to host events in which sounds could be amplified. In relation to the soundscape of Tom McCall Waterfront Park, they pointed out the idea to mitigate the sounds coming from the freeways and other traffic in order to highlight the nature sounds (birds, fountains, water). Finally, they commented that having the opportunity to preplan this park, they would add more quiet areas, enhance water sounds, and designate areas specially designed to accommodate large events, i.e., concerts or festivals.

\section{NARRATIVE OF P2}

P2 is a Noise Control Official with ten years of experience inspecting two different metropolitan and geographic areas; their main job duties are noises inspection and dealing with complaints. Also, they assist with noise studies, and provide permits for large and loud events, taking into account the different means to reduce the impacts on the community. Also, they help to enforce the municipal noise code (Title 18). Additionally, they are focused on using education as a method to teach people about sounds in the city and what type of sounds are allowable and enforceable and the best way to handle potential conflict with neighbors related to noise. P2 is not surprised by the park's soundscape. It seems that their soniferous experience is similar to what they were expecting of a park situated near freeways and close of arterial traffic routes. They indicated that near the Steel Bridge was an unpleasant area along with the MAX line, the trains, and the helicopter landing zones. Specifically, they mentioned: "... the volume from the traffic on the Steel Bridge and helicopter is not really what I would have in a park." They commented about the assessment of the park and how to manage the soundscape, beginning by divided the park into areas and take systematic sound measurements to determine the path of noise according to the date and hour. These measurements must be followed for a period long enough to permit the emergence of a sound behavior pattern. Besides the systematic sound measurements, P2 also recommended monitoring events for compliance with the permit emitted. They suggested the removal of the Steel Bridge, MAX lines, the rail lines, and resurfacing the Hawthorne Bridge. Such removal would enhance the enjoyment of this section of the park. Finally, they would construct a building in the park "... for crew equipment, barricades, etc., 
public toilets, cafeteria". This would be a type of multi-purpose facility offering public services and serve as a buffer zone to reflect sounds from the rail lines, MAX and sounds coming from the distance. Water features would also be an element to incorporate to reduce/balance the loudest sounds.

\section{NARRATIVE OF P6}

P6 is an urban designer working for the Bureau of Planning and Sustainability. With an experience of twenty years, they have studied, explored, tested, and designed some of the existing public spaces and created new public spaces in the City of Portland. Also, they have maintained contact with different groups of people, which gives them a broad experience being in direct contact with the general public and particular organizations. For them, the sound is considered a pivotal factor in conditioning the success or failure of a public space. According to them, the proximity to freeways with the consequent noises is a prior element that will impact the area's success. Regarding Tom McCall Waterfront Park, they commented that the soundscape is interesting; it is characterized by a typical sound, i.e., the noises coming from the freeways at the North section of the park. In addition to the mentioned noise, P6 pointed out the people chatter as another sonorous element characterizing the soundscape of the park.

Part of their job is to be a part of the technical advisory team working on the improvement of the master plan for Tom McCall Waterfront Park. Master plan improvements for the project area include new bridges, new transit lines, and new places and communities around these infrastructures. In their opinion, the soundscape of the park is not positive or negative. However, they admit that the freeways noises are more present than they had thought. They would like to explore new ways to mitigate to some extent the noises coming from the highways because this implementation would have an enormous impact on the soundscape of the park and would allow creating new spaces for new sounds in the area. Having the opportunity to plan the park, they would suggested specific uses for some sections of the park, and how these new sections would enhance and blend with the overall soundscape of the park. They would also work with government partners: "... to turn some of the noise into acoustic art moments, maybe at some spots along the corridor."

\section{NARRATIVE OF P8}

P8 is a cultural landscape designer working for MIG. They incorporate sound in their practice primarily in the more developed areas of National Parks. According to them, Tom McCall Waterfront Park has a noticeable soundscape which is louder than what they expected. They particularly commented about the sounds of the fountains which were incorporated to drown out traffic noises but were louder and more conflicting than they would have thought. Similarly, they commented about the river's sounds, which were less prominent than expected. They suggested the addition of more vegetation buffers strategically placed around the park in such a way to balance the soundscape. Also, they suggested the incorporation of more places with fewer noises and more sounds to 
promote contemplation. They would remove bikes from the waterfront area and would redirect bike traffic closer to Naito Parkway. Finally, they would place loud noise elements on the street side and quieter elements on the riverside. Equally, develop more sections near the river, i.e., a variety of spaces, especially in the central part of the park.

\section{NARRATIVE OF P13}

P13 works for Portland Parks \& Recreation, but has also worked in other parks in the USA, and New Zealand as well. They transitioned from an interpretive National Park Ranger to a park planner in Portland. They have also worked with the planning team in public involvement processes, issuing permits for non-park (construction, utility work, etc.) on public property. For the last ten years, they have worked in park operations/maintenance. In their job, they do not incorporate sound, but they mentioned two occasions in which sound has been considered, the first was work developed for Director Park where they organized the park's "Quiet Hours, "for event load-in/out times to honor the neighboring businesses. The second occasion was the development of the Skate Park System Plan, which included the development of criteria to be used in decision-making about whether existing parks (and other public lands) would fit. They have worked with the City's Noise Control Office to determine the best practice for a distance of skate parks to the nearest residence; this was one of the criteria. According to P13, the experience of Tom McCall Waterfront Park depends on the reasons that lead a person to visit the park. It seems that it is not the same experience if you visit the park because a music festival or you go there to walk along the river. The parks offer a variety of experiences, and the soundscape can be described as a mix of urban and human sounds. In their opinion, consistent sound measurements must be done to determine the types and the levels of the sounds coming from various sources. They also admits that many of the sounds in the park come from traffic, bridges, helicopter landing, and construction. They commented that new sounds must be incorporated into the park. Sounds coming from vibrant art sculptures or the sound produced as a product of the interaction between people and "...the sound tubes, or shared xylophone toys we have in our newer parks would be worth considering here." These new sounds will balance the current soundscape of the park.

\section{NARRATIVE OF P17}

P17 is an urban planner working for Portland Parks \& Recreation. They have an undergraduate degree in Urban \&Regional Planning and a Masters in Arts Management. They have worked as a planner for Parks and worked on the City's first 20-year visionary parks \& recreation master plan. In their job, they do not incorporate sounds, and they considered it only if the park or public space in which they are working is located near significant sources of noises. Among their experiences, they commented about a past project concerning a 50-meter pool on a college campus. The neighborhood was disturbed by the noises coming from the pool events. This issue was solved by using a specific sound-attenuating product name Cal-Wall. For them, the soundscape of Tom McCall Waterfront Park can be summarized by saying that it is "... urban, active, social, 
and constant". They admit that sometimes the sound coming from the park can be unpleasant. In 2004, a master plan was created for this park, including improvements on the Saturday Market installations and the Blues Festival, which impact the park's soundscape. To manage the soundscape of the park, P17 mentioned that they would look for a strategy to reduce the sounds coming from adjacent construction, as well as the freeways. Also, they recommended planting vegetation to add more nature sounds to the park. In their opinion, the park will gain in attractiveness if it was possible to remove the noise coming from freeways and bridges. This would significantly improve the park experience. Finally, they would add piped-in and pedestrian-level ethereal/soft music to reduce the noises coming from the traffic and the freeway.

\section{NARRATIVE OF P20}

P20 is an urban planner working for Crandall Arambula. From architecture and landscape architecture to philosophy and linguistics, they are focusing in the study of communication between inner worlds and the outer social and environmental world. Currently, they do not work with sound, but believe that considering the soundscape created by different elements in relation to the design and location of affordable housing is a topic that will need consideration. For instance, in their opinion, the soundscape of the park was "... severely impacted by the overhead roadways at regular intervals, resulting in an overall soundscape that is chaotic."

As their current practice focuses on reducing car-dependency, they think that the same strategy could be implemented in Portland to reduce the impact of traffic noise. This strategy would reduce in a significant amount of traffic noise, enhancing at the same time, the typical natural sounds of the park, and incorporating sounds from across the river and downtown. Finally, they would close Naito Parkway to create a connection between the park and the downtown. They also would modify the topography within the park, which would add texture to the soundscape of the park.

\section{NARRATIVE OF P21}

P21 is an urban planner working for the Portland Parks \& Recreation. They have studied urban geography and theories of space and place, as well as environmental studies for their undergraduate degree in Geography. They also studied urban design and planning for their master's degree. In their experience, they have worked on public space planning for tactical urbanism projects to reclaim road space for pedestrians. Similarly, they were involved in master planning large redevelopment sites, including open space and park planning. For the past four years, they have focused on park and recreation planning for densifying urban environments. They commented that sound as an element to be considered when planning and designing public open spaces is not an element that has received all the needed attention. They stated: "There are typically so many constraints and challenges in planning urban space, that sound and the experience of it often gets lost." 
Regarding the park, P21 declared that the soundscape varies according to the time and the day of the week. Even if there are a lot of activities in the park, it is possible to find quiet moments visiting the park in the early hours of the morning. They pointed out: "... being there on a quiet morning, the activity was concentrated to sections of the park farther south". However, during this quiet visit, the presence of campers and homeless people has provoked unusual and disgusting sensation in them, due to the absence of the usual activity that characterizes the park. Likewise, they commented about the excess sound coming from the construction sites, which reduce the calming sounds of nature (birds and water fountains). They also mentioned that they will not have the occasion to create a park-specific policy to impact the sounds because the park possesses a Master Plan that is still under implementation. However, they will keep in mind the soundscape as an element to be considered when they work on planning or designing other public spaces. To assess the soundscape, they purposed taking sound measurements at different times of the day, different days of the week, and different weeks of the year. Also, they would incorporate the opinion and sound experiences of the public who visit the parks through the use of a survey.

They will also incorporate: “... public art that makes noises like wind chimes or mimics the sound of water and/or birds..." which would benefit the Waterfront section of the park. However, they also said such incorporation must be considered in light of the impact it would have during more significant events. Finally, P21 declared that they would study the soundscape by sections of the park through public, stakeholder, and staff engagement to determine the desired character of each section. Creative solutions would be required of artist and designers to achieve the desired soundscape results.

\section{NARRATIVE OF P22}

P22 commented about his broad experience during twenty years in the planning field, ten of which have been dedicated to urban space. They found that walking the park was an exciting activity in which they focused on determining the impact of the transportation system. Their practice does not lead them to incorporate sounds, but they manifested their concern about sounds that cannot be controlled. They wondered: "How can we offer protected spaces that are not as prone to those distractions?" This question seems to be related to the soundscape that they appreciated while being at the park. On this occasion, they refer to busy, loud, and traffic noises that seem to overlap the natural sounds coming from birds or water fountains. They said that they could influence the urban area "in terms of heights, building bulk, and zoning." In short, they possess the knowledge to assess and balance the different sounds of the park. They seems to be conscious of the role played by the bridges, but they would like to reduce the freeway noise. According to their opinion, the park must bring equal opportunities to hear other sounds, such as birds, fountains, and children playing. They insists on saying that natural sounds need to come forward and stand out above the noise. Finally, they have recommended installing bird feeders to attract different types of birds to this park. Also, they recommended to build access down to the river to allow people to enjoy the water sounds. 
Appendix D - Participant Demographics

Demographics - What is your age?

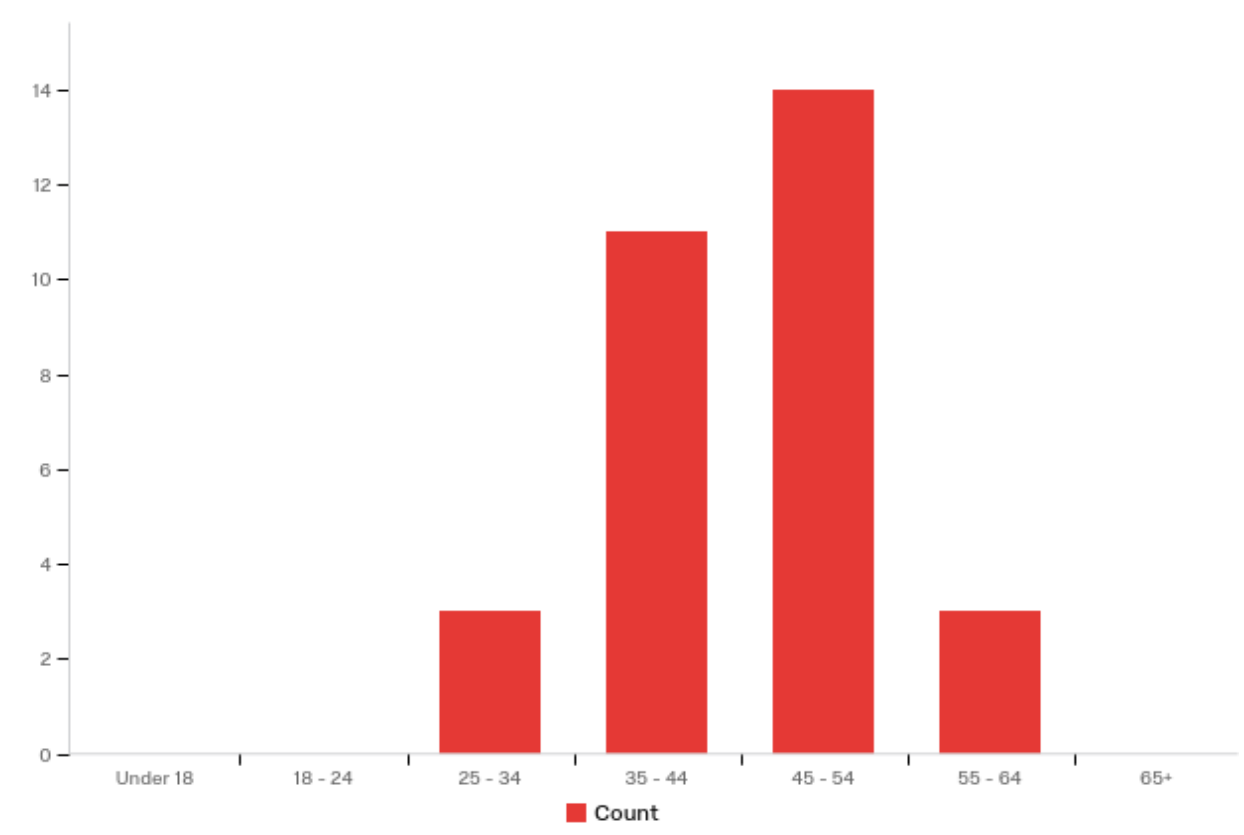

Demographics - What best describes your gender?

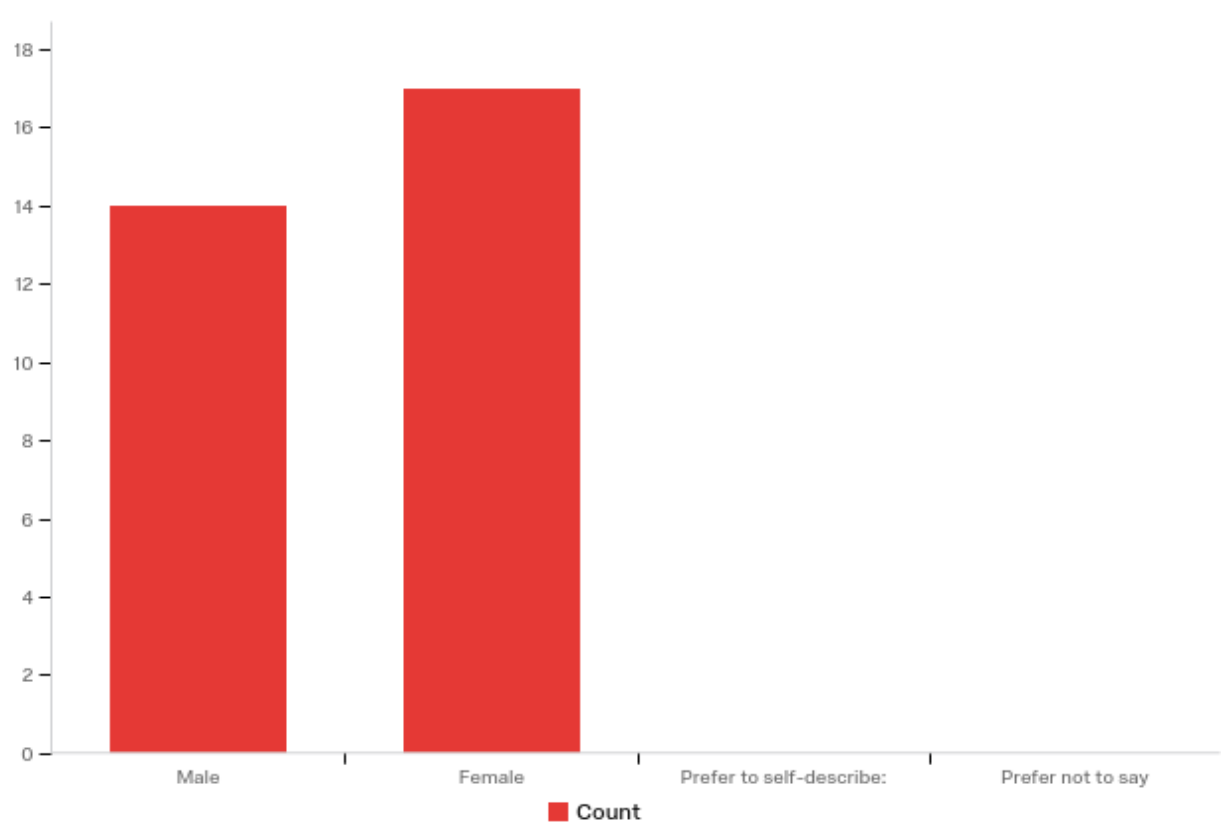


Demographics - What best describes your ethnicity?

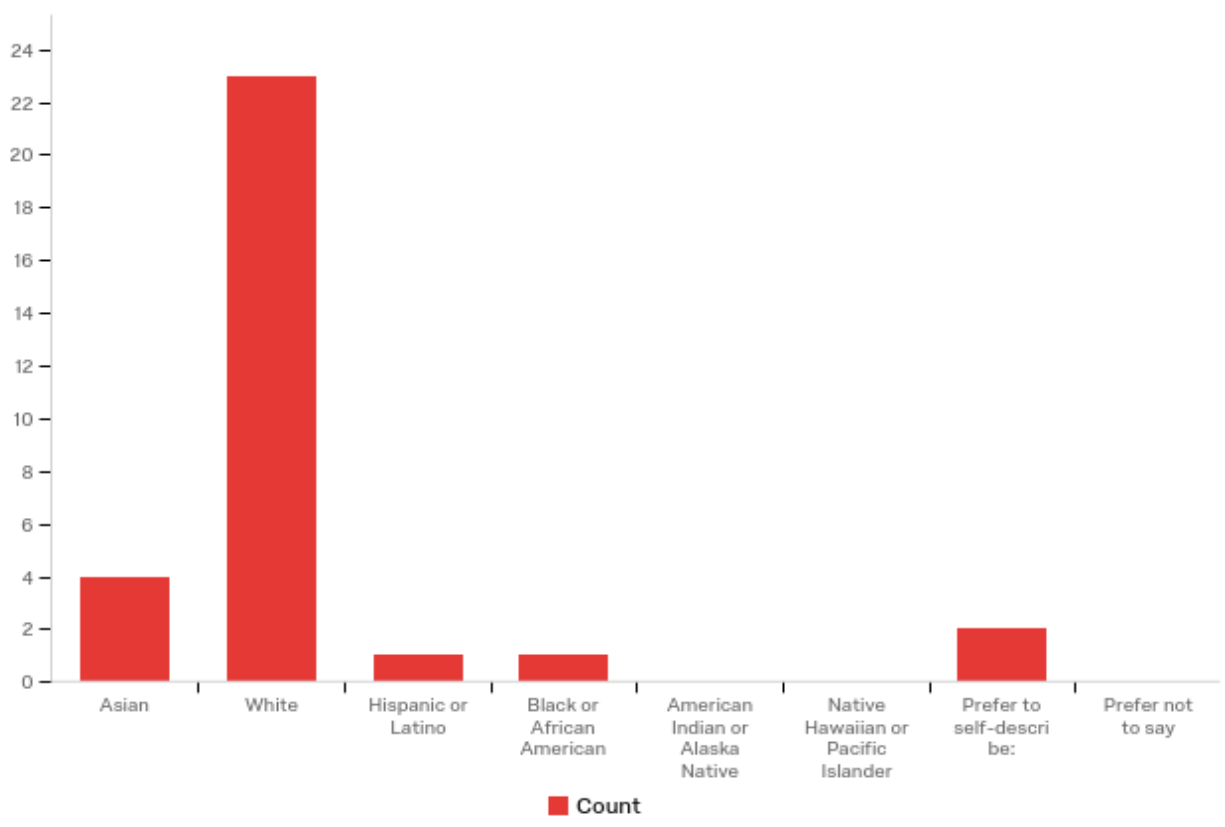

Demographics - Prefer to self-describe:

Prefer to self-describe: - Text

Asian and Latinx

Indonesian-American 
Demographics - What is the highest degree or level of school you have completed?

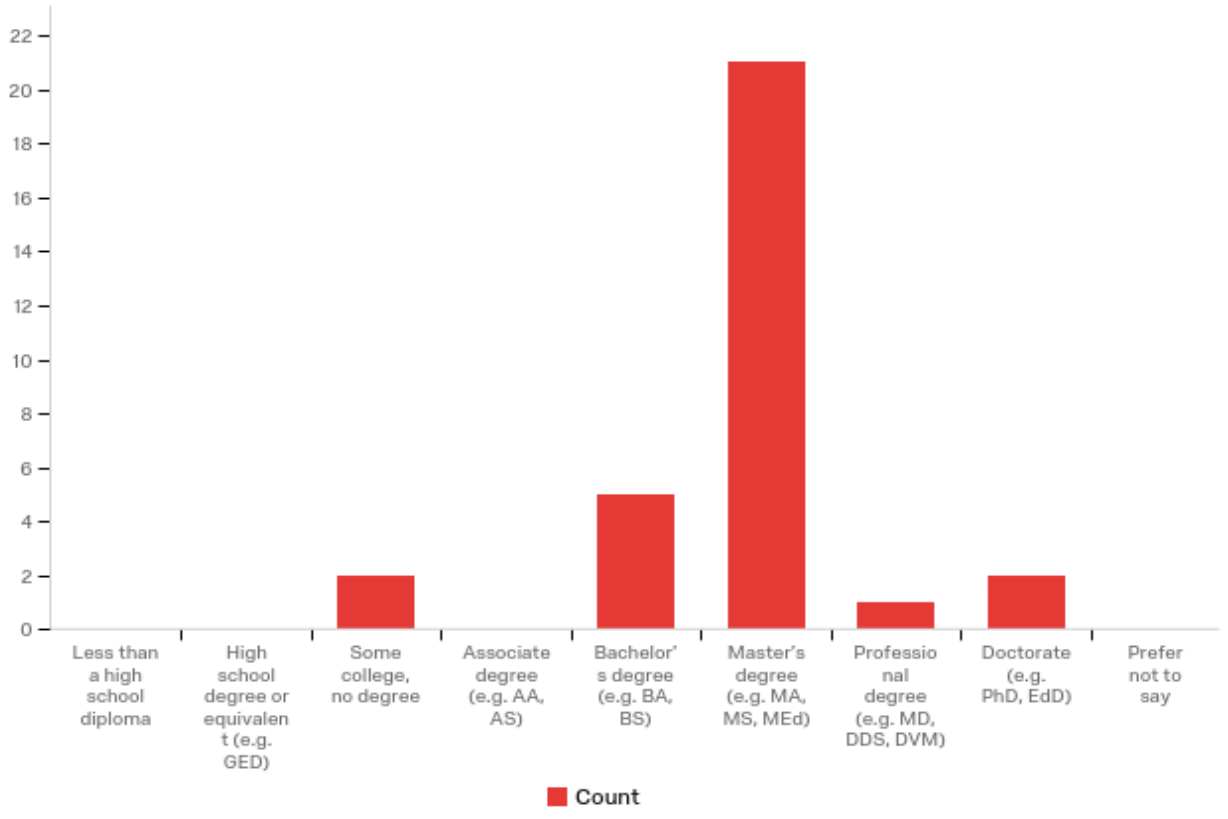




\section{Appendix E - Quadrant Soundscape Analysis}

All participants started from the same location at South Waterfront Park Garden. After beginning the soundwalk at this location, participants could explore each quadrant of the park at-will. As the participants explored the park, they answered survey questions related to each park quadrant. After they completed the soundwalk and answering the survey questions, they automatically received an email with a link to the post-soundwalk survey questions.

\section{Quadrant 1: South Waterfront Park Garden to Hawthorne Bridge}

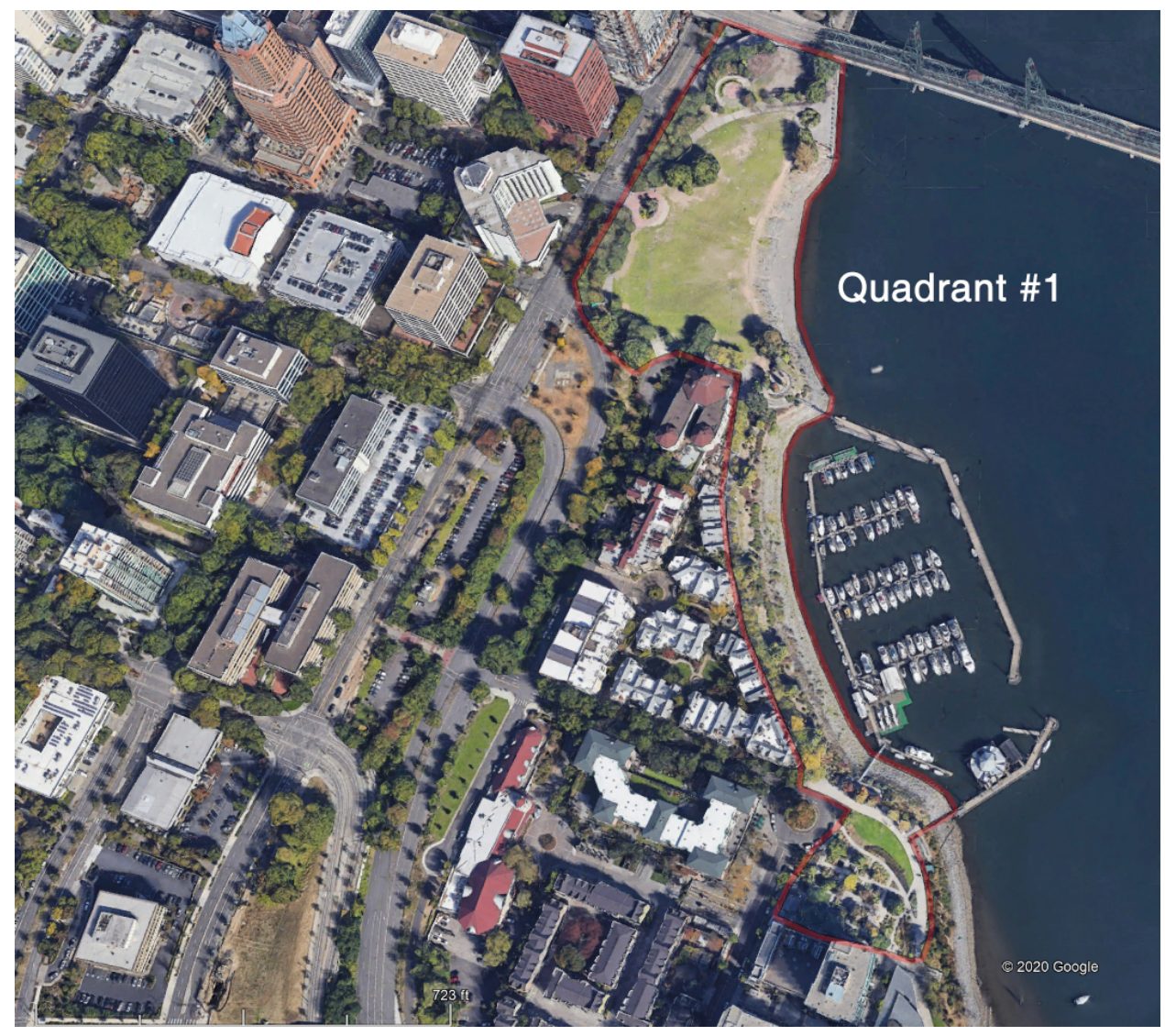




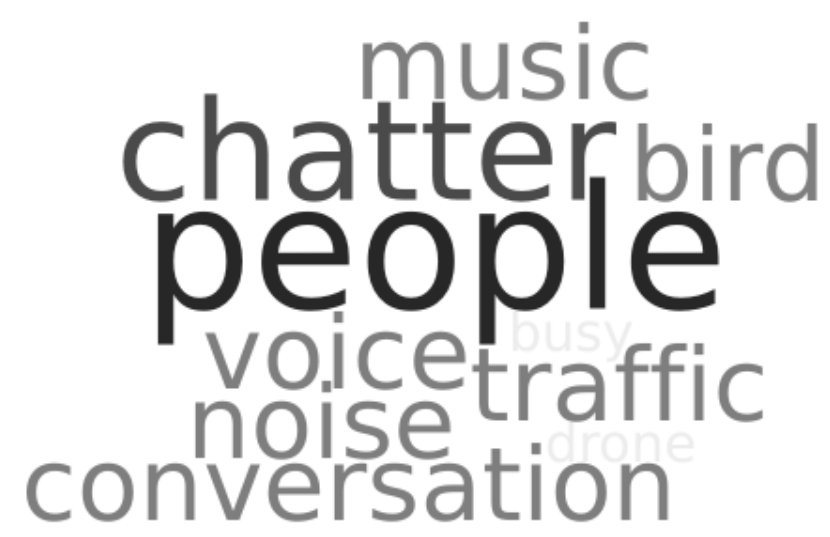

Q1 - What do you feel or think about the sound in this quadrant?

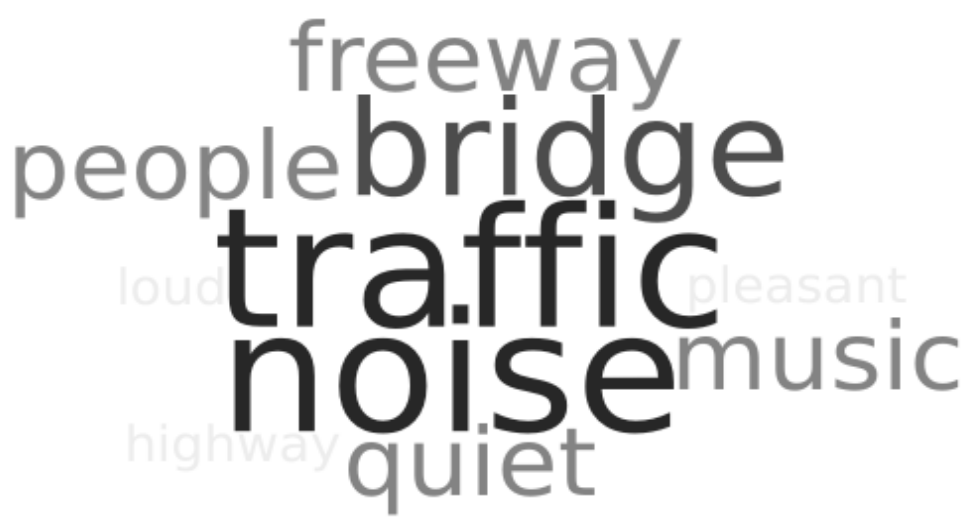


Q1 - Rate the overall soundscape of this quadrant:

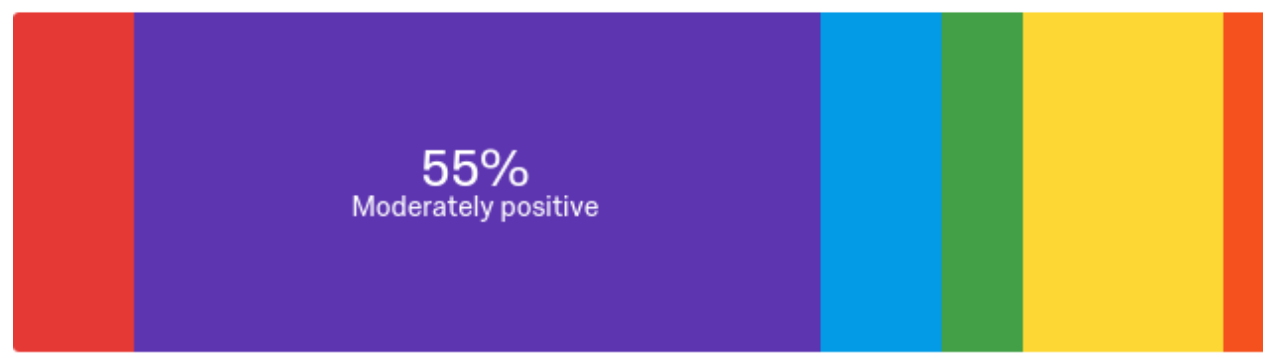

Extremely positive (3) Moderately positive (17) Slightly positive (3)

Neither positive nor negative (2) Slightly negative (5) Moderately negative (1)

Extremely negative (0)

Q1 - Please explain your rating for this quadrant:

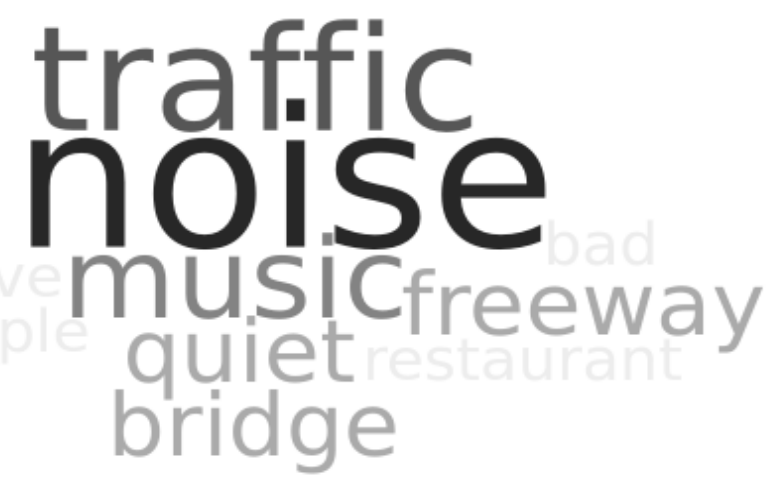




\section{Quadrant 2: Hawthorne Bridge to Morrison Bridge}

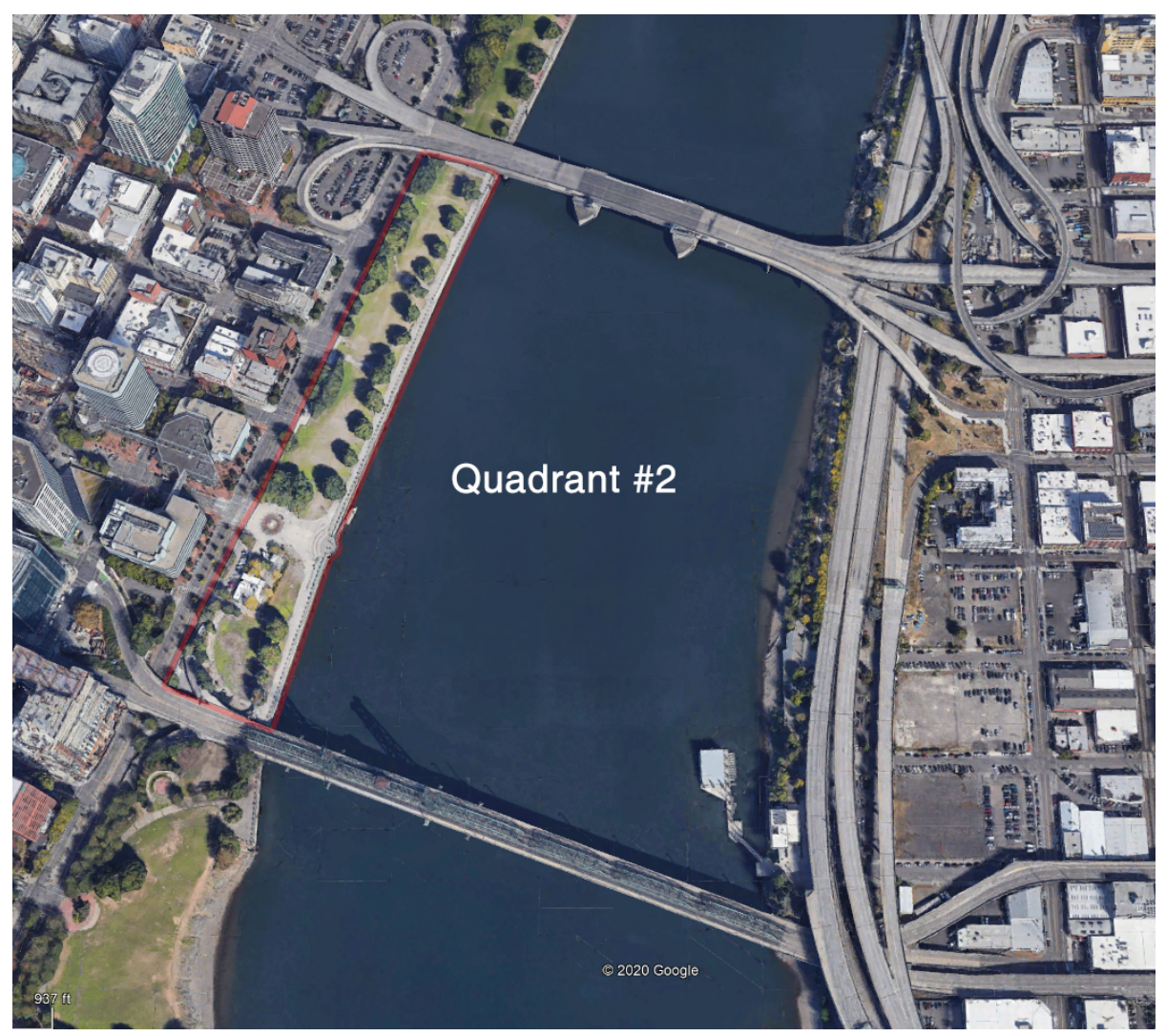

Q2: In 3 to 5 words, describe the sound in this quadrant?

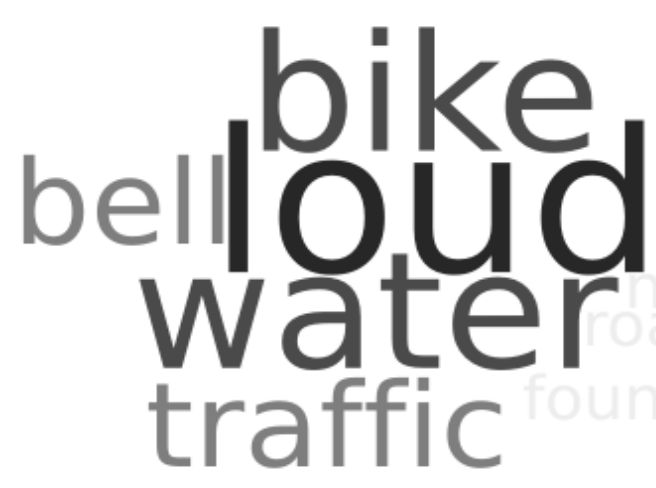


Q2 - What do you feel or think about the sound in this quadrant?

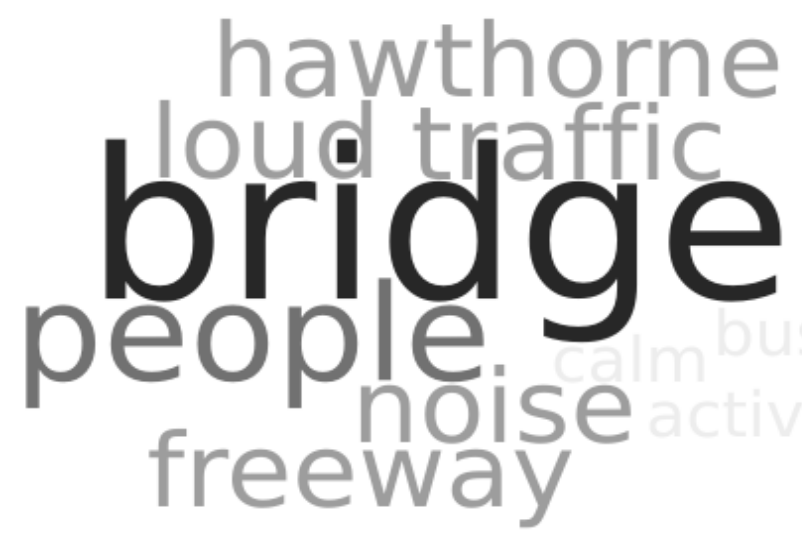

Q2 - Rate the overall soundscape of this quadrant:

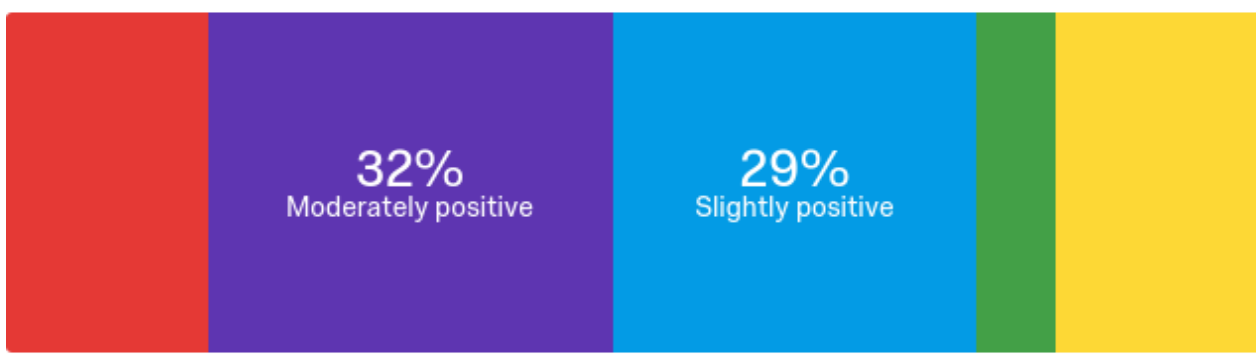

Extremely positive (5) Moderately positive (10) Slightly positive (9)

Neither positive nor negative (2) Slightly negative (5) Moderately negative (0)

Extremely negative (0) 
Q2 - Please explain your rating for this quadrant:

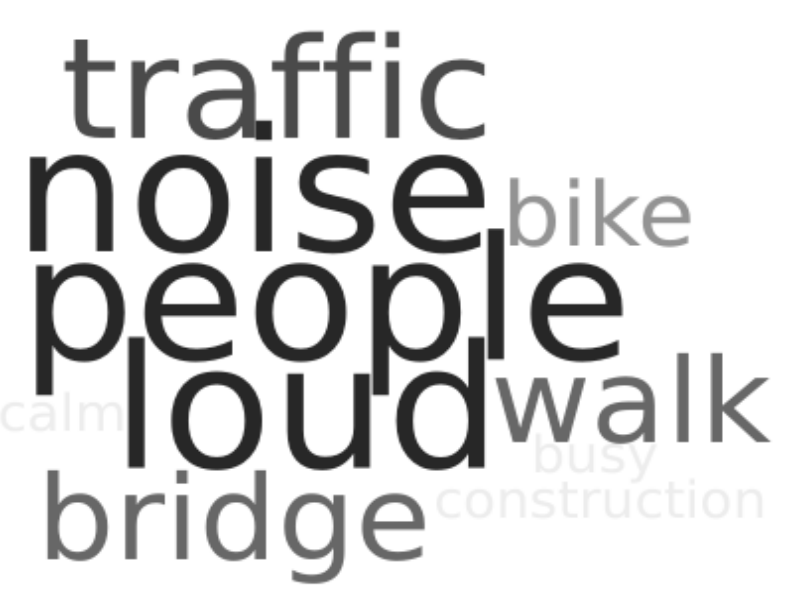

Quadrant 3: Morrison Bridge to Burnside Bridge

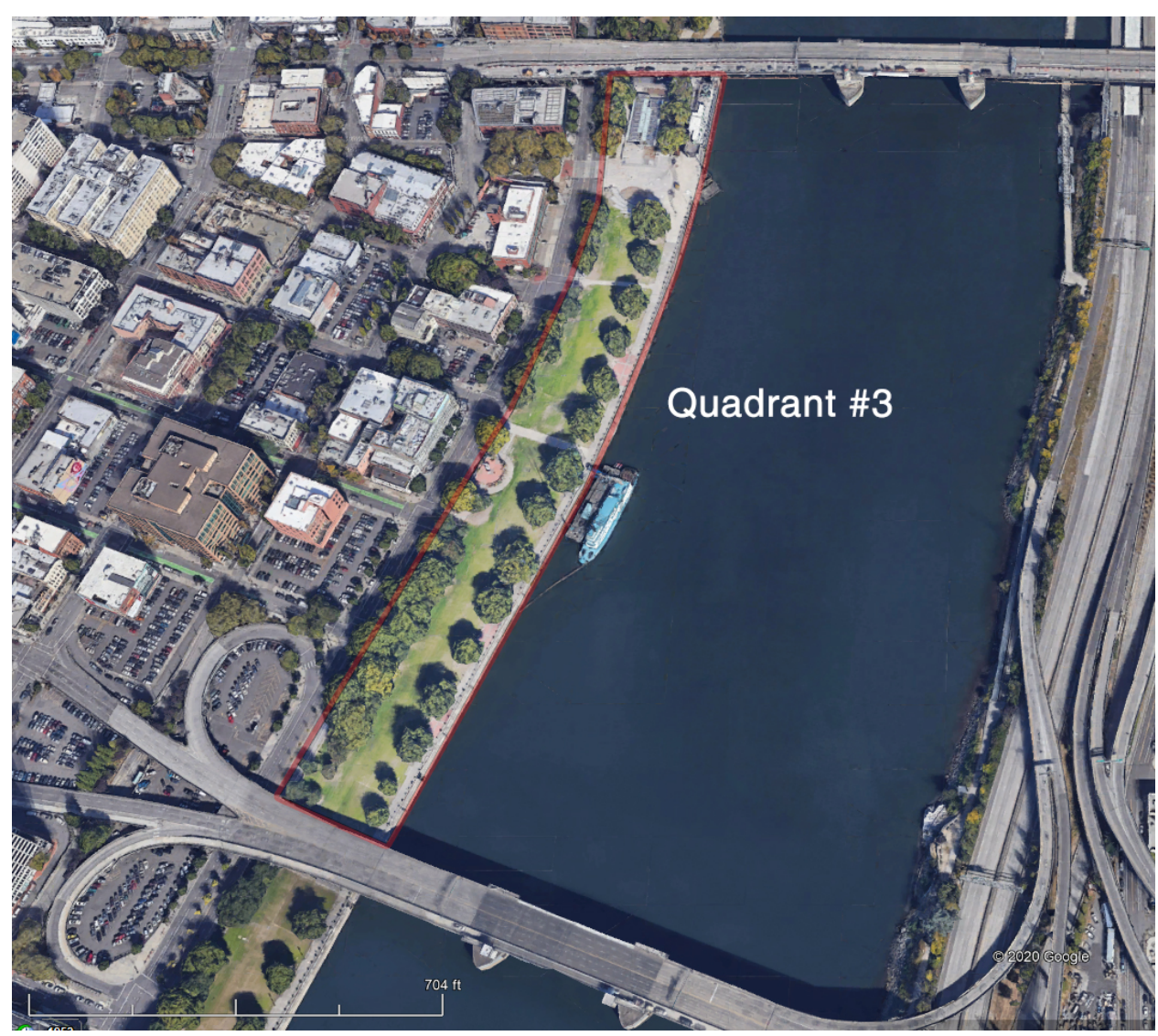




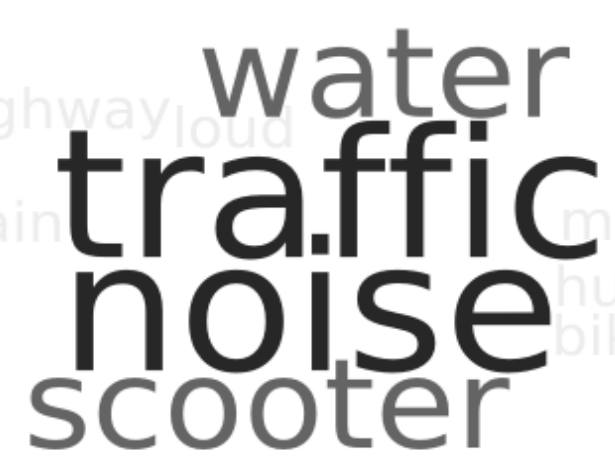

Q3 - What do you feel or think about the sound in this quadrant?

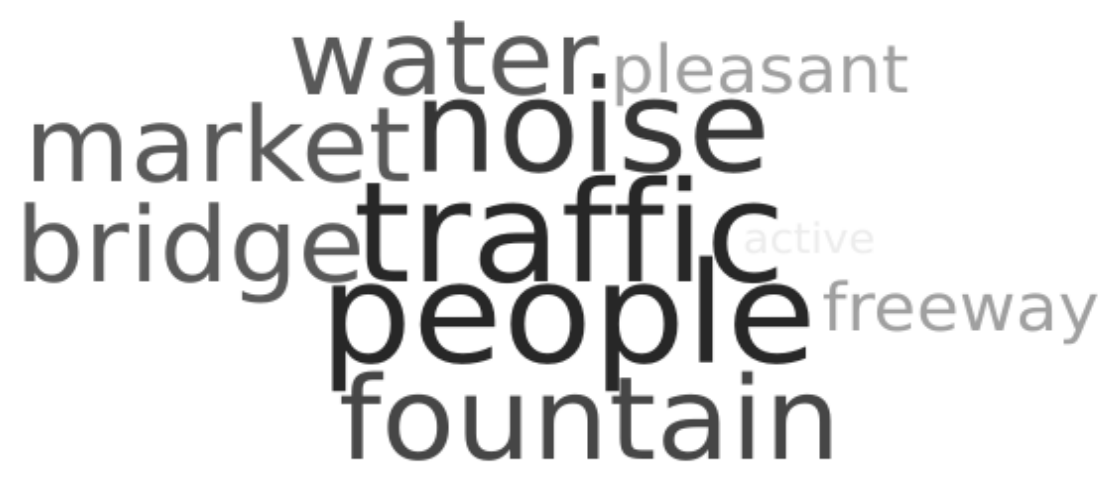


Q3 - Rate the overall soundscape of this quadrant:

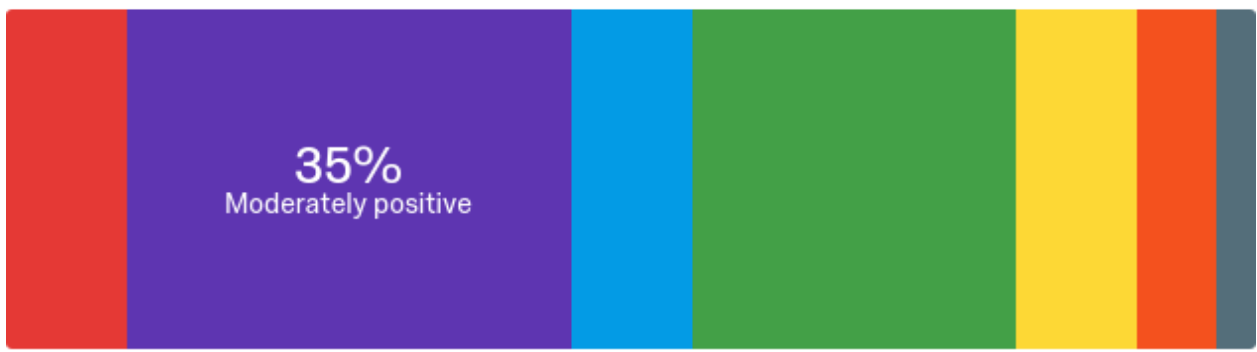

Extremely positive $\square$ Moderately positive $\quad$ Slightly positive

Neither positive nor negative Slightly negative $\square$ Moderately negative

Extremely negative

Q3 - Please explain your rating for this quadrant:

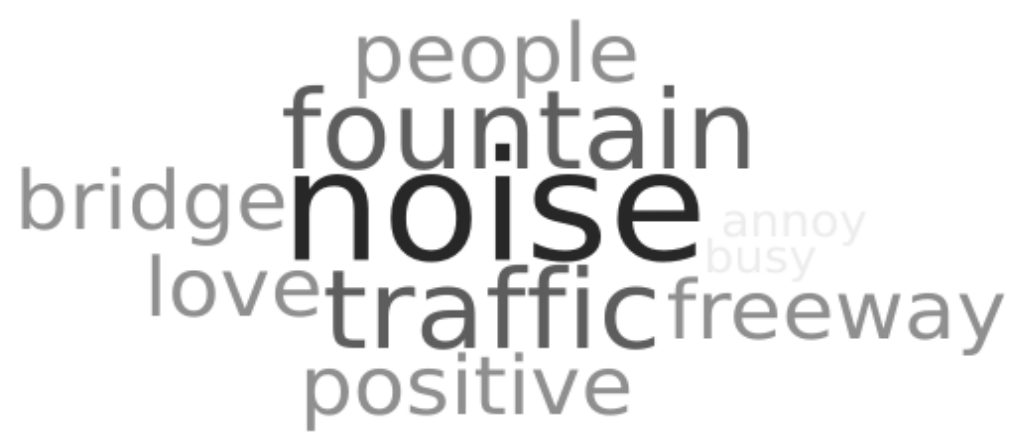




\section{Quadrant 4: Burnside Bridge to Steel Bridge}

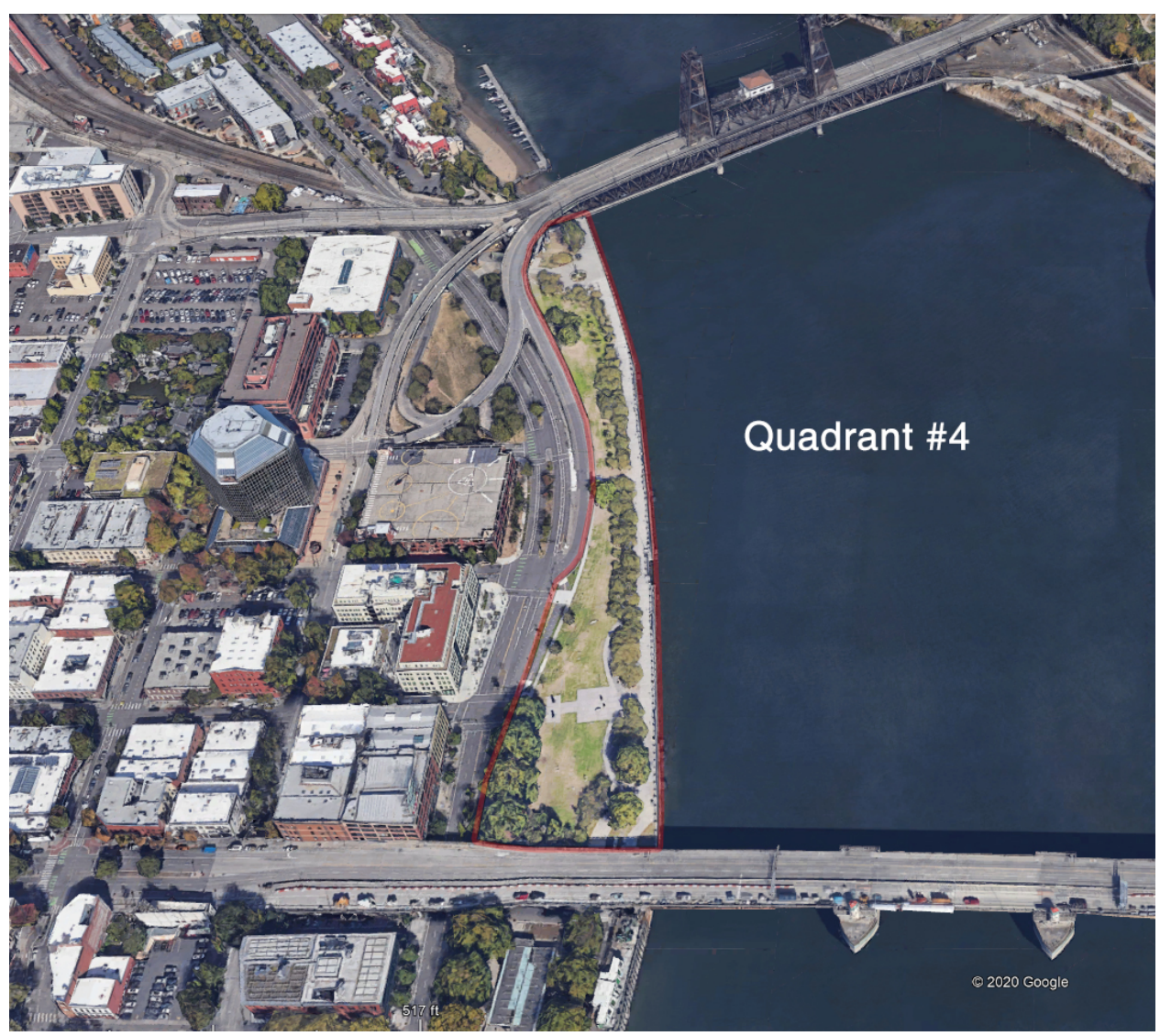

Q4 - In 3 to 5 words, describe the sound in this quadrant?

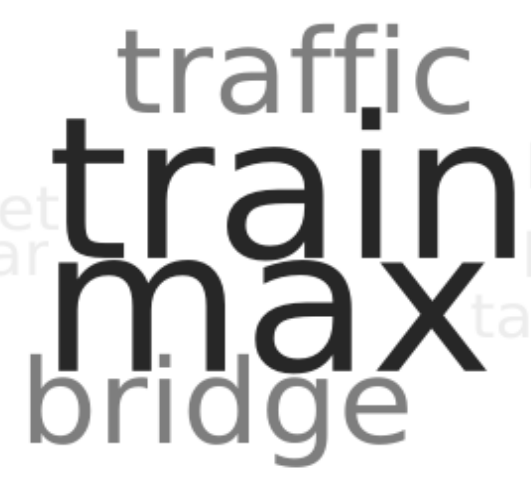


Q4 - What do you feel or think about the sound in this quadrant?

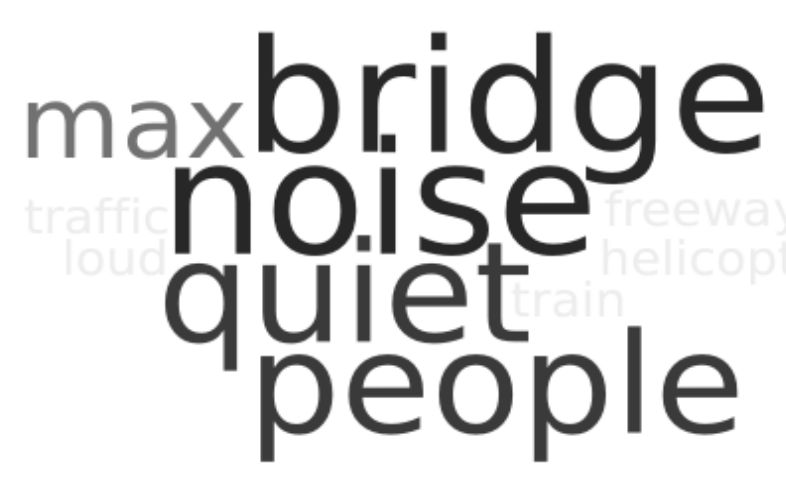

Q4 - Rate the overall soundscape of this quadrant:

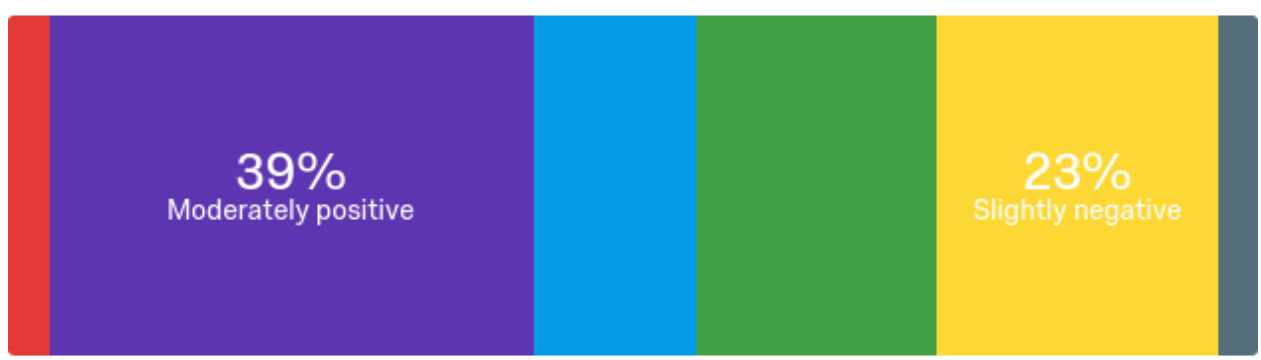

Extremely positive (1) Moderately positive (12) $\square$ Slightly positive (4)

Neither positive nor negative (6) Slightly negative (7) Moderately negative (0)

Extremely negative (1) 
Q4 - Please explain your rating for this quadrant:

$$
\begin{gathered}
\text { traffictrike } \\
\text { bridgine } \\
\text { peopleriver }
\end{gathered}
$$

\section{Overall Park Soundscape}

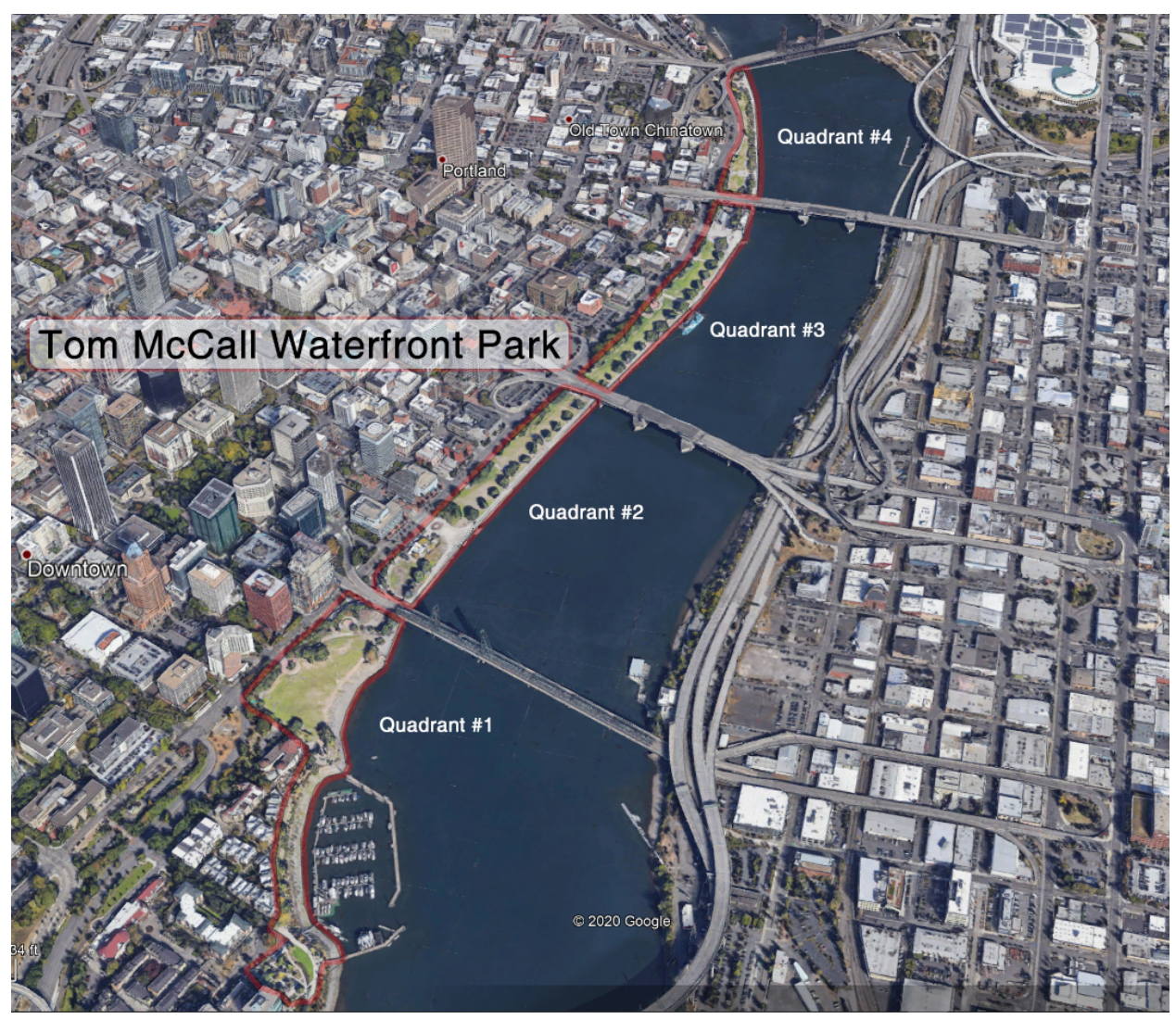


Overall - The loudest sound I heard in the park today was? (select one)

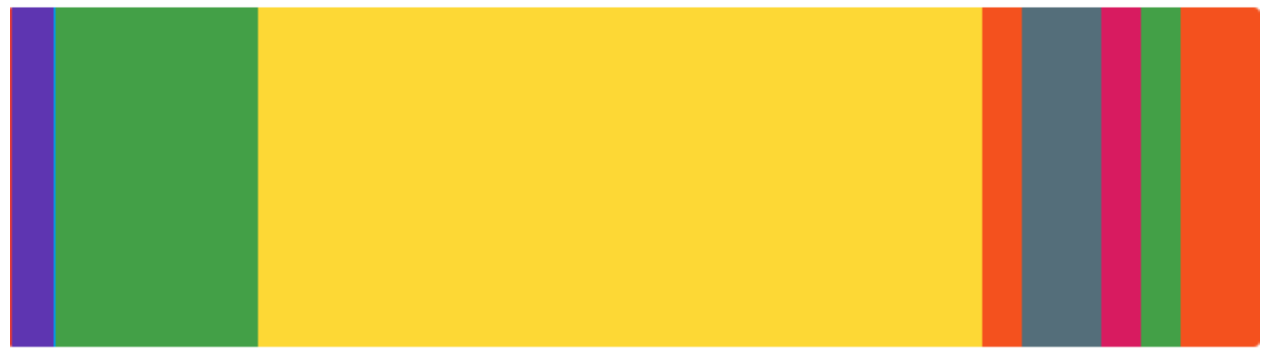

Natural sounds (e.g., natural sources, bird sounds, etc.) (0)

Human sounds (e.g., human activities, people, etc.) (1)

Technological sounds (e.g., artificial sounds, cell phones, etc.) (0)

Mechanical sounds (e.g., machine-related sounds, etc.) (5)

Traffic (e.g., cars, public transportation, road sounds, etc.) (18)

Music (e.g., from event, PA system, street performance, etc.) (1) Construction sounds (2)

Voices (e.g., conversations, etc.) (1) Children (e.g., voices, playing, etc.) (0)

Barking dogs (0) Event sounds (e.g., concert, special event, etc.) (0)

Water Feature (e.g., fountain, public art, etc.) (1) Weather (e.g., rain, wind, etc.) (0)

Other (2)

Overall - The loudest sound I heard in the park today was? (other)

Other - Text

Helicopter

Helicopter landing across the street on a parking garage. 
Overall - The most distant sound I heard in the park today was? (select one)

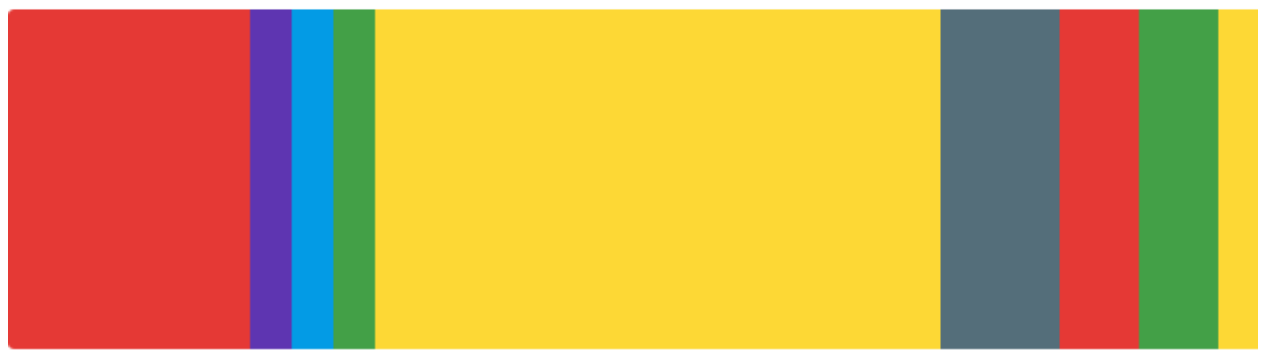

Natural sounds (e.g., natural sources, bird sounds, etc.) (6)

Human sounds (e.g., human activities, people, etc.) (1)

Technological sounds (e.g., artificial sounds, cell phones, etc.) (1)

Mechanical sounds (e.g., machine-related sounds, etc.) (1)

Traffic (e.g., cars, public transportation, road sounds, etc.) (14)

Music (e.g., from event, PA system, street performance, etc.) (0)

Construction sounds (3) Voices (e.g., conversations, etc.) (0)

Children (e.g., voices, playing, etc.) (2) Barking dogs (0)

Event sounds (e.g., concert, special event, etc.) (0)

Water Feature (e.g., fountain, public art, etc.) (2) Weather (e.g., rain, wind, etc.) (1)

Other (0)

Overall - The most distant sound I heard in the park today was? (other) Other - Text 
Overall - Overall, my favorite sound heard in the park today was? (select one)

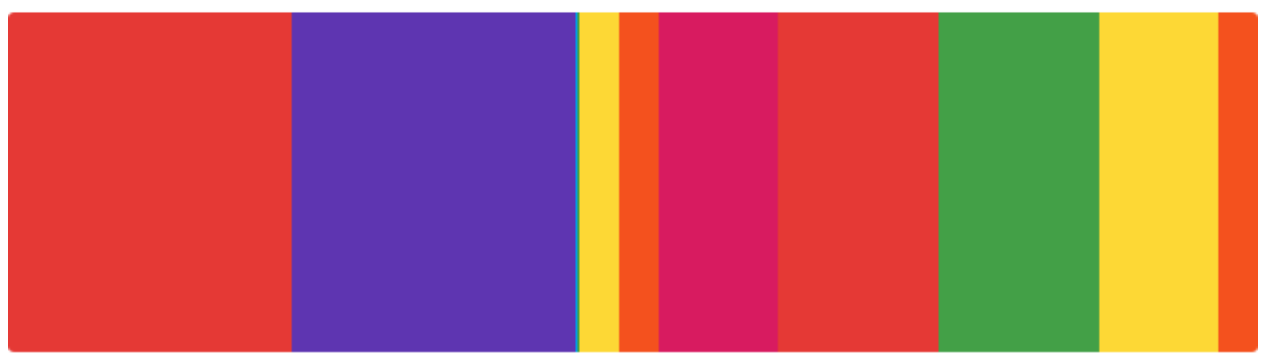

Natural sounds (e.g., natural sources, bird sounds, etc.) (7)

Human sounds (e.g., human activities, people, etc.) (7)

Technological sounds (e.g., artificial sounds, cell phones, etc.) (0)

Mechanical sounds (e.g., machine-related sounds, etc.) (0)

Traffic (e.g., cars, public transportation, road sounds, etc.) (1)

Music (e.g., from event, PA system, street performance, etc.) (1)

Construction sounds (0) Voices (e.g., conversations, etc.) (3)

Children (e.g., voices, playing, etc.) (4) Barking dogs (0)

Event sounds (e.g., concert, special event, etc.) (0)

Water Feature (e.g., fountain, public art, etc.) (4) Weather (e.g., rain, wind, etc.) (3)

Other (1)

Overall - Overall, my favorite sound heard in the park today was? (other)

Other - Text

Tires on steel grates from under Hawthorne Bridge 
Overall - Overall, my least favorite sound heard in the park today was? (select one)

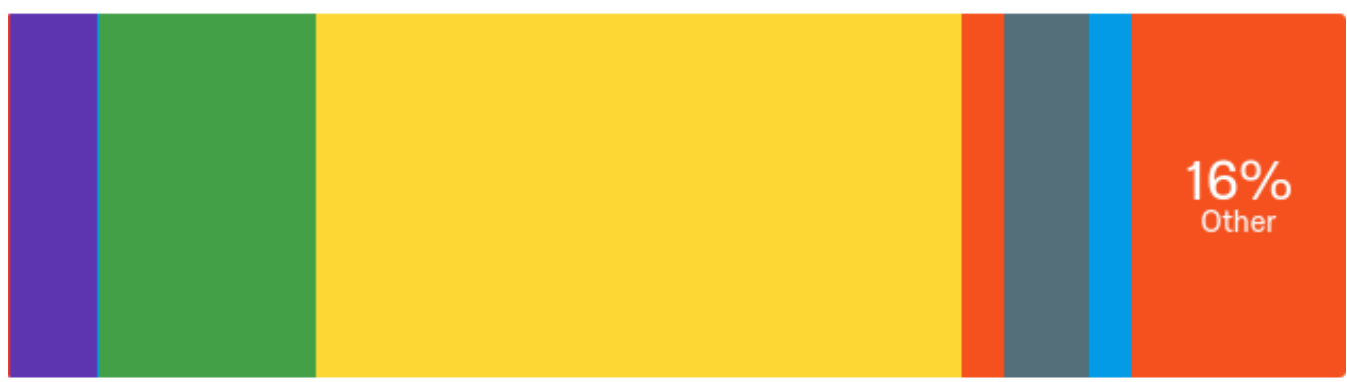

Natural sounds (e.g., natural sources, bird sounds, etc.) (0)

Human sounds (e.g., human activities, people, etc.) (2)

Technological sounds (e.g., artificial sounds, cell phones, etc.) (0)

Mechanical sounds (e.g., machine-related sounds, etc.) (5)

Traffic (e.g., cars, public transportation, road sounds, etc.) (15)

Music (e.g., from event, PA system, street performance, etc.) (1) $\quad$ Construction sounds (2)

Voices (e.g., conversations, etc.) (0) Children (e.g., voices, playing, etc.) (0)

Barking dogs (0) Event sounds (e.g., concert, special event, etc.) (1)

Water Feature (e.g., fountain, public art, etc.) (0) Weather (e.g., rain, wind, etc.) (0)

Other (5)

Overall - Overall, my least favorite sound heard in the park today was?

(other)

Other - Text

Angry yelling

Bike bells

Can honestly say none were offensive or out of place

The max line on the steel Bridge

Helicopter 
Overall - What sounds did you not expect to hear in the park today? (check all that a...

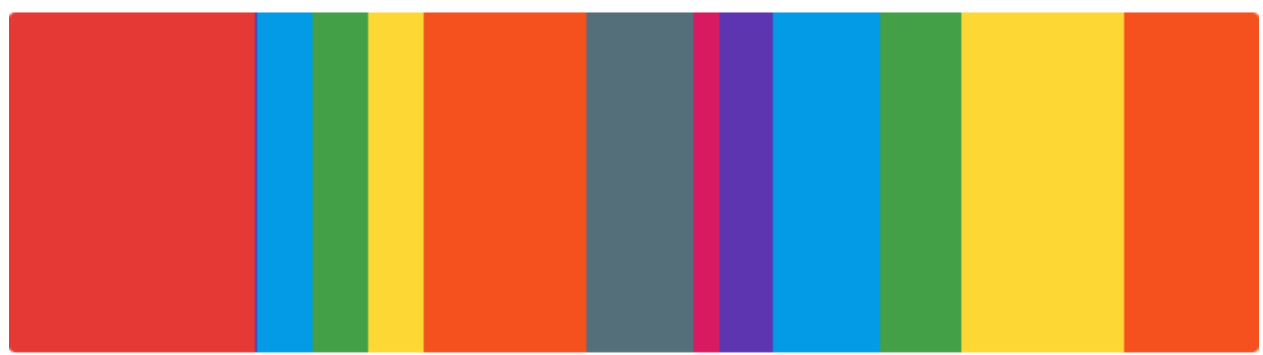

Natural sounds (e.g., natural sources, bird sounds, etc.) (9)

Human sounds (e.g., human activities, people, etc.) (0)

Technological sounds (e.g., artificial sounds, cell phones, etc.) (2)

Mechanical sounds (e.g., machine-related sounds, etc.) (2)

Traffic (e.g., cars, public transportation, road sounds, etc.) (2)

Music (e.g., from event, PA system, street performance, etc.) (6)

Construction sounds (4) $\square$ Voices (e.g., conversations, etc.) (1)

Children (e.g., voices, playing, etc.) (0) Barking dogs (2)

Event sounds (e.g., concert, special event, etc.) (4)

Water Feature (e.g., fountain, public art, etc.) (3) Weather (e.g., rain, wind, etc.) (6)

Other (5)

Overall - What sounds did you not expect to hear in the park today? (other)

Other - Text

Angry yelling

E scooters

None 
the whining sound from the elevator at the construction site on the new courthouse building those interested that I was able to pick that out of her all the other stuff

\section{Helicopter}

Overall - Overall, how do you rate the quality of the soundscape in the park?

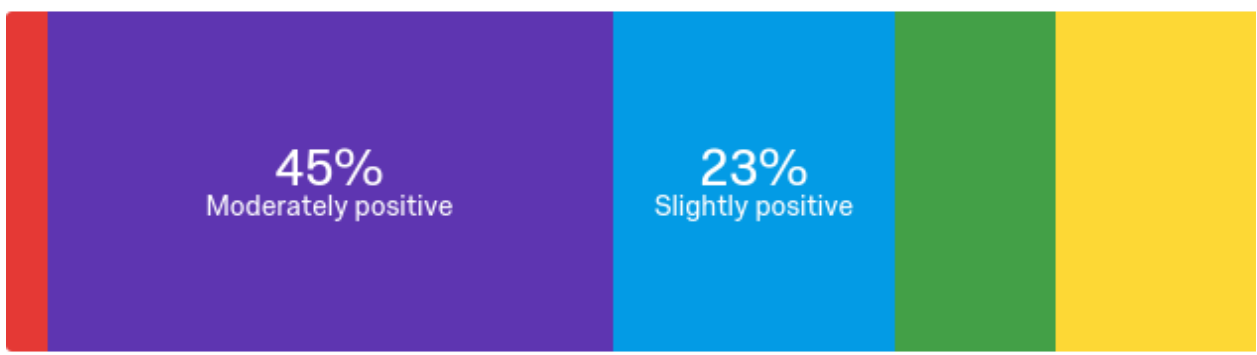

Extremely positive (1) $\square$ Moderately positive (14) $\quad$ Slightly positive (7)

Neither positive nor negative (4) Slightly negative (5) Moderately negative (0)

Extremely negative (0)

Overall - Has this soundwalk changed your perception or understanding of sound in par...

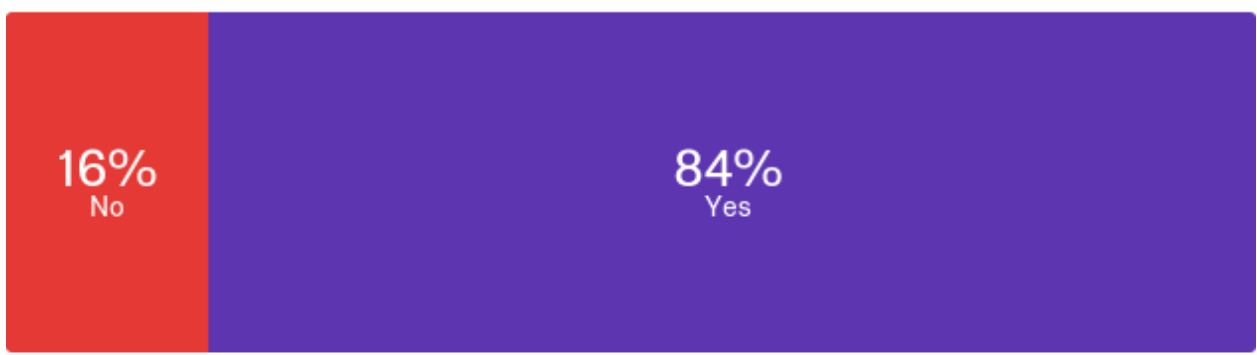

No (5) Yes (26) 


\section{Appendix F: Invitation to Participate \\ The Soniferous Experience of Public Space: A Soundscape Approach}

You are being asked to participate in a research study that is being conducted by Kenya Williams as part of his research towards receiving his doctoral degree from the Nohad A. Toulan School of Urban Studies \& Planning, at Portland State University in Portland, Oregon. This research is studying the soundscape of Tom McCall Waterfront Park, its meaning to practitioners and policy officials, and how their assessment and management of the soundscape could be incorporated on behalf of public goals.

Your opinions are critical to the future implementation of a soundscape approach in urban planning practice as well as the soundscape preferences of everyday park users.

\section{What is a soundscape?}

A soundscape is a sound or combination of sounds that forms or arises from an immersive environment. A soundscape is an acoustic environment consisting of events heard, rather than objects seen.

\section{What is a soundwalk?}

A soundwalk is a walk with a focus on listening to the environment. Soundwalking provokes deep listening, which exercises our ears and helps us develop a closer, more nuanced relationship with the soundscapes around us.

\section{What will happen if I decide to participate?}

If you agree to participate, the following things will happen:

\section{Part 1}

Participants will take a self-guided soundwalk through Governor Tom McCall Waterfront Park. Participants will be asked to answer survey questions on their mobile device or provided paper survey that correspond with each designated research area.

\section{Part 2}


After participants complete the soundwalk, a series of follow-up questions will be emailed to each participant. Participants will have a choice to answer questions via email or in-person interview.

\section{How long will I be in this study?}

Participation in this study will vary depending on the time it takes a participant to explore Tom McCall Waterfront Park and complete the survey questions of each designated research area.

\section{What are the benefits to being in this study?}

The data produced from this research about the soundscape within the park may reveal that sound is important to park users and as a result increase soundscape awareness in urban planning theory and practice. Furthermore, the urban planning literature does not recognize sound as a primary contributor to the experience of place or the urban environment. This research and data could be especially important to diminishing the gap in knowledge for urban planning theory and practice. In addition, this research and data could also be useful for cities that are creating new public spaces in areas that are public space deficient.

\section{How will my information be kept confidential?}

We will take measures to protect the security of all your personal information, but we cannot guarantee confidentiality of all study data. For this research, participants will only be asked questions that are related to this research study. The real names of participants will be excluded and each participant will be assign a pseudonym or number.

Data confidentiality and security during collection, analysis, and storage will be ensured through the following methods:

- All paper forms including consent forms and completed survey forms will be stored securely in a locked file cabinet.

- All removable media such as portable hard drives and SD cards will be stored securely in a locked file cabinet. If media is transferred, media will be stored on a password protected computer and/or cloud server.

- All electronic files will be compressed and encrypted before they are transferred from one location to another. 
- Data will not be accessed or stored on a laptop or any other device that is connected to a public Wi-Fi network.

- Once data collection and analysis is complete, all unused or irrelevant data will be either shredded or delete permanently deleted.

If you would like to participate in this study, please email Kenya Williams at kenya@pdx.edu to register for your self-guided soundwalk through Governor Tom McCall Waterfront Park or for more detailed participation information and instructions. 


\title{
Appendix G: Consent to Participate in Research
}

\section{The Soniferous Experience of Public Space: A Soundscape Approach}

\author{
September 1,2016-November 1, 2016
}

\section{Introduction}

You are being asked to participate in a research study that is being done by Kenya Williams as part of his research towards receiving his doctoral degree under the supervision of Ethan Seltzer, of the Nohad A. Toulan School of Urban Studies \& Planning, at Portland State University in Portland, Oregon. This research is studying the soundscape of Tom McCall Waterfront Park, its meaning to and impact on park visitors, and the roles that plans and planners can play in utilizing and managing the soundscape on behalf of public goals.

You are being asked to participate in this study because as an urban planning, landscape architecture or noise management professional, you have agency and a responsibility to either plan public spaces or regulate the sound that occurs in those spaces. Your opinions are critical to the future implementation of a soundscape approach in urban planning practice as well as the preferences of everyday park users.

This form will explain the research study, and will also explain the possible risks as well as the possible benefits to you. We encourage you to talk with your family and friends before you decide to take part in this research study. If you have any questions, please ask one of the study investigators.

\section{What will happen if I decide to participate?}

If you agree to participate, the following things will happen:

Participants will be guided through Governor Tom McCall Waterfront Park stopping at different seating areas, water features and open spaces. Participants will be asked to answer survey questions that correspond with each location. Additionally, participants will have the opportunity to provide open-end comments and descriptions on the survey form at any time during the soundwalk.

\section{How long will I be in this study?}

Participation in this study will take a total of 2 hours over a period of 1 day. 


\section{What are the risks or side effects of being in this study?}

There are risks of stress, emotional distress, inconvenience and possible loss of privacy and confidentiality associated with participating in a research study.

There are no risks to individuals participating in this research beyond those that exist in daily life.t.

For more information about risks and discomforts, ask the investigator.

\section{What are the benefits to being in this study?}

The data produced from this research about sound preferences within the park may reveal that sound is important to park users and as a result increase soundscape awareness in urban planning theory and practice. Furthermore, the urban planning literature does not recognize sound as a primary contributor to the experience of the urban environment. This research and data could be especially important to diminishing the gap in knowledge for urban planning theory and practice. In addition, this research and data could also be useful for the City of Portland's goal of creating new public spaces as part of complete neighborhoods by 2035 in areas of the city that are public space deficient as described in The Portland Plan, and in other cities facing similar challenges and attempting to meet similar goals.

\section{How will my information be kept confidential?}

We will take measures to protect the security of all your personal information, but we cannot guarantee confidentiality of all study data. For this research, participants will only be asked questions that are related to this research study. The real names of participants will be excluded and each participant will be assign a pseudonym or number.

Data confidentiality and security during collection, analysis, and storage will be ensured through the following methods:

- All paper forms including consent forms and completed survey forms will be stored securely in a locked file cabinet.

- All removable media such as portable hard drives and SD cards will be stored securely in a locked file cabinet. If media is transferred, media will be stored on a password protected computer and/or cloud server.

- All electronic files will be compressed and encrypted before they are transferred from one location to another.

- Data will not be accessed or stored on a laptop or any other device that is connected to a public Wi-Fi network. 
- Once data collection and analysis is complete, all unused or irrelevant data will be either shredded or delete permanently deleted.

Information contained in your study records is used by study staff. The Portland State University Institutional Review Board (IRB) that oversees human subject research and/or other entities may be permitted to access your records, and there may be times when weare required by law to share your information. It is the investigator's legal obligation to report child abuse, child neglect, elder abuse, harm to self or others or any life-threatening situation to the appropriate authorities, and; therefore, your confidentiality will not be maintained.

Your name will not be used in any published reports about this study.

Will I be paid for taking part in this study?

Participants will not be compensated but food and beverages will be provided before or after the survey period in the park.

\section{Can I stop being in the study once I begin?}

Your participation in this study is completely voluntary. You have the right to choose not to participate or to withdraw your participation at any point in this study without penalty or loss of benefits to which you are otherwise entitled.

\section{Whom can I call with questions or complaints about this study?}

If you have any questions, concerns or complaints at any time about the research study, Kenya Williams, or his/her associates will be glad to answer them at 503-267-2224.

If you need to contact someone after business hours or on weekends, please call 503-267-2224 and ask for Kenya Williams.

\section{Whom can I call with questions about my rights as a research participant?}

If you have questions regarding your rights as a research participant, you may call the PSU Office for Research Integrity at (503) 725-2227 or 1(877) 480-4400. The ORI is the office that supports the PSU Institutional Review Board (IRB). The IRB is a group of people from PSU and the community who provide independent oversight of safety and ethical issues related to research involving human participants. For more information, you may also access the IRB website at https://sites.google.com/a/pdx.edu/research/integrity. 


\section{CONSENT}

You are making a decision whether to participate in this study. Your signature below indicates that you have read the information provided (or the information was read to you). By signing this consent form, you are not waiving any of your legal rights as a research participant.

You have had an opportunity to ask questions and all questions have been answered to your satisfaction. By signing this consent form, you agree to participate in this study. A copy of this consent form will be provided to you.

Name of Adult Subject (print) Signature of Adult Subject $\quad$ Date

\section{INVESTIGATOR SIGNATURE}

This research study has been explained to the participant and all of his/her questions have been answered. The participant understands the information described in this consent form and freely consents to participate.

Name of Investigator/ Research Team Member (type or print)

(Signature of Investigator/ Research Team Member) Date 


\section{Appendix H: The Textural Description}

\section{The Perceived Atmosphere of Activities at Tom McCall Waterfront Park}

Survey respondents reported a wide spectrum of perspectives about the soundscape at Tom McCall Waterfront Park. It's essential to consider the experiences narrated by the participants (see Appendix C). Some main aspects are highlighted below.

\section{The Illustrative Statement about the Soniferous Experience of Governor Tom McCall Waterfront Park.}

Textural description

The park is immense. It was the first thing that caught my attention. It is challenging to cover all the places it offers. In a way, it is another reality offering an atmosphere that is a pure vibration of colors, smells, and sounds. The park fills the senses and stimulates them, provoking a strange sensation of pleasure and tranquility.

It is possible to feel isolated from the world in this park... except for the mechanical sounds that remind you that indeed, you are in the center of a big city.

The view of the river and the bridges delight you in the distance.

Being attracted by two choices, you fight with yourself: should I go and walk among the cherry blossom trees, or should I stay alongside the river listening to the water and the sounds of the city?

Meanwhile, the bicycles continuously pass, giving me the inspiration to venture and explore the distant places that are seen far away.

Visiting this park is a strange experience that reconciles you with nature in a timeless relationship, while at the same time, it is reminding you that civilization is very close, almost within reach. 


\section{Appendix I: The Final Phenomenological Nature of the Soundscape Experience of the Governor Tom McCall Waterfront Park}

This section presents the final meaningful description of the phenomenon that we have studied, i.e., the soundscape and the practitioners' soniferous experiences while being in Tom McCall Waterfront Park.

This research aimed to explore the practitioners' experiences when they did a soundwalk of Tom McCall Waterfront Park. Our participants, thirty-one professionals currently working in areas related to public urban spaces that are designed for the use and enjoyment by the public, held the following positions: urban planner, landscape designer, architects, and city officials working in different offices, such as the Noise Control Office, Portland Parks \& Recreation, Office of Community \& Civic Life, and the Bureau of Planning and Sustainability. These individuals have broad experiences in their areas, i.e., they could be considered experts whose opinions and valid points of view were taken into account when evaluating Tom McCall Waterfront Park's soundscape.

The participants' soniferous experiences have shown the park's soundscape's enormous complexity, with a particular focus on transportation noise. They shared their impressions, suggested considerations to balance the park's soundscape, and transformed the public's experience of an area located in downtown Portland, surrounded by many freeways that impact the park experience with consistent noise.

The following composite first-person narratives capture the themes and sub-themes in one narrative (Wertz et al. 2011; Conklin, 2007). The final phenomenological account allows us to understand the phenomenological experience of taking a soundwalk in Tom McCall Waterfront Park.

The park is immense! It was the first thing that caught my attention. It is challenging to cover all the places it offers. I think that entering the park is arriving to another reality that gives me an urban atmosphere composed of a mix of human, nature, and civilization's sounds. I believe that it is a pure vibration of colors, smells, and noises. The park filled my senses and stimulated me by provoking a strange sensation of pleasure, tranquility, and attentiveness. Really, I think that it was almost possible to feel isolated from the world in this park... except for the mechanical sounds that continuously remind me that indeed, I was in the downtown of a city. 
I realized that there were many elements whose sounds come together to create the soundscape of the park. I heard the horns of the vehicles passing by, and even further noises were coming from the freeways and the helicopters landing. Thus, these noises startled me altering the quiet I was looking for, I believe that those sounds do not combine, do not fit together, with the sounds of birdsong, the water of the fountain, and the breeze blowing between the branches of the trees. Ifelt that the highways were a sharp contrast when compared to the sounds of nature. This is why I considered that this was a park of contrast, the juxtaposed sounds can saturate the visitor. I finally realized that there are zones where the traffic and vehicle noises dominate the soundscape, and that alters me and strongly affects my visit to the park.

What were the sources producing these noises? That could be a good start to alleviate the sharp contrast between natural sounds and vehicle noises.

Looking for calm and tranquility during the soundwalk, I was startled at times by other unexpected factors. When I entered the park, I was scared because there were not many people, and suddenly, I found some persons sleeping in the park, who apparently are houseless. And urine smells! That was a surprise to me since I was not expecting that odor in the park. To complete the scene, in the distance, I could see some people possible smoking drugs. I decided to get away from that area. In spite of how pleasant the park can be, I strongly believe that some things must be amended, such as the issues of homeless people and drugs.

I would like to say that for me, the park is a living entity! It is alive, and that can be felt as one enters any of its multiple walkways. Some walkers may feel satisfied with the sounds of the park, and the noise of the vehicles does not alter their experience... However, I do wonder how to harmonize the sounds, which seems to be somewhat tricky to achieve, given the proximity of many streets and freeways. I realize that the park is downtown, it can be challenging to mitigate the natural noises of a city this size. Perhaps, it would be interesting to integrate other sounds, I would place more water sources, more trees, or even put feeders to attract more birds. I believe that metallic tones from artistic sculptures combined with sounds of water running in the fountain, pure air, and birdsongs, would help to balance the soundscape of the park. With such pleasant sounds, I would forget somewhat about the sounds of the highways, and this would make my walk more pleasant. Only, I wonder how to achieve it?

In addition, there are music events, whose sounds came to me while I completed my soundwalk. Large speakers announced the next event reminding me of the people movement that is typical in these types of events. People enjoy these shows that sometimes go on at night. I only hoped that the permitted schedules were respected in terms of hours and high volume. I admit that a park is indeed an ideal place for these types of festivals and social meetings... In the end, these features are part of the park's identity, as if it were a living being in a constant give-and-take with the visitor.

The view of the river and the bridges delighted me in the distance. As I approached the side of the park that borders the river, I felt a calmer area where 
new ventures, small restaurants, or stores, could be developed. It occurred to me that walks along the river bank could be a different attraction that would charm people, provoking the opening of new spaces where it would be possible to enjoy the river sounds.

What is there was a plan to redevelop the park? If so, I would like them to take into account the visitors' opinions. Why? Because I cross this park every day, and it allowed me to form a useful idea about what I would like to find or what I would like to modify in this space. I would increase nature's sounds with more trees to isolate the noises. Also, I would build paths on the banks of the river. I would develop areas dedicated only to musical events, and meanwhile, I will maintain the infrastructure of the area. I genuinely believe that these will be the immediate demands that I would make if someone asked me for recommendations that considers the soundscape of Tom McCall Waterfront Park.

At this point, I felt that I was attracted by two parallels, I fight with myself: must I go and walk among the cherry blossoms, or should I stay alongside the river listening to the water and the sounds of the city? Meanwhile, the bicycles continuously pass, giving me the inspiration to venture and explore the distant places that are heard far away. Visiting this park was a strange experience that reunites me with nature, in a timeless relationship. At the same time, it is reminding me that civilization and the grind of a modern city is very close, almost within reach and unavoidable. 


\section{Appendix J: Approved IRB Application}

\section{舟P Portland $\underset{\text { UNIVERSITY }}{\text { State }}$}

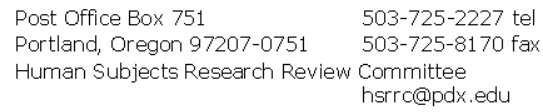

Date: July 7,2016

To: Ethan Seltzer; seltzer@pdx.edu; Kenya D. Williams, kenya@pdx.edu

From: Karen Cellarius, HSRRC Chair

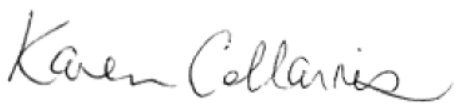

Re: HSRRC approval for your project titled, "The Soniferous Experience of Public Space: A Soundscape Approach"

HSRRC Proposal \# 163835

Review Type: Exempt, Category 2

In accordance with your request, the Human Subjects Research Review Committee has reviewed your proposal referenced above for compliance with PSU and DHHS policies and regulations covering the protection of human subjects. The Committee is satisfied that your provisions for protecting the rights and welfare of all subjects participating in the research are adequate, and your project is approved. Please note the following requirements:

Approval: You are approved to conduct this research study after receipt of this approval letter, and the research must be conducted according to the plans and protocol submitted (approved copy enclosed).

Consent: Signed consent is required from all participants in this study.

Changes to Protocol: Any changes in the proposed study, whether to procedures, survey instruments, consent forms or cover letters, must be outlined and submitted to the Committee immediately. The proposed changes cannot be implemented before they have been reviewed and approved by the Committee.

Adverse Reactions and/or Unanticipated Problems: If any adverse reactions or unanticipated problems occur as a result of this study, you are required to notify the Committee immediately. If the issue is serious, approval may be withdrawn pending an investigation by the Committee.

Completion of Study: Please notify the Committee as soon as your research has been completed. Study records, including protocols and signed consent forms for each participant, must be kept by the investigator in a secure location for three years following completion of the study (or per any requirements specified by the project's funding agency).

If you have questions or concerns, please contact the Office of Research Integrity in the PSU RSP at 503-7252227,1600 SW $4^{\text {th }}$ Ave., Market Center Building, Suite 620. 
Human Subject Research Review Committee

PSU Research and Strategic Partnerships (RSP) Page 1 of 9

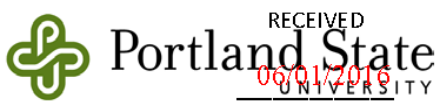

Portland State University

IRB APPLICATION FOR EXEMPT REVIEW

Instructions: PSU faculty and students must submit any research plan involving Human Subjects to the IRB for review. If you believe that your project meets one of the regulatory defined exemption categories, you may submit this shorter form or the full review form. If you submit this form only and the IRB determines that the work is not exempt, you will be asked to submit a completed application for expedited/full review. This may slow down your approval process. If you believe that the activities do not meet the definition of "human subjects" or of "research" complete and submit the Review not required form to hsrrc@pdx.edu.

\section{Section 1: Investigator's Assurance}

Faculty advisor: Ethan Seltzer E-Mail seltzer@pdx.edu

Co-Principal Investigator E-Mail

Other Personnel (GA, Project Mgr., etc.) E-Mail

Dept. TSUSP Campus Mail Code USP/URBN 350 Preferred Phone \# 503-725-5169

Title of Proposal The Soniferous Experience of Public Space: A Soundscape Approach

Mailing Address TSUSP; USP/URBN 350

Proposed Duration of Project (months/years) 18 mos. Anticipated Start Date: June 15, 2016

Funded?

Yes

$\square$ Not yet (Application has been submitted)

$\square$ No [Skip to Investigator's Responsibilities]

Type of Funding:

$\square$ Federal $\square$ Federal pass-through $\square$ State $\square$ Foundation $\square$ other

Funding Agency: PIAF \#

STUDENTS ONLY:

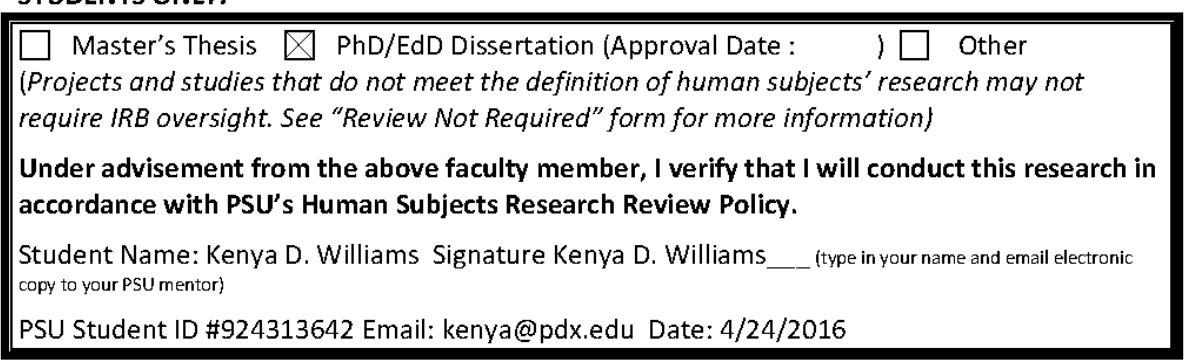

APPROVED

IRB APPLICATION FOR EXEMPT REVIEW

1

07/07/2016

Portland State University

Office of Research Integrity 
Human Subject Research Review Committee

PSU Research and Strategic Partnerships (RSP) Page 2 of 9

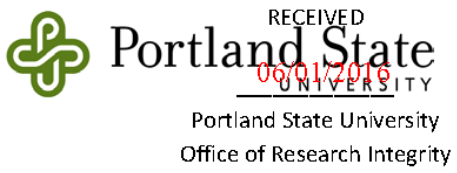

Investigator's Responsibilities and Assurances:

Office of Research Integrity

(Mark each box with an $\mathbf{\nabla}$ wen understood/agreed/certified)

I understand PSU's policies concerning research involving human subjects and:

1. $x$ I understand that I have ultimate responsibility for the protections of the rights and welfare of human participants, the conduct of this study, and the ethical performance of this research.

2. $x I$ will maintain IRB related documents (to include signed consent forms as applicable) for a minimum of three years after the completion of the study.

3. $x I$ understand that it is my responsibility to ensure that all study personnel receive the mandatory human subjects' research protection education (either $\mathrm{CITI}$ or $\mathrm{NIH}$ ) and to maintain a training documentation file.

I agree to:

4. $x$ Comply with all PSU/IRB policies, decisions, conditions and requirements.

5. $x$ Obtain prior approval from the IRB before amending or altering the research protocol or changing the approved consent/assent form;

6. $x$ Notify the Office of Research Integrity of the development of any financial interest not already disclosed.

7. $x$ Notify the Office of Research Integrity for all adverse events and unanticipated problems as soon as possible. In case of DHHS supported activities, I will also report these problems to the Department of Health and Human Services (through the respective granting office).

I certify that:

8. x The time and resources are available to complete this project.

9. $x$ The equipment, facilities, and procedures to be used in this research meet recognized standards for safety

10. $x$ New information that may affect the risk-benefit assessment for this research will be reported to the PSU Office of Research Integrity.

11. $x I$ agree to ensure adequate supervision of all research study personnel and to meet with the investigator(s), if different then myself, on a regular basis to monitor progress.

12. $x$ The information provided in this application and all attachments is complete and correct.

Signature of Principal Investigator or Faculty Advisor: Ethan Seltzer Date: May 24, 2016

APPROVED

IRB APPLICATION FOR EXEMPT REVIEW

07/07/2016

Portland State University

Office of Research Integrity 
Human Subject Research Review Committee

Instructions for students only:

sertation prior to $\underline{\text { IRB }}$

- Graduate Studies requires PhD students to h submission (contact GSE for more details).

- Graduate and/or undergraduate students cannot function as Primary investigators (PIs).

- The faculty advisor overseeing the student research must complete and sign the investigator's Assurance form as PI

- The student must sign the bottom portion and provide their PSU ID number.

- The signed application must be submitted by the advisor/PI.

- In accordance with Human Subjects Research professional standards student investigators may not include themselves as a human participant in their research. They should also avoid recruitment of human participants from their immediate circle of family, friends and associates.

Instructions: Federal regulations and PSU policy specify that certain activities are excluded from being considered exempt. Place an $\boldsymbol{\otimes}$ in the Yes or No box for each question in the following checklist. If yes to any of the questions (1-12), the project does not qualify for exempt status. Stop and complete the IRB application for Expedited/Full Review.

\section{Section 2. Activities that do NOT qualify for an exemption:}

If yes to any of questions (1-12) below, the project does not qualify for exempt status. Stop and complete the IRB application for Expedited/Full Review.

1. $\triangle$ No $\square$ Yes Does the project involve prisoners, or participants confined in a correctional or detentional facility?

2. $\triangle$ No $\square$ Yes Do survey or interview techniques include minors as subjects? (Applies to exemption category \#2 only).

3. No $\square$ Yes Will minors be observed such that the investigator participates in the activities being observed (Applies to exemption category \#2 only).

4. $\triangle$ No $\square$ res Does the project include Food and Drug Administration (FDA) regulated research (Applies to exemption categories 1-5 and includes projects for which the data will be submitted to or held for inspection by the FDA, or projects for which the investigator gathers data on participants who serve as controls for participants who receive FDA-regulated drugs or medical devices, other than in the course of medical practice.)

5. $\nabla$ No $\square$ Yes Will participants be asked to report their own or others' sexual experiences, alcohol or drug use, and will their identities be known to you?

6. $\triangle$ No $\square$ res Are the participants' data directly or indirectly identifiable, and could these data place subjects at risk for criminal or civil liability, or might they be damaging to subjects' financial standing, employability or reputation?

7. $\triangle$ No $\square$ Yes Are participants involved who may not be legally/mentally/ APPROVED 
Human Subject Research Review Committee

PSU Research and Strategic Partnerships (RSP) Page 4 of 9

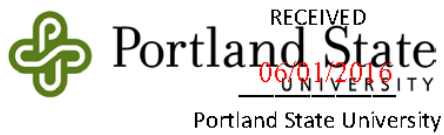

cognitively competent? (Exception to this is for Category Officeofiafeduldatlongrity research.)

8. $\$ No $\square$ Yes Are personal records (medical, academic, etc.) used with identifiers and without written consent?

9. $\mathrm{Xno} \square$ Yes

Will alcohol or drugs be administered? (Exception is wine tasting activities where alcohol is expectorated after tasting rather than swallowing.)

10. $\mathrm{N}$ No $\mathrm{W}$ Yes Will blood or body fluids be drawn?

11. $\mathrm{N}$ No $\mathrm{W}$ Yes Will you be using pregnant women by design?

12. $\triangle$ No $\square$ Yes Are live fetuses participants in this research?

NOTE: Even if you answered no to all of the above, your study may still not qualify as exempt. The IRB makes the final decision as to whether planned activities are exempt or not.

\section{Section 3. Types of research that QUALIFY for exemption IF LIMITED to specific} activities:

Instructions: Your project may qualify for an exemption if the ONLY involvement of human subjects falls within these categories below. Check the appropriate categories that apply to your research project.

(1) Research conducted in established or commonly accepted educational settings, involving normal educational practices, such as

(i) research on regular and special educational instructional strategies, or

(ii) research on the effectiveness of or the comparison among instructional techniques, curricula, or classroom management methods.

(2) Research involving the use of educational tests (cognitive, diagnostic, aptitude, achievement), survey procedures, interview procedures or observation of public behavior, unless:

(i) information obtained is recorded in such a manner that human subjects can be identified, directly or through identifiers linked to the subjects; and

(ii) any disclosure of the human subjects' responses outside the research could reasonably place the subjects at risk of criminal or civil liability; or

(iii) be damaging to the subjects' financial standing, employability, or reputation.

PLEASE NOTE: According to 45 CFR 46.401(b), this exemption does NOT apply to survey or interview procedures when the participants are minors. This exemption also does not apply to observational studies of minors when the investigator interacts or intervenes with the minors.

IRB APPLICATION FOR EXEMPT REVIEW 4
APPROVED

07/07/2016

Portland State University

Office of Research Integrity 
Human Subject Research Review Committee

PSU Research and Strategic Partnerships (RSP) Page 5 of 9

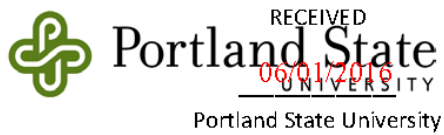

(3) Research involving the use of educational tests (cognitive, diagnoffice, afpetifeurche, Integrity achievement), survey procedures, interview procedures, or observation of public behavior that is not exempt under category (2) of this section, if:

(i) the human subjects are elected or appointed public officials or candidates for public office; or

(ii) federal statute(s) require(s) without exception that the confidentiality of the personally identifiable information will be maintained throughout the research and thereafter

(4) Research involving the collection or study of existing data, documents, records, pathological specimens, or diagnostic specimens, if these sources are publicly available or if the information is recorded by the investigator in such a manner that subjects cannot be identified, directly or through identifiers linked to the subjects. PLEASE NOTE: According to the Office for Human Research Protections (OHRP), "to qualify for this exemption the data, documents, records, or specimens must be in existence before the project begins.

(5) Research and demonstration projects which are conducted by or subject to the approval of department or agency heads, and which are designed to study, evaluate, or otherwise examine:

(i) public benefit or service programs;

(ii) procedures for obtaining benefits or services under those programs;

(iii) possible changes in or alternatives to those programs or procedures;

(iv) possible changes in methods or levels of payment for benefits or services under those programs;

(v) projects for which there is no statutory requirement for IRB review;

(vi) projects that do not involve significant physical invasions or intrusions upon the privacy interests of participants;

(vii) authorization or concurrence by funding agencies that exemption from IRB review is acceptable.

(6) Taste and food quality evaluation and consumer acceptance studies:

(i) if wholesome foods without additives are consumed or

(ii) if a food is consumed that contains a food ingredient at or below the level and for a use found to be safe, or agricultural chemical or environmental contaminant at or below the level found to be safe, by the Food and Drug Administration or approved by the Environmental Protection Agency or the Food Safety and Inspection Service of the U.S. Department of Agriculture.

APPROVED

07/07/2016

Portland State University

Office of Research Integrity 
Human Subject Research Review Committee

Section 4. Justification of Exemption Category

Office of Research Integrity

Instructions: Complete explanation under the category selected in Section 3 above.

Category 1: Specify whether 1 (i) or $\mathbf{1}$ (ii) applies and briefly explain: N/A

Category 2: Explain briefly how conditions 2(i), 2(ii) and 2 (iii) will not occur:

For this research, participants will only be asked questions that are related to this research study. The real names of participants will be excluded and each participant will be assign a pseudonym or number. I will stay true to the responses of the participants by using verbatim quotes to any open-end questions and offer member checks. After the survey, participants will be allowed to read transcripts of their responses and will be allowed to modify their responses if needed.

Category 3: Explain why conditions 2(i) and 2(ii) cannot be met; and attach a copy of test/survey/interview questions or items; and either assure and briefly explain that condition 3(ii) applies, or explain subject's public office and how it precludes anonymity [i.e., 3 (i)]: N/A

Category 4: Briefly explain the nature of the existing data/documents and briefly explain either their public availability or the procedures to ensure anonymity and confidentiality: N/A

Category 5: Briefly explain method by which the project is reviewed and approved by a federal department/agency head; and identify and describe which of the 5(i)-5(iv) categories apply: N/A

Category 6: Assure that condition 6(i) will be met; and assure via documentation regarding approved safety levels that condition 6 (ii) will be met: N/A

\section{Section 5. Study Specific Questions}

Instructions: Provide below brief details of the proposed research. Use lay language and avoid technical terms.

1. Specific Aims / Research Question / Study Goals:

The purpose of this research is to explore the role of the soundscape in understanding and managing critical public spaces. This research will examine the soundscape of Tom McCall Waterfront Park, its meaning to and impact on park visitors, and the roles that plans and planners can play in utilizing and managing the soundscape on behalf of public goals. By doing so, this research will add to the ways that planning can contribute to creating livable, meaningful cities.

This study will address this research question:

RQ1. How does the soundscape reveal participant understanding of Governor Tom McCall Waterfront Park and provide a model for enhancing the soniferous experience of the park?

IRB APPLICATION FOR EXEMPT REVIEW

6
APPROVED

07/07/2016

Portland State University

Office of Research Integrity 
Human Subject Research Review Committee

PSU Research and Strategic Partnerships (RSP) Page 7 of 9

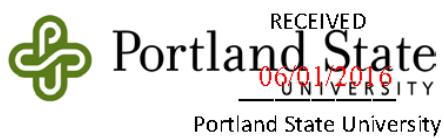

This question connects to the purpose of this study by providing informatffif abouthoblhtegrity people understand the relationship between their experiences while in the park and the soundscape they experience in the park. This is important because it has the potential to reveal what activities in the park impact the soundscape and how the soundscape may impact users or activities. This question also connects to the purpose of this study by serving as a guide to potentially enhancing the soundscape of the park.

2. Participants (describe your inclusion criteria and methods of recruiting):

The ideal participant for this research will be an individual who does not identify as deaf or hard of hearing. The candidate should be familiar with the location of the park and has visited the park at least one time prior to the survey. This is important because participants should be familiar with the topography of the park and accessibility options since participants will move throughout the park.

Individuals will be asked to participate in this research by various outreach methods such as person to person, phone and email. Participants will not be compensated but food and beverages will be provided before or after the survey period in the park. Surveys at the park will start when at least 10 individuals have responded, been vetted, scheduled and agree to participate in the research. The group of participants I will contact to participate in this study will include professionals and representatives drawn from:

- The City of Portiand - Office of Planning and Sustainability

- The City of Portiand - Noise Management Office

- Port of Portiand-Noise Management Office

- Port of Portland-Citizen Noise Advisory Committee

- Various urban planning and landscape architecture firms

Urban planning, landscape architecture and noise management professionals will be recruited to participate in this study due to the fact that they have agency and a responsibility to either plan/design public spaces or regulate the sound that occurs in those spaces. All of these select groups are critical to the future implementation of a soundscape approach in urban planning practice as well as the preferences of everyday park users.

3. Procedures (describe your data collection methods, etc.):

The primary data collection tool for this research will be a sound preference survey that will be administered to participants. Participants will be guided through Governor Tom McCall Waterfront Park stopping at different seating areas, water features and open spaces. Participants will be asked to answer questions that correspond with each location. Additionally, soundwalk participants will have the opportunity to provide openend comments and descriptions on the survey form at any time during their time in the park.

APPROVED

07/07/2016

Portland State University

Office of Research Integrity 
Human Subject Research Review Committee

PSU Research and Strategic Partnerships (RSP) Page 8 of 9

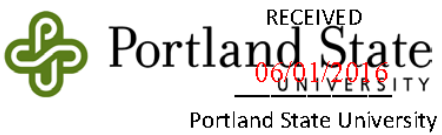

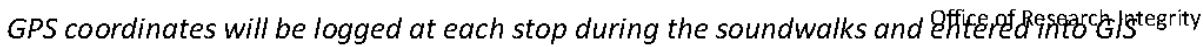
software to produce maps of the soundwalk and surrounding features such as topographical feature and proximity to major arterials. The maximum number of participants per survey will be limited to 6 people in order to ensure that all survey questions can be completed in a reasonable amount of time - two hours or less.

All participants will be assigned a number and will only be referenced by their assigned number as a measure to protect their privacy. The duration of the survey is expected to be completed within two hours.

4. Data confidentiality and security during collection, analysis, and storage: Data confidentiality and security during collection, analysis, and storage will be ensured through the following methods:

- All paper forms including consent forms and completed survey forms will be stored securely in a locked file cabinet.

- All removable media such as portable hard drives and SD cards will be stored securely in a locked file cabinet. If media is transferred, media will be stored on a password protected computer and/or cloud server.

- All electronic files will be compressed and encrypted before they are transferred from one location to another.

- Data will not be accessed or stored on a laptop or any other device that is connected to a public Wi-Finetwork.

- Once data collection and analysis is complete, all unused or irrelevant data will be either shredded or delete permanently deleted.

5. Risks (describe any potential risks to participants-physical, psychological, social, legal or other): N/A

6. Benefits (describe any benefits to the participants and society):

The data produced from this research about sound preferences within the park may reveal that sound is important to park users and as a result increase soundscape awareness in urban planning theory and practice. Furthermore, the urban planning literature does not recognize sound as a primary contributor to the experience of the urban environment. This research and data could be especially important to diminishing the gap in knowledge for urban planning theory and practice. In addition, this research and data could also be useful for the City of Portland's goal of creating new public spaces as part of complete neighborhoods by 2035 in areas of the city that are public space deficient as described in The Portland Plan, and in other cities facing similar challenges and attempting to meet similar goals.

IRB APPLICATION FOR EXEMPT REVIEW 8
APPROVED

07/07/2016___

Portland State University

Office of Research Integrity 
Human Subject Research Review Committee

PSU Research and Strategic Partnerships (RSP) Page 9 of 9

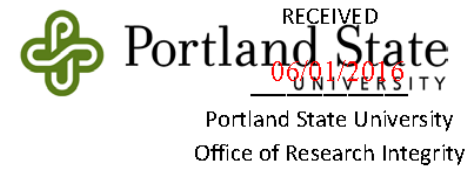

Section 6. Attachments

Office of Research Integrity

Instructions: Attach the following materials with the protocol submission:

1. Required $\mathrm{CITI}$ or NIH human subjects education training certificates (Instructions: https://sites.google.com/a/pdx.edu/research/integrity/responsible-conduct)

2. Consent form / consent process description

3. Surveys/interview questions

*Completed applications must be submitted by email to hsrrc@pdx.edu*

DATA COLLECTION CANNOT BEGIN UNTIL APPROVAL IS GRANTED BY IRB!

IRB APPLICATION FOR EXEMPT REVIEW
APPROVED

07/07/2016

Portland State University

Office of Research Integrity 


$$
\begin{array}{cc}
\text { RECEIVED } & 06 / 01 / 2016 \\
\text { The Portland State University } & \begin{array}{c}
\text { Portland State University } \\
\text { Office of Research Integrity }
\end{array} \\
\text { Consent to Participate in Research } &
\end{array}
$$

The Soniferous Experience of Public Space: A Soundscape Approach

\author{
September 1,2016- November 1, 2016
}

\title{
Introduction
}

You are being asked to participate in a research study that is being done by Kenya Williams as part of his research towards receiving his doctoral degree under the supervision of Ethan Seltzer, of the Nohad A. Toulan School of Urban Studies \& Planning, at Portland State University in Portland, Oregon. This research is studying the soundscape of Tom McCall Waterfront Park, its meaning to and impact on park visitors, and the roles that plans and planners can play in utilizing and managing the soundscape on behalf of public goals.

You are being asked to participate in this study because as an urban planning, landscape architecture or noise management professional, you have agency and a responsibility to either plan public spaces or regulate the sound that occurs in those spaces. Your opinions are critical to the future implementation of a soundscape approach in urban planning practice as well as the preferences of everyday park users.

This form will explain the research study, and will also explain the possible risks as well as the possible benefits to you. We encourage you to talk with your family and friends before you decide to take part in this research study. If you have any questions, please ask one of the study investigators.

\section{What will happen if I decide to participate?}

If you agree to participate, the following things will happen:

Participants will be guided through Governor Tom McCall Waterfront Park stopping at different seating areas, water features and open spaces. Participants will be asked to answer survey questions that correspond with each location. Additionally, participants will have the opportunity to provide open-end comments and descriptions on the survey form at any time during the soundwalk.

\section{How long will I be in this study?}

Participation in this study will take a total of 2 hours over a period of 1 day.

\section{What are the risks or side effects of being in this study?}

There are risks of stress, emotional distress, inconvenience and possible loss of privacy and confidentiality associated with participating in a research study.

$$
\begin{gathered}
\text { APPROVED } \\
-07 / 07 / 2016 \overline{-}-\overline{\text { Portland State University }} \\
\text { Office of Research Integrity }
\end{gathered}
$$


There are no risks to individuals participating in this research beyond those thadeisistinedaitgh Integrity life.

For more information about risks and discomforts, ask the investigator.

\title{
What are the benefits to being in this study?
}

The data produced from this research about sound preferences within the park may reveal that sound is important to park users and as a result increase soundscape awareness in urban planning theory and practice. Furthermore, the urban planning literature does not recognize sound as a primary contributor to the experience of the urban environment. This research and data could be especially important to diminishing the gap in knowledge for urban planning theory and practice. In addition, this research and data could also be useful for the City of Portland's goal of creating new public spaces as part of complete neighborhoods by 2035 in areas of the city that are public space deficient as described in The Portland Plan, and in other cities facing similar challenges and attempting to meet similar goals.

\section{How will my information be kept confidential?}

We will take measures to protect the security of all your personal information, but we cannot guarantee confidentiality of all study data. For this research, participants will only be asked questions that are related to this research study. The real names of participants will be excluded and each participant will be assign a pseudonym or number.

Data confidentiality and security during collection, analysis, and storage will be ensured through the following methods:

- All paper forms including consent forms and completed survey forms will be stored securely in a locked file cabinet.

- All removable media such as portable hard drives and SD cards will be stored securely in a locked file cabinet. If media is transferred, media will be stored on a password protected computer and/or cloud server

- All electronic files will be compressed and encrypted before they are transferred from one location to another.

- Data will not be accessed or stored on a laptop or any other device that is connected to a public Wi-Fi network.

- Once data collection and analysis is complete, all unused or irrelevant data will be either shredded or delete permanently deleted.

Information contained in your study records is used by study staff. The Portland State University Institutional Review Board (IRB) that oversees human subject research and/or other entities may be permitted to access your records, and there may be times when we are required by law to share your information. It is the investigator's legal obligation to report child abuse, child neglect, elder abuse, harm to self or others or any life-threatening situation to the appropriate authorities, and; therefore, your confidentiality will not be maintained.

Your name will not be used in any published reports about this study.

\author{
APPROVED \\ $07 / 07 / 2016$ \\ Portland State University \\ Office of Research Integrity
}


Participants will not be compensated but food and beverages will be provided before or after the survey period in the park.

\section{Can I stop being in the study once I begin?}

Your participation in this study is completely voluntary. You have the right to choose not to participate or to withdraw your participation at any point in this study without penalty or loss of benefits to which you are otherwise entitled.

\section{Whom can I call with questions or complaints about this study?}

If you have any questions, concerns or complaints at any time about the research study, Kenya Williams, or his/her associates will be glad to answer them at 503-267-2224.

If you need to contact someone after business hours or on weekends, please call 503-267-2224 and ask for Kenya Williams.

\section{Whom can I call with questions about my rights as a research participant?}

If you have questions regarding your rights as a research participant, you may call the PSU Office for Research Integrity at (503) 725-2227 or 1(877) 480-4400. The ORI is the office that supports the PSU Institutional Review Board (IRB). The IRB is a group of people from PSU and the community who provide independent oversight of safety and ethical issues related to research involving human participants. For more information, you may also access the IRB website at https://sites.google.com/a/pdx.edu/research/integrity.

\section{CONSENT}

You are making a decision whether to participate in this study. Your signature below indicates that you have read the information provided (or the information was read to you). By signing this consent form, you are not waiving any of your legal rights as a research participant.

You have had an opportunity to ask questions and all questions have been answered to your satisfaction. By signing this consent form, you agree to participate in this study. A copy of this consent form will be provided to you.

\footnotetext{
Name of Adult Subject (print) Signature of Adult Subject Date
} 


$$
\begin{gathered}
\text { RECEIVED } \\
\frac{06 / 01 / 2016}{\text { Portland State University }} \\
\text { Office of Research Integrity }
\end{gathered}
$$

\section{INVESTIGATOR SIGNATURE}

This research study has been explained to the participant and all of his/her questions have been answered. The participant understands the information described in this consent form and freely consents to participate.

Name of Investigator/ Research Team Member (type or print)

(Signature of Investigator/Research Team Member) Date 
Kenya D. Williams

RECEIVED

The Soniferous Experience of Public Space: A Soundscape Approach

$06 / 01 / 2016$

Survey Questions

Portland State University

Participant \#

The following questions will be asked at 6 to 8 locations in the park:

Location $\# 1$

Q1. How would you describe the sound at this location?

Q2. What do you like about the sound of this location? Why?

Q3. What do you not like about the sound of this location? Why

Q4. Rate the sound of this location:

$\square \quad$ Highly Appealing [+2]

$\square \quad$ Appealing [+1]

口 Neutral [0]

Somewhat Appealing [-1]

$\square \quad$ Not Appealing [-2]

The following questions will be asked about sound in the park in general:

Q1. The loudest sound I heard in the park today was?

Q2. The most distant sound I heard in the park today was?

Q3. My favorite sound heard today was?

Q4. My least favorite sound heard today was? 